
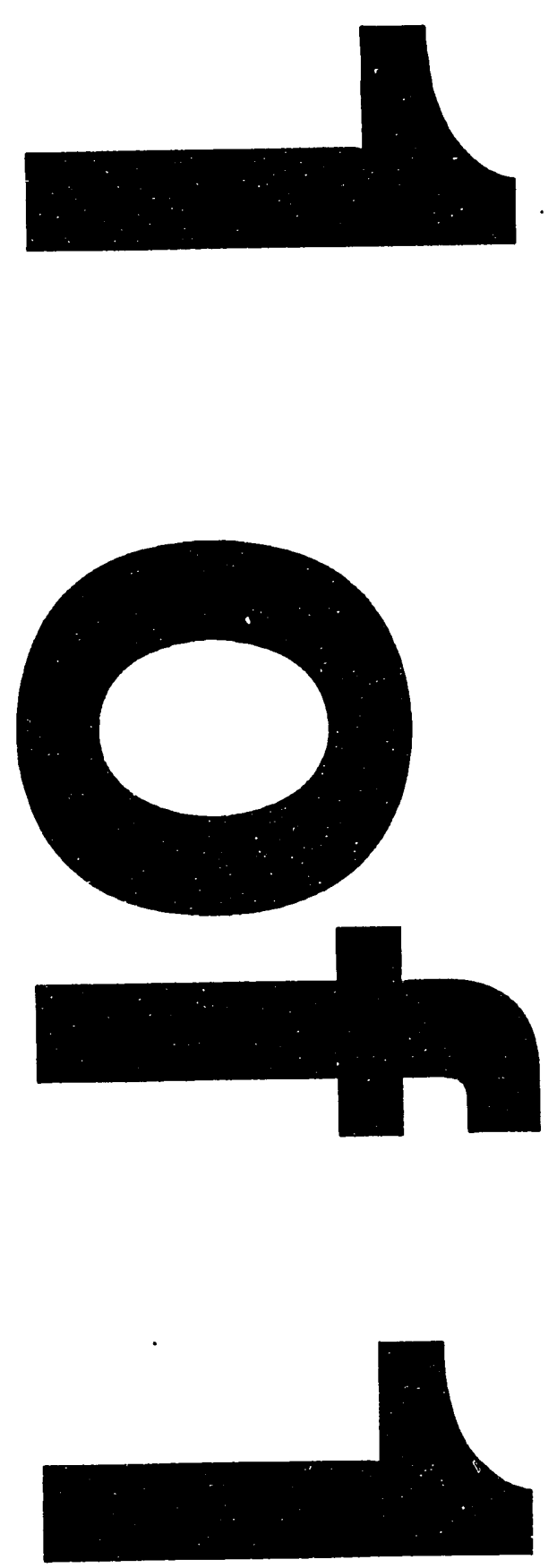


\section{Progress Report for}

I'S. Department of Energy Grant DE-FGill2-86ER60)+17

Do Report \#D()E/ER/60417-0018

\section{FAST NEUTRON DOSIMETRY}

For the periond 30-Angust-1992 to 1-September-1993; 
Progress Report for

U.S. Department of Energy Grant DE-FG02-86ER60417

DOE Report \# DOE/ER/60417-008

FAST NEUTRON DOSIMETRY

For the period

\author{
30-Aug-1992 - 01-Sep-1993 \\ Principal Investigator: \\ Co-Principal Investigator: \\ Consultant: \\ Consultant: \\ Paul M. DeLuca, Jr., Ph.D. \\ Professor of Medical Physics \\ D. W. Pearson, Ph.D. \\ Associate Scientist \\ Department of Medical Physics \\ F. H. Attix, M.S. \\ Professor Emeritus \\ Department of Medical Physics \\ H. H. Barschall, Ph.D. \\ Professor Emeritus \\ Departments of Medical Physics, \\ Physics, and Nuclear Engineering
}

\author{
Department of Medical Physics \\ 1530 Medical Sciences Center \\ 1300 University Avenue \\ University of Wisconsin \\ Madison, WI 53706 \\ USA
}

\title{
DISCLAIMER
}

\begin{abstract}
This report was prepared as an account of work sponsored by an agency of the United States Government. Neither the United States Government nor any agency thereof, nor any of their employees, makes any warranty, express or implied, or assumes any legal liability or responsibility for the accuracy, completeness, or usefulness of any information, apparatus, product, or process disclosed, or represents that its use would not infringe privately owned rights. Reference herein to any specific commercial product, process, or service by trade name, trademark, manufacturer, or otherwise does not necessarily constitute or imply its endorsement, recommendation, or favoring by the United States Government or any agency thereof. The views and opinions of authors expressed herein do not necessarily state or reflect those of the United States Government or any agency thereof.
\end{abstract}




\section{Contents}

1 PROGRESS SUMMARY 1992-1993 5

1.1 Introduction . . . . . . . . . . . . . . . 5

1.2 Fast Neutron Kerma Factor Determinations . . . . . . . . . . 6

1.3 Ultra-Soft X-ray TLD Measurements . . . . . . . . . . . . . 6

2 Publications/Presentations 1992-1993 8

2.1 Publication Bibliography 1992-1993 . . . . . . . . . . . . 8

2.2 Invited Presentations 1992-1993 . . . . . . . . . . . . . . 9

3 Status of Carbon and Oxygen Fast Neutron Kerma Factor Measurements 10

3.1 Participants ........................ 10

3.2 Introduction ........................ 10

3.3 Overview ............................ 10

3.4 Methods and Materials .................. 11

3.4.1 Los Alamos Neutron Source and Flight Paths _. . . . . 11

3.4.2 Low Pressure Proportional Counters . . . . . . . . . . . . 15

3.4.3 Cylindrical $\mathrm{Zr}$ and $\mathrm{ZrO}_{2}$ LPPCs ............ . 17

3.4.4 Rossi Type LPPCs . . . . . . . . . . . . . . . . 18

3.5 Analysis and Results So Far . . . . . . . . . . . . . . . . 21

3.5.1 Oxygen Absorbed Dose by Subtraction of Matched Pair LPPC Spectra ................... 21

3.5.2 Absorbed Dose Gas-to-Wall Conversion Factor $r_{m, g}$ Determi-

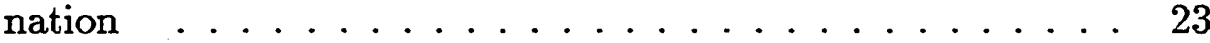

3.5.3 LPPC Time-of-Flight Measurement . . . . . . . . . . . 24

3.5.4 LPPC TOF Calibration ................ 24

3.5.5 LPPC TOF and PH Electronics . . . . . . . . . . 25

3.5.6 Neutron Fluence Measurement Techniques Used at LANL . 26

3.5.7 FFC Fluence Calibration . . . . . . . . . . . . . 29

3.5.8 FFC Signal Processing Electronics . . . . . . . . . . . 29

3.6 Data Acquisition Systems . . . . . . . . . . . . . . 34

3.7 Data Reduction Techniques for Kerma Determinations . . . . . . 34

3.8 Results . . . . . . . . . . . . . . . . . 35

3.8 LANL 92 Results .................... 35

3.9 Summary ........................... 41

3.10 BIBLIOGRAPHY ...................... 42 
4 Ultra-soft X-Ray Response of TLD 50

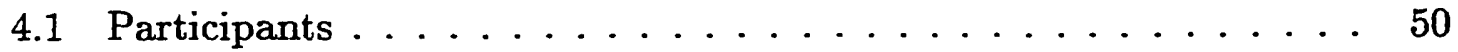

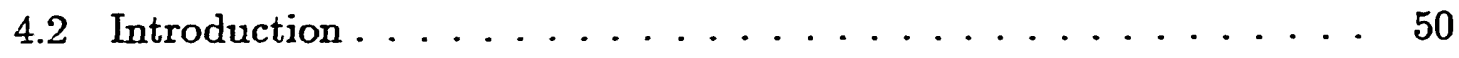

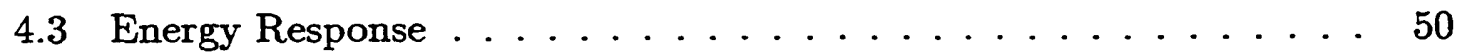

4.4 Supra-Linearity . . . . . . . . . . . . . . 55

5 Carbon to Oxygen Kerma Factor Ratio Measurements 62

5.1 Participant. . . . . . . . . . . . . . . . 62

5.2 Introduction . . . . . . . . . . . . . . 62

5.3 Treatment Facility . . . . . . . . . . . . . 64

5.4 Measurements . . . . . . . . . . . . . . . . . . 64

5.5 Electronics . . . . . . . . . . . . . . 67

5.6 Results. . . . . . . . . . . . . . . 67

\section{List of Figures}

1 WNR targets and neutron flight paths . . . . . . . . 13

2 WNR neutron spectra . . . . . . . . . . . . . . 14

3 Wisconsin cylindrical $\mathrm{Zr}$ and $\mathrm{ZrO}_{2} \mathrm{LPPC}$ schematic diagram. . . . 19

4 Schematic diagram of the metal /metal-oxide Rossi counters . . . . . 21

5 Fission foil counter mechanical schematic diagram . . . . . . . 27

6 Fission foil counter electrical schematic diagram . . . . . . . . . 28

7 Fission foil counter two parameter spectrum . . . . . . . . . 30

8 Fission foil counter one parameter TOF spectrum . . . . . . . . 31

9 Fission foil counter one parameter PH spectrum . . . . . . . . . . 32

10 Uranium differential neutron fission cross section . . . . . . . . 33

11 LPPC two parameter spectrum . . . . . . . . . . . . 36

12 LPPC electron drift-time in two two-parameter data. . . . . . . . . 37

13 Low pressure proportional counter TOF spectrum . . . . . . . . 38

14 High gain low pressure proportional counter TOF spectrum . . . . 39

15 Low pressure proportional counter energy spectrum . . . . . . . . . 40

$16 \mathrm{Zr}$ microdosimetric spectrum . . . . . . . . . . . . 45

$17 \mathrm{ZrO}_{2}$ microdosimetric spectrum . . . . . . . . . . 46

18 A-150 plastic microdosimetric spectrum . . . . . . . 47

19 C microdosimetric spectrum without additional buildup . . . . . 48

$20 \mathrm{C}$ microdosimetric spectrum with additional buildup . . . . . . 49

21 TLD-100 crystals response vs. energy deposited . . . . . . . . 51

22 TLD-200 response vs. energy deposited . . . . . . . . . . 52

23 Glow curves for $\mathrm{LiF}$ crystals exposed through $\mathrm{Al}$ or $\mathrm{Be}$ windows . . . 54

$24 \quad$ Supra-Linearity Determination for LiF . . . . . . . . . . 56

25 Gershenson Radiation Oncology Neutron Facility: Cross-Section . . 65 
26 Gershenson Radiation Oncology Neutron Facility: Median View . . . 66

27 A-150 plastic event-size weighted dose distribution . . . . . . . 69

\section{List of Tables}

$1 \quad$ LPPC geometries, cavity diameters, fill gasses, and biases . . . . 16

$2 \quad$ LPPC charged particle build up materials . . . . . . . . . . 17

3 LPPC wall and build up materials . . . . . . . . . . . . . . 18

4 TLD-100 crystal supra-linearity factors . . . . . . . . . . . . 57

$5 \quad$ Elemental Composition of ICRU muscle tissue and A-150 plastic. . . 63 


\section{$1 \quad$ PROGRESS SUMMARY 1992-1993}

\subsection{Introduction}

Research concentrated on three major areas during the last twelve months: [1] investigations of energy fluence and absorbed dose measurements using crystalline and hot pressed TLD materials exposed to ultrasoft beams of photons, [2] fast neutron kerma factor measurements for several important elements as well as NE-213 scintillation material response function determinations at the intense "white" source available at the WNR facility at LAMPF, and [3] kerma factor ratio determinations for carbon and oxygen to A-150 tissue equivalent plastic at the clinical fast neutron radiation facility at Harper Hospital, Detroit, MI. Progress summary reports of these efforts are given below.

As suggested above and expanded below, our purpose is to investigate fundamental dosimetric quantities that are important to bridging basic science and applied technology. Such research is essential to the proper implementation of a rapidly expanding technology base. We have targeted experiments that include collaborations in the target technologies.

Our efforts in kerma factor determinations at various point neutron energies have suggested a technique for effective kerma ratio determinations important for clinical neutron beams or, in fact, any broad spectrum source. This technique offers the possibility for improved A-150 plastic to tissue absorbed dose conversion factors specific to the neutron distribution. For this work, we established a collaboration with Dr. Richard Maughan of Harper Hospital, Detroit, MI. During this grant period, we were able to perform some preliminary measurements to resolve anticipated experimental difficulties.

During the recent grant period, our research at the USDOE supported WNRLAN $F$ facilities broadened considerably. Recognizing the limitations on energy resolution and detector matching, new matched $\mathrm{Zr}$ and $\mathrm{ZrO}_{2}$ proportional counters identical to our carbon and A-150 devices were designed, constructed, and tested. Measurements were made using a $90 \mathrm{~m}$ neutron flight path to further improve the energy resolution. Our collaborators were Drs. Robert C. Haight (P-15), John Ullmann (P-17), and group leader Paul Lisowski (P-17). Because of the improved beam conditions at $90 \mathrm{~m}$, we also opened a collaboration with Drs. H.J. Brede, T.J. Schewe, and R. Nolte of Physikalisch-Technische Bundesanstalt (PTB) of Braunschweig, Germany. Their efforts were supported by the PTB and the Commission of European Communities through the efforts of Professor Hans Menzel.

Our work on TLD response to low energy photons is largely complete. These investigations have yielded a new technique to provide high precision and wide dynamic range energy fluence determinations for ultra-soft $x$-rays such as employed in $\mathrm{x}$-ray assisted lithography. This work is reported in the attached thesis and 
summarized below.

Once again we have postponed the measurements at the Loma Linda University Proton Therapy facility due to severe budgetary constraints.

\subsection{Fast Neutron Kerma Factor Determinations}

The research into kerma factor ratio determinations in a clinical fast, neutron beam is based upon the difficulty of simultaneously knowing the complete neutron spectrum as well as the appropriate fluence to absorbed dose conversion factors for all neutron energies present. In previous efforts (see for example: $[2,3,4,5,6,10,8,9]$ ), we have extended the carbon and oxygen data base to $\sim 30 \mathrm{MeV}$. In collaboration with researchers from the Physikalisch-Technische Bundesanstalt (PTB) we are extending this work to $\sim 60 \mathrm{MeV}$ in work at PSI Switzerland, while our efforts at WNR-LAMPF will extend the data base at several energies to $\sim 300 \mathrm{MeV}$. However, using the best available techniques we are limited to an overall uncertainty of $\pm 10 \%$. By making measurements in ratio, we have the possibility of reducing the uncertainty to less than $\pm 5 \%$ as needed by clinicians, albeit producing values unique to the specific clinical beam used. In these efforts we are pleased to collaborate with Dr. Richard Maughan, lead physicist, at the Harper Hospital Fast Neutron Therapy facility. As such, we have open and cost-free access to the facility.

\subsection{Ultra-Soft X-ray 'TLD Measurements}

Ultra-soft photon $(<3,000 \mathrm{eV})$ irradiation of cells for radiobiology studies pursued under this grant in previous years, as well as similar beam irradiation employed for x-ray lithography, identified the need for a practical, economical, and nonintrusive dosimeter that could be used concurrently during the exposure in such experiments. This would allow precise determination of the exposure and would permit accounting for any changes in the photon beam power during the exposure. Thermoluminescent dosimeters were proposed due to their sniall size and proven ability to successfully monitor shallow penetrating beta rays and photons of higher $(>15 \mathrm{keV})$ and lower ( $<100 \mathrm{eV}$, UV light) energy than those generated by electron synchrotrons. However, only one work has reported TLD response at $i 500 \mathrm{eV}$ photon energy. For the last two and one half years, we investigated the response of $\mathrm{LiF}$ and $\mathrm{CaF}_{2}$ :Dy to photons from $275 \mathrm{eV}$ to $2500 \mathrm{eV}$ energy. Both crystalline and hot-pressed powder forms were employed. Our results indicate that TL-response linearity is excellent and independent of energy for energy fluences of $10^{-9}$ to $10^{-5}$ : for both materials. Above about $10^{-5} \mathrm{~J}$ supralinearity was observed $\sim 1.5 \pm 0.3$ for $\mathrm{LiF}$ and $\sim 2.4 \pm 0.3$ for $\mathrm{CaF}_{2}: \mathrm{Dy}$. One inierssting and unexpected effect was UV-light induced response bleaching resulting from stray UV-light present under certain conditions. In the summary below, an overview of the results is presented. 
Full details may be found in Carrillo's Thesis [1].

\section{References}

[1] Carrillo R.E., Ph.D. Thesis, "The Thermoluminescent Response of Several Phosphors to Monoenergetic Photon Beams With Energies From 275 to 2,500 eV, "University of Wisconsin-Madison, February 24, 1993.

[2] DeLuca, P.M., Jr., 1984, "Neutron Kerma Factor Measurements Near $15 \mathrm{MeV}$ Using Microdosimetric Techniques," Nuci. Instr. Meth., B10/11, 915-918.

[3] DeLuca, P.M., Jr., Barschall, H.H., Haight, R.C. and McDonald, J.C., 1984, "Carbon Neutron Kerma Factor Determinations at $14.1 \mathrm{MeV}$," Radiat. Res. 100, 78-86.

[4] DeLuca, P.M., Jr., Barschall, H.H., Burhoe, M., and Haight, R.C., 1986, "Carbon Kerma Factor for 18- and 20-MeV Neutrons," Nucl. Sci. Eng. 94(2), 192-198.

[5] Deluca, Jr. P.M., Barschall, H.H., Sun, Y., and Haight R.C., 1988, Kerma Factors of Oxygen, Aluminum, and Silicon For $15-$ to $20 \mathrm{-MeV}$ Neutrons, Radiat. Prot. Dosim., 23(1/4), 27-30.

[6] DeLuca, Jr. P.M., Barschall, H.H., Hartmann, C.L., and Pearson, D.W., 1989, Corrections to Kerma Factor Measurements Made by Integral Techniques, Nucl. Inst. Meth. 40/41, 1279-1281.

[7] Hartmann CL, DeLuca Jr. PM, 1991, Measurement of the ${ }^{19} \mathrm{~F}(\mathrm{n}, 2 \mathrm{n}){ }^{18} \mathrm{~F}$ Cross Section from 18 to $27 \mathrm{MeV}$, Nuclear Science and Engineering, 109, 319-323.

[8] Hartmann, CL, DeLuca, Jr. PM, and Pearson, DW, Measurement of C, Mg, and $\mathrm{Fe}$ kerma factors and the ${ }^{19} \mathrm{~F}(\mathrm{n}, 2 \mathrm{n}){ }^{18} \mathrm{~F}$ cross section for 18 to $27 \mathrm{MeV}$ neutrons, Nuclear Data for Science and Technology Ed: S.M. Qaim, SpringerVeriag, Berlin, 1992, 589-591.

[9] Hartmann C.L., DeLuca Jr. P.M., and Pearson D.W., Measurement of Neutron Kerma Factors in C, O, and $\mathrm{Si}$ at 18, 23, and $25 \mathrm{MeV}$, Radiat. Prot. Dos. 44(1/4), 25-30, 1992.

[10] Schell, M.C., Pearson, D.W., DeLuca, Jr., P.M., Haight, R.C., 1@90, Measurement of Dose Distributions of Linear Energy Transfer in Matter h radiated by Fast Neutrons, Med. Phys. 17(1), 1-10. 


\section{Publications/Presentations 1992-1993}

\subsection{Publication Bibliography 1992-1993}

1. Carrillo, R.E., Pearson, D.W., DeLuca, Jr. P.M., and Mackay, J.F., "Thermoluminescent Response of Lithium Fluoride (TLD-100) to Monoenergetic Photon Beams of 600, 730, 900, and 1,500 eV", Radiat. Prot. Dos. 47(1/4), 519-524, 1993.

2. Carrillo, R.E., Pearson, D.W., DeLuca, Jr. P.M., and Mackay, J.F., 1992, "Preliminary Results for the Thermoluminescent Response of Dysprosiumdoped Calcium Fluoride (TLD-200) to Monoenergetic Photon Beams of 600, 730, 900, and 1,500 eV", Proc. of the V Congreso Nacional sobre Dosimetria Termoluminiscente, Mexico DF, Sept. 3-5, 1992.

3. Hartmann C.L., DeLuca Jr. P.M., and Pearson D.W., Measurement of Neutron Kerma Factors in C, O, and Si at 18, 23, and $25 \mathrm{MeV}$, Radiat. Prot. Dos. 44(1/4), 25-30, 1992.

4. Hartmann, C.L., DeLuca, Jr., P.M., and Pearson, D.W., "Measurement of C, $\mathrm{Mg}$, and Fe Kerma Factors and the ${ }^{19} \mathrm{~F}(\mathrm{n}, 2 \mathrm{n}){ }^{18} \mathrm{~F}$ Cross Section for 18 to 27 MeV Neutrons," Nuclear Data for Science and Technology Ed: S.M. Qaim, Springer-Verlag, Berlin, 1992, 589-591.

5. Siebers J.V., DeLuca Jr. P.M., Pearson D.W., and Coutrakon G., "Measurement of Neutron Dose Equivalent and Penetration in Concrete for $230 \mathrm{MeV}$ Proton Bombardment of Al, Fe, and Pb Targets," Radiat. Prot. Dos. 44(1/4), 247-251, 1992.

6. Siebers J.V., DeLuca Jr. P.M., Pearson D.W., and Coutrakon G., "Shielding Measurements for 230-MeV Protons," Nucl. Sci. and Eng. 115(1), 13-23, 1993.

7. White R.M., DeLuca Jr. P.M., Dietze G., Haight R.C., Kawashima K., Menzel H.G., Olsson N., and Wambersie A., "Status of Nuclear Data for Use in Neutron Therapy," Radiat. Prot. Dos. 44(1/4), 11-20, 1992.

8. Carrillo R.E., Ph.D. Thesis, "The Thermoluminescent Response of Several Phosphors to Monoenergetic Photon Beams With Energies From 275 to 2,500 eV," University of Wisconsin-Madison, February 24, 1993.

9. DeLuca Jr. P.M., "Dosimetric Instruments and Methods," In: ICRU Report on Proton Beam Dosimetry for Therapy, ICRU Committee on Proton Therapy, Chapter 5, International Commission on Radiation Units and Measurements, Inc., Bethesda, MD (to be published). 
10. Schrewe U.J., de Aro A.C.A., Brede H.J., Dangendorf V., DeLuca Jr. P.M., Gerdung S., Lim T., Newhauser W., Nolte R., Schmelzbach P., Schumacher H., and Scott M.C., "Ionization Yield Spectra in Nitrogen and Oxygen for Neutron Energies of $17 \mathrm{MeV}, 45 \mathrm{MeV}$ and $66 \mathrm{MeV}$, Proc. of the Eleventh Symposium on Microdosimetry, Gatlinburg, TN, September 1992 (in press).

\subsection{Invited Presentations 1992-1993}

1. Carrillo R.E., Pearson D.W., DeLuca, Jr. P.M., and Mackay J.F., "Preliminary Results for the Thermoluminescent Response of Dysprosium-doped Calcium Fluoride (TLD-200) to Monoenergetic Photon Beams of 600, 730, 900, and 1,500 eV", V Congreso Nacional sobre Dosimetria Termoluminiscente, Sept. 3-5, 1992, Mexico City.

2. Gould M.N., Mackay J.F., Pearson D.W., Kennan W., Muller S., Shulman P., Mackie T.R., Hill C., and DeLuca, Jr. P.M., "The Use of SynchrotronProduced Ultrasoft X-rays to Model Radiobiological Processes," Proc. of the 4th Int. Conf. on Biophysics and Synchrotron Radiation, August 30-Sept. 5, 1992, Tsukuba, Japan.

3. Schrewe U.J., de Aro A.C.A., Brede H.J., Dangendorf V., DeLuca Jr. P.M., Gerdung S., Lim T., Newhauser W., Nolte R., Schmelzbach P., Schumacher H., and Scott M.C., "Ionization Yield Spectra in Nitrogen and Oxygen for Neutron Energies of $17 \mathrm{Me} \overline{\mathrm{V}}, 45 \mathrm{MeV}$ and $66 \mathrm{MeV}$, Eleventh Symposium on Microdosimetry, Gatlinburg, TN, September 1992.

4. DeLuca Jr. P.Mí., "Proton Radiation Therapy: A New Modality," Cleveland Area Medical Physics Society, Cleveland, OH, November 4, 1992.

5. Gould M., MacKay J., Pearson D., Kennan W., Shulman P., Hill C. and DeLuca Jr., P.M., "A Synchrotron Beamline to Study the Radiobiology of Ultrasoft X-rays," presented at Radiation Research Society/North American Hyperthermia Society Annual Meeting, Reston, VA, March 1993.

6. DeLuca Jr. P.M., "Integral Determinations of Fast Neutron Kerma Factors, Department of Nuclear Engineering, Massachusetts Institute of Technology," Cambridge, MA, June 17, 1993. 


\section{Status of Carbon and Oxygen Fast Neutron Kerma Factor Measurements}

\subsection{Participants}

Wayne Newhauser, P.M. DeLuca, Jr., K. Langen, J. Miranda, R.C. Haight, U. Schrewe, and D.W. Pearson

\subsection{Introduction}

Neutron kerma factors, integral charged-particle production cross sections, are needed to understand exposure to energetic neutrons. They are especially important for the successful treatment of tumors with external beams of fast neutrons. The efficacy of such fast neutron treatments depends strongly on the neutron absorbed dose to both the tumor and normal tissue. Too little dose results in failure to control the tumor; too much causes excessive damage to normal tissues. Successful therapy requires an accurate treatment plan as well as accurate dosimetric measurements to ensure precise delivery of the prescribed dose.

The accuracy of dosimetry is limited by our lack of knowledge of how neutrons interact with carbon and oxygen, the predominant tissue elements, excepting hydrogen. Presently, absorbed dose is measured in a tissue equivalent plastic which, unfortunately, contains an excess of carbon and too little oxygen relative to real tissue. While accurate corrections for this defect below about $30 \mathrm{MeV}$ neutron energy are now possible, the newer neutron therapy facilities are treating with neutron energies above $60 \mathrm{MeV}$. In order to improve the overall accuracy of tissue absorbed dose, this correction factor must be established with an uncertainty of less than five percent. To that end, we have investigated the charged particle production in carbon and oxygen at the Los Alamos National Laboratory Meson Facility (LAMPF).

This report focuses upon the work at LAMPF and discusses only the work involving carbon, oxygen, and A-150 plastic. The measurements made during August 1993 are just now being analysed.

\subsection{Overview}

As the clinical efficacy of neutron therapy depends so strongly on the appropriate specification and delivery of absorbed dose, which in turn depends on the tissue composition, our efforts have been towards improving the accuracy of dosimetry though better kerma factors. As previously discussed, the adopted dosimeter materials introduce errors due to differences in composition relative to real tissues. Hydrogen, the dominant contributor to kerma, is fairly uniform in abundance throughout the body (about 10\%) and is included in the correct proportion in the A-150 TE plastic. 
Therefore, hydrogen does not pose a significant dosimetric problem. Rather, it is the mismatched abundance of carbon ( $15 \%$ in tissue versus $77 \%$ in A-150 plastic) and oxygen ( $70 \%$ in tissue versus $5 \%$ in A-150 plastic) which induce dosimetric errors. In fact, this is presently the dominant error in the determination of tissue absorbed dose from neutrons above about $30 \mathrm{MeV}$.

The goal of improving the accuracy of clinical dosimetry for fast neutron therapy is realized though the measurement of carbon and oxygen kerma factors, which give cor ection factors for the inadequacies of A-150 plastic dosimeter. These correction factors are of immediate relevance in clinical measurements. New techniques, developed this year at the Unive:sity of Wisconsin - Madison, as well as those previously used by DeLuca, Schrewe Hartmann, Binns, and others have been assembled to realize these measurements.

\subsection{Methods and Materials}

The major facility and equipment used in this experiment was the Los Alamos National Laboratory's pulsed "white" Weapons Neutron Research neutron source (WNR). Low-pressure proportional counters measured neutron kerma and energy. Differential neutron fluences were measured with a fission foil ionization chamber, and various scintillation detectors. Pulsed neutron sources, used at the WNR, enable determination of the neutron energy from its flight time. In the case of the WNR source, this feature, combined with the nearly fiat neutron energy distribution, enabled simultaneous measurement of kerma factors from 20 to $100 \mathrm{MeV}$.

\subsubsection{Los Alamos Neutron Source and Flight Paths}

The Los Alamos Meson Physics Facility (LAMPF) is a three stage, high-intensity proton accelerator which drives the Weapons Neutron Research (WNR) and the Los Alamos Neutron Scattering Center (LANCE) neutron sources. The WNR facility has two targets, called Target 2 and Target 4, each with about 6 flight paths. Figure 1 shows the WNR targets and flight paths. The present measurements were made in a detector station on the $30^{\circ}$ Left, $40 \mathrm{~m}$ flight path of Target 4 . The circular beam spot at $37.3 \mathrm{~m}$ is approximately $8 \mathrm{~cm}$ in diameter. Several collimators are used along the $30^{\circ} \mathrm{L}$ beamline. The beamlines are not evacuated. A beam stop is located below grade several meters behind the detector station. Electrically controlled beam shutters are available on each flight path. Entrances to experimental areas with beam, such as the $30 \mathrm{~L} 40 \mathrm{~m}$ detector station, are interlocked to the beam shutters and other radiation safety systems.

A bunched and chopped proton beam bombards the WNR tungster target producing spallation neutrons with energies from $100 \mathrm{keV}$ to about $700 \mathrm{MeV}$. Figure 2 shows a calculated neutron spectrum at $30 \mathrm{~L} 40 \mathrm{~m}$ with $2.5 \mathrm{~cm}$ poiyethylene filtration. 
Note the flat or "white" portion of the spectrum extends roughly from 20 to 100 $\mathrm{MeV}$.

The beam time structure is defined by micropulses and macropulses. A macropulse is comprised of about 350 micropulses, each separated by $1.8 \mu \mathrm{s}$, forming a $625 \mu \mathrm{s}$ pulse train. There are nominally 40 macro pulses per second, or about 14000 micro pulses per second, delivering about $900 \mathrm{nA}$ of protons on target. The time interval between macropulses results in a duty cycle of $2.5 \%$. The proton pulse width at the tungsten target is $150 \mathrm{ps}$ and is treated as an instantaneous pulse in all calculations here. Momentum dispersion of the neutrons as they travel down the flight path is negligibly small compared to the time resolution, $60 \mathrm{nsec}$, of the low pressure proportional counters and no accounting of this effect is necessary. The pulse separation can apparently be increased to $3.6 \mu \mathrm{s}$, although all measurements were made at $1.8 \mu \mathrm{s}$ spacing. Lisowski et al. describes the LANL neutron sources in detail[19]. 


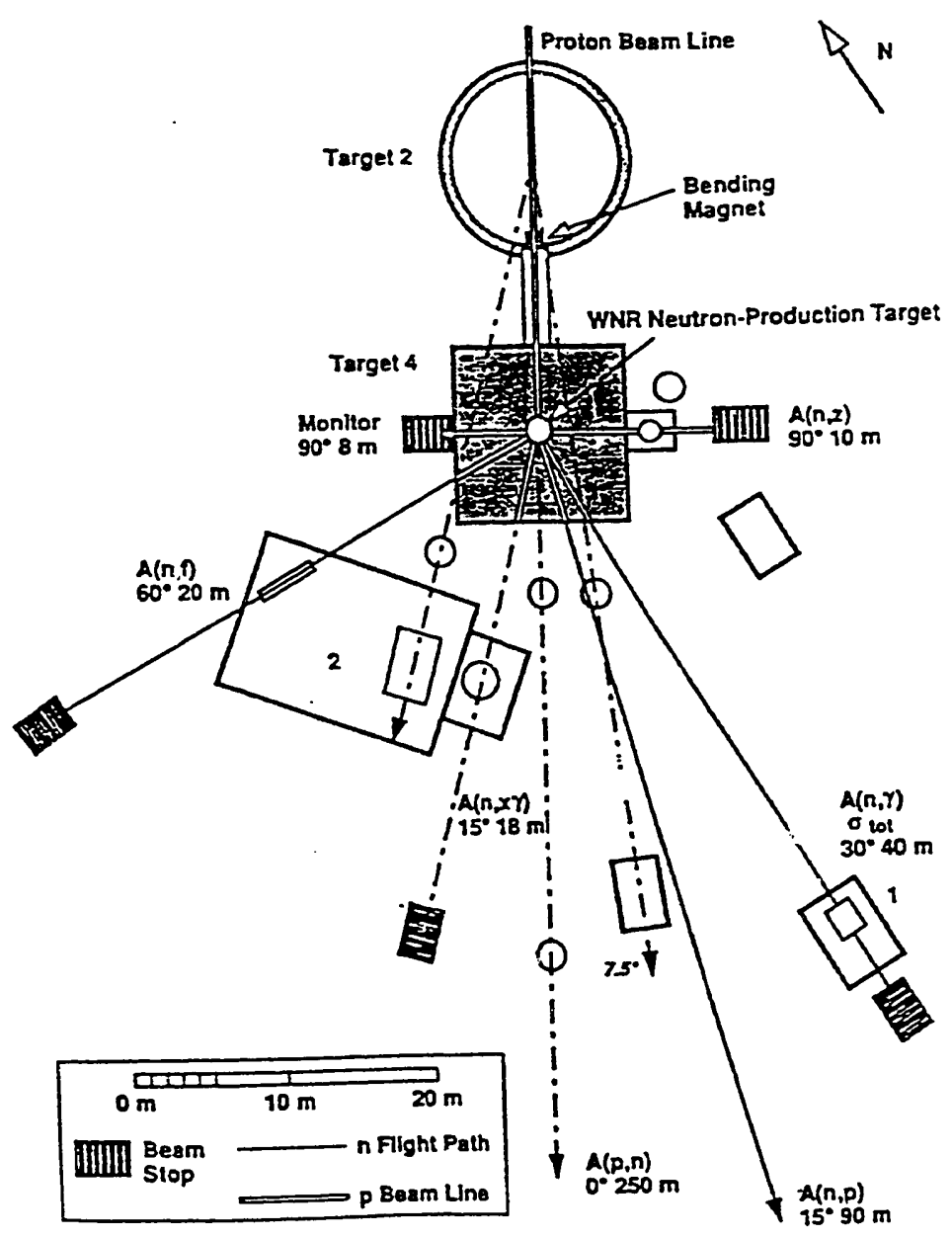

Figure 1: Targets and neutron flight paths at the Los Alamos National Laboratory's Weapons Neutron Research Facility, after Lisowski et al. [19]. Present work used the $30^{\circ}$ left, $40 \mathrm{~m}$ flight path of Target 4 . The detectors and electronics were located in a temperature controlled detector station (1). Also shown are the proton beam from LAMPF, the low current target 2 area, the high current target 4 area, (2) the experimental support building, the time of flight yard. 


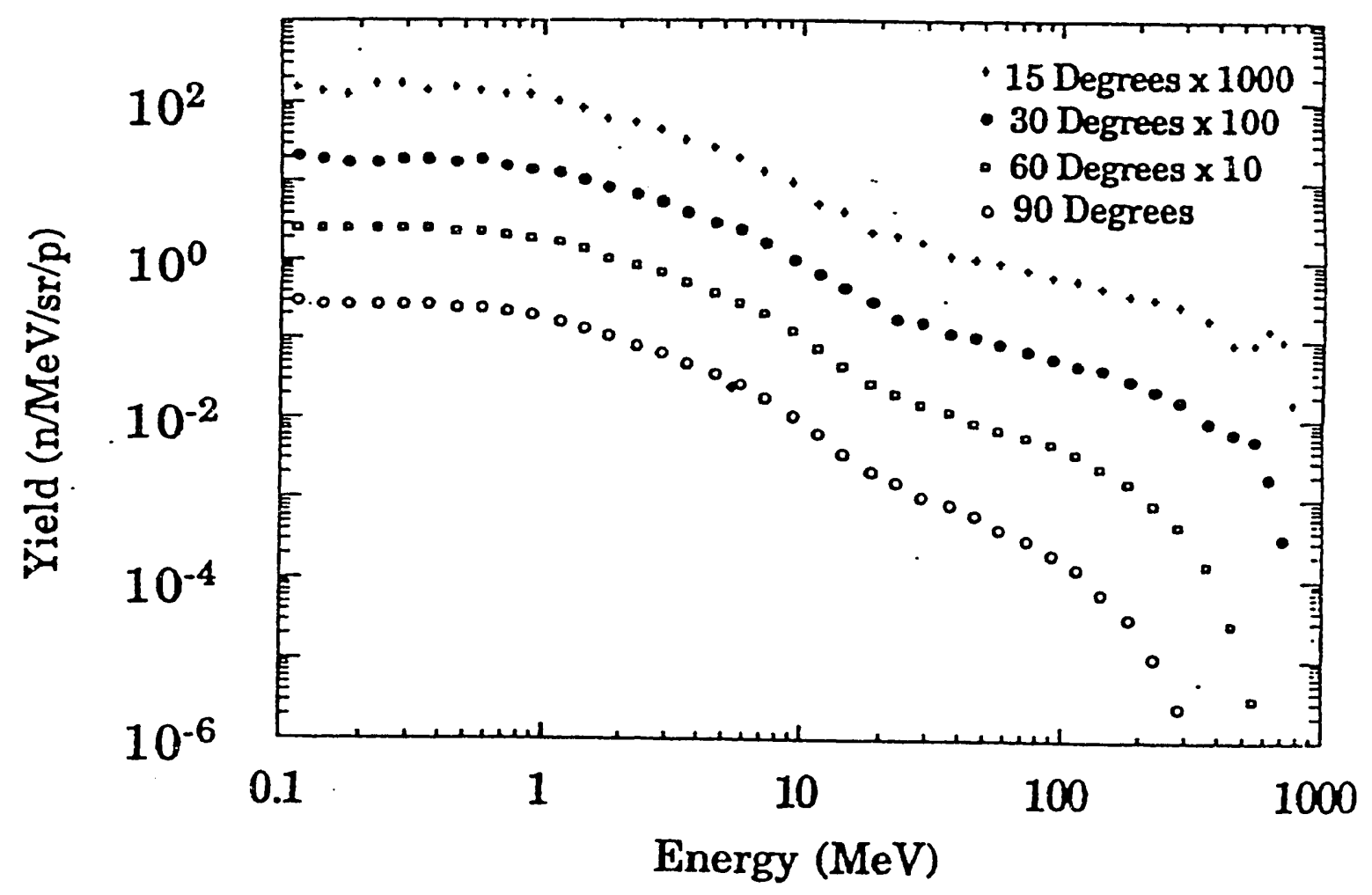

Figure 2: Several calculated neutron beams available at WNR[19]. Present work used the $30^{\circ}$ left, $40 \mathrm{~m}$ tlight path of Target 4 with $2.5 \mathrm{~cm}$ polyethylene filtration. 


\subsubsection{Low Pressure Proportional Counters}

Low-pressure proportional counters (LPPC) have several characteristics which make them the preferred detector for measuring fast neutron kerma. They allow precise determination of the absorbed dose (and kerma) in the wall material. Also, they provide ionization pulse-height distributions which provide qualitative information about the LET and lineal energy of a radiation. Proportional counters can be used with ioth microdosimetric and time-of-flight techniques to simultaneously measure ne1tron kerma and energy. Finally, LPPCs are readily calibrated directly to absorbed dose with built in aipha particle calibration sources.

LPPCs are gas filled ionization chambers which are oper ated in the proportional region. The cavity gas pressure is kept low for several reasons. Cavity theory, which ultimately gives wall kerma, requires that the charged particle fluence crossing the cavity must not be significantly perturbed by the gas and that all charged particles are released from the wall. Lower cavity mass results in less pertubation of the charged particle spectrum and fewer neutron interaction in the gas. Also, the gas gain and time response are improved at low pressures.

The cavity is surrounded by a grounded conducting spherical wall of the material of interest. The wall serves as an equipotential surface for the electric field and as a source of charged particles which ionize the gas. As ions and electrons are collected, their motion induces a voltage pulse across the anode and ground. A pulse height may be converted to absorbed dose if the gas mass and amount of energy expended in the cavity are both known.

Cavity theory can be used to relate the absorbed dose in one material to that in another. In this case, it provides the relationship between the ionization charge produced in a gas cavity and the absorbed dose in the wall material. The measured. absorbed dose to one material, TE gas in this case, can be used to predict the absorbed dose to another material, such as TE plastic.

Bragg-Gray cavity theory states that the wall absorbed dose is related to the gas absorbed dose by the ratio of wall to gas stopping powers $s_{m, g}[2]$. Several conditions must be met for the theory to be valid. The dimensions of the cavity must be small compared to the range of charged particles crossing it, so that the gas does not perturb the charged particle fluence. Also, the dose to the cavity gas must be deposited by charged particles crossing the cavity - not "starters", "stoppers", or "insiders". To this end, gas pressures were kept at 8.0 to $9.3 \mathrm{kPa}$ (60 to 70 Torr) to minimize perturbation of the charged particle fluence and to minimize neutron interactions in the gas.

We also take advantage of the fact that the absorbed dose is numerically equal to kerma if charged particle equilibrium (CPE) exists in the material of interest (the proportional counter wall in this case). CPE exists in a volume if each charged particle of a given type and energy is replaced by an identical particle of the same 
energy entering the volume, in terms of expectation values[2].

If the wall and gas are of the same atomic composition, the ratio of stopping powers $s_{m, g}$ is unity. If the wall and cavity are dissimilar, $s_{m, g}$ must be evaluated for the different secondary particle spectra. Therefore the ICRU recommends that if the wall aisd gas are of different elemental composition, as are A-150 plastic and TE propane gas, a gas-to-wall absorbed dose conversion factor $\left(r_{m, g}\right)_{n}$ be used instead of $s_{m, g}[20] .\left(r_{m, g}\right)_{n}$ accounts for the difference in stopping powers due to differences in atomic compositions of the gas and wall and for gas cavity's contribution to the secondary spectrum.

Several physical processes occur in the generation of a proportional counter pulse. First, a neutron interacts in the wall, releasing a variety of charged particles which then traverse the gas. The energy deposition rates of these secondary particles span several orders of magnitude, ranging from $1 \mathrm{MeV} \mathrm{cm} \mathrm{g}^{-1}$ for electrons to $10,000 \mathrm{MeV} \mathrm{cm} \mathrm{g}^{-1}$ for heavy recoil ions. Some of the energy deposited produces ionizations in the gas. The free electrons produced by ionizations migrate inward toward an anode at positive potential. Very near the anode the intense electric field causes charge multiplication, thereby inducing an electronic pulse. The charge multiplication in the gas reduces the amplification burden on subsequent signal processing electronics.

For the LPPCs used in these experiments, Table 1 gives the LPPCs geornetries, fill gasses and pressures, and operating potentials. Table 2 describes the geometry, dimensions, and composition of the build-up materials. Note that the spherical $\mathrm{Zr}$ $/ \mathrm{ZrO}_{2}$ Rossi counters became available in 1993, replacing the cylindrical $\mathrm{Zr} / \mathrm{ZrO}_{2}$ proportional counters. Table 3 lists the combined wall and build-up area densities and the resulting maximal energy for which $\mathrm{CPE}$ is established.

\begin{tabular}{|l|l|l|c|c|c|}
\hline \hline $\begin{array}{l}\text { Detector } \\
\text { Wall }\end{array}$ & $\begin{array}{l}\text { Cavity } \\
\text { Material }\end{array}$ & $\begin{array}{l}\text { Diameter } \\
\text { Geometry }\end{array}$ & $\begin{array}{c}\text { Fill } \\
\text { Gas }\end{array}$ & $\begin{array}{c}\text { Gas } \\
\text { Pressure } \\
{[\mathrm{kPa}]}\end{array}$ & $\begin{array}{c}\text { Anode } \\
\text { Bias } \\
{[\text { volts] }}\end{array}$ \\
\hline $\mathrm{C}$ (graphite) & spherical & $1.27 \pm 0.01$ & $\mathrm{ArCO}_{2}$ & 9.0 & +323 \\
$\mathrm{C}$ (graphite) & spherical & $1.27 \pm 0.01$ & $\mathrm{PTE}^{\prime}$ & 9.0 & +323 \\
$\mathrm{~A}-150$ plastic & spherical & $1.27 \pm 0.01$ & $\mathrm{PTE}^{2}$ & 9.0 & +600 \\
$\mathrm{ZrO}$ & cylindrical & $1.59 \pm 0.01$ & $\mathrm{ArCO}_{2}$ & 9.0 & +536 \\
$\mathrm{Zr}$ & cylindrical & $1.59 \pm 0.01$ & $\mathrm{ArCO}_{2}$ & 9.0 & +536 \\
$\mathrm{ZrO}$ & spherical & $1.27 \pm 0.01$ & $\mathrm{PTE}_{2}$ & 9.0 & +600 \\
$\mathrm{Zr}$ & spherical & $1.27 \pm 0.01$ & $\mathrm{PTE}$ & 9.0 & +600 \\
\hline \hline
\end{tabular}

Table 1: LPPC cavity geometries, cavity diameters, fill gas compositions, and anode biases used in this work. The $\mathrm{ArCO}_{2}$ mixture is $90 \% \mathrm{Ar}$ and $10 \% \mathrm{CO}_{2}$. PTE denotes a tissue equivalent mixture of propane based gas. 


\begin{tabular}{|l|l|c|c|c|}
\hline \hline $\begin{array}{l}\text { Build-Up } \\
\text { Material }\end{array}$ & Geometry & $\begin{array}{c}\text { Thickness } \\
{[\mathrm{cm}]}\end{array}$ & $\begin{array}{c}\text { Density } \\
{\left[\mathrm{g} \mathrm{cm}^{-3}\right]}\end{array}$ & $\begin{array}{c}E_{n}^{\max } \\
\text { for } \phi_{T}^{\text {cpe }} \\
{[\mathrm{MeV}]}\end{array}$ \\
\hline $\mathrm{C}$ (graphite) & right cylinder & $3.80 \pm 0.30$ & $1.116 \pm 0.10$ & 67 \\
$\mathrm{~A}-150$ plastic & right cylinder & $4.00 \pm 0.01$ & $1.138 \pm 0.01$ & 75 \\
$\mathrm{ZrO}_{2}$ & right cylinder & $1.06 \pm 0.01$ & $2.700 \pm 0.10$ & 50 \\
$\mathrm{Zr}$ & plate & $1.20 \pm 0.01$ & $6.777 \pm 0.01$ & 75 \\
\hline \hline
\end{tabular}

Table 2: LPPC charged particle build up material geometries, thicknesses, densities, and maximum neutron energy for which the build up caps provide a equilibrium charged particle spectra. The later figure is based on proton energy loss calculations using the stopping power tabulations of Anderson and Ziegler[1]. Thickness for the right circular cylinders are the difference of the outer and inner radii. Graphite density is highly variable, typically ranging from 2.3 to $2.7 \mathrm{~g} \mathrm{~cm}^{-3}$, with values as low as 1.6 reported. The $\mathrm{Zr}$ and $\mathrm{ZrO}_{2}$ densities listed are from mass and volume measurements of the build-up material. A-150 plastic deisity is from manufacturers' specifications.

\subsubsection{Cylindrical $\mathrm{Zr}$ and $\mathrm{Z}_{\mathrm{rO}_{2}}$ LPPCs}

A matched pair of cylindrical proportional counters were previously constructed to determine the oxygen neutron kerma by subtraction[10]. Otherwise identical in design, one counter cavity wall was made of zirconium metal while the other counter was made of zirconium oxide ceramic.

Figure 3 shows the basic features of the detectors. Field tubes, surrounding both ends of the anode, prevent gas multiplication near the ends of the chamber where the electric field is not axially uniform. The field tubes each extend $0.7 \mathrm{~cm}$ into the cylinders. The $\mathrm{Zr}$ and $\mathrm{ZrO}_{2}$ cylinders are $5.23 \mathrm{~cm} \pm 0.01 \mathrm{~cm}$ long, $1.59 \mathrm{~cm} \pm 0.01$ $\mathrm{cm}$ inside diameter, and $0.318 \mathrm{~cm} \pm 0.004 \mathrm{~cm}$ thick. To provide equilibrium spectra of charged particles, additional $\mathrm{Zr}$ or $\mathrm{ZrO}_{2}$ was placed outside the detectors during some irradiations. A $11.0 \mathrm{~cm}$ square $\mathrm{Zr}$ plate, $1.2 \mathrm{~cm}$ thick, was placed just upbeam of the detector. This additional thickness of $\mathrm{Zr}$ provides charged particle equilibrium up to $86 \mathrm{MeV}$. A right circular cylinder build-up cap of $\mathrm{ZrO}_{2}$ powder was placed over the $\mathrm{ZrO}_{2}$ detector during some irradiations. The $\mathrm{ZrO}_{2}$ powder encapsulated in $0.1 \mathrm{~cm}$ thick Al. The $\mathrm{ZrO}_{2}$ thickness was $1.06 \mathrm{~cm} \pm 0.01 \mathrm{~cm}$, providing charged particle equilibrium up to $66 \mathrm{MeV}$. Both counters were filled with a mixture of Ar $(8.55 \mathrm{kPa})$ and $\mathrm{CO}_{2}(0.45 \mathrm{kPa})$ gas. The proportional counter absorbed dose calibration was similar to that used in previous investigations $[9,8,10,15,16]$.

In order to deduce absorbed dose, the active volume of the cylindrical counters, which is less than the geometric volume because of the field tubes, must be known. Actually, the ratio of the detector diameter to active volume $d / V$ is required 


\begin{tabular}{|l|l|c|c|c|}
\hline \hline $\begin{array}{l}\text { Build-Up } \\
\text { Material }\end{array}$ & Geometry & $\begin{array}{c}\text { Wall } \\
\text { Thickness } \\
{\left[\mathrm{g} \mathrm{cm}^{-2}\right]}\end{array}$ & $\begin{array}{c}\text { Build-up } \\
\text { thickness } \\
\left.\text { [g cm } \text { cm }^{-2}\right]\end{array}$ & $\begin{array}{c}E_{n}^{\text {max }} \\
\text { for } \phi_{T}^{\text {cpe }} \\
{[\mathrm{MeV}]}\end{array}$ \\
\hline $\mathrm{C}$ (graphite) & spherical & $0.34 \pm 0.01$ & $4.24 \pm 0.10$ & 70 \\
$\mathrm{~A}-150$ plastic & spherical & $0.14 \pm 0.01$ & $4.55 \pm 0.01$ & 80 \\
$\mathrm{ZrO}_{2}$ & cylindrical & $1.87 \pm 0.01$ & $2.86 \pm 0.10$ & 66 \\
$\mathrm{Zr}$ & cylindrical & $2.16 \pm 0.01$ & $8.14 \pm 0.01$ & 86 \\
\hline
\end{tabular}

Table 3: LPPC charged particle wall and build up material geometries, areal densities, and maximum proton energy for which the material provide a equilibrium charged particle spectra. The later figure is based on proton energy loss calculations using the stopping power tabulations of Anderson and Ziegler[1].

and was previously determined by Hartmann et al. by simultaneously irradiating spherical and cylindrical A-150 plastic-walled proportional counters with $1.85-\mathrm{MeV}$ neutrons[14]. The cylindrical $\mathrm{Zr}$ and $\mathrm{ZrO}_{2}$ counters were of very similar dimension. $d / V$ for the $\mathrm{Zr}$ and $\mathrm{ZrO}_{2}$ detectors is $0.289 \mathrm{~cm}^{-2} \pm 1.5 \%$.

This method of gas mass determination introduces additional uncertainty and is one of the principle reasons that a pair of spherical Rossi counters of the same materials were built. See section 3.4 .4 of this report for discussion of the new counters.

\subsubsection{Rossi Type LPPCs}

Rossi type counters are small spherical gas filled ionization chambers which are operated in the proportional region. Gas multiplication makes the counter sensitive to events too small to measure directly. A central anode is surrounded by a helix held at an intermediate potential, which makes the electric field near the anode (where gas multiplication occurs) axially uniform. As a result, gas multiplication is uniform along the anode axis and is independent of the location within the cavity where a primary ionization occurs.

The spherical C and A-150 plastic detectors are commercially available units ${ }^{1}$. An internal gravity operated alpha calibration source is installed in each LPPC. The diameters of the cavity, helix, and anode are $1.27 \mathrm{~cm}, 395 \mu \mathrm{m}$, and $46 \mu \mathrm{m}$, respectively. The cavity walls, $0.127 \mathrm{~cm}$ thick in the $\mathrm{C}$ and A-150 counters, provide equilibrium charged particle spectra to $12.3 \mathrm{MeV}$ and $11 \mathrm{MeV}$ protons, respectively. Additional build-up material, indicated in Table 2, provided charged particle equilibrium spectra to higher neutron energies.

\footnotetext{
${ }^{1}$ Model LET 1/2, Far West Technologies, Goleta.
} 


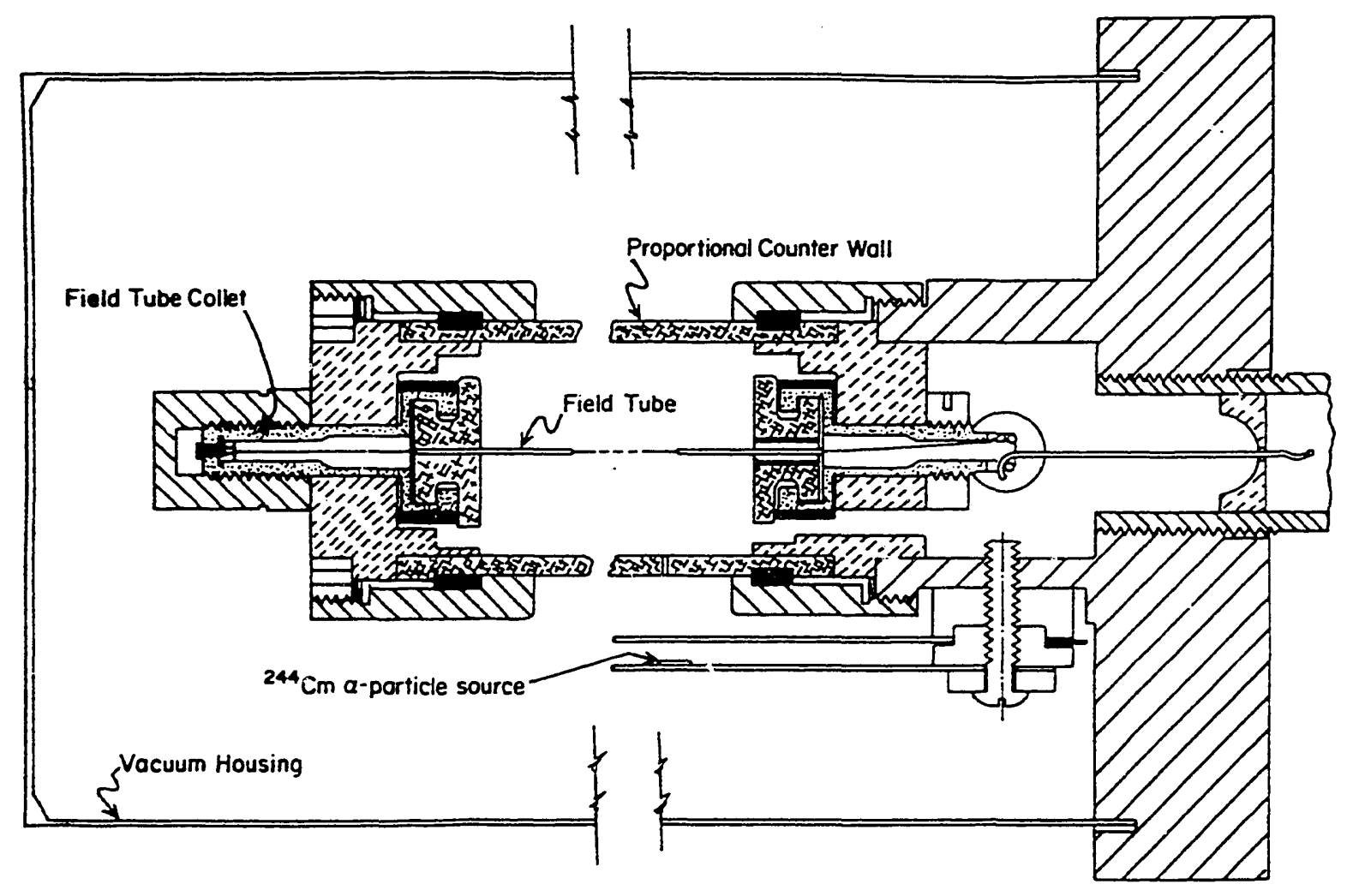

Figure 3: Schematic diagram of the Wisconsin cylindrical $\mathrm{Zr}$ and $\mathrm{ZrO}_{2}$ low pressure proportional counters[10]. An internally contained gravity operated alpha particle source calibrates pulse height directly to dose. Field tubes surrounding the anode restrict gas multiplication near the ends of the cavity where the electric field is not axially uniform. Since $\mathrm{ZrO}_{2}$ is an insulator, a thin coating of $\mathrm{Ag}$ was evaporated onto the cavity walls to provide an electrically conductive surface. The detector is connected by an aluminum tube to a connector block (not shown), containing a gas inlet, an isolation valve and a single electrical connection for signal and high voltage. 
The A-150 plastic counter was filled with TE propane gas, similar in composition to A-150 plastic, so that the ratio of average mass stopping powers is close to unity. TE propane has good gas gain and suitably fast electron drift velocities, giving good time response. The gas does, however, contain hydrogen which has a stronger velocity dependence in its $W / e$ value than $\mathrm{ArCO}_{2}$. Two otherwise identical C LPT 1/2 counters were filled with $\mathrm{ArCO}_{2}$ or TE-propane gas.

In order to improve the accuracy of dose and kerma measurements for oxygen, a matched pair of metal/metal-oxide Rossi type counters were built. In choosing materials for the matched pair dosimeters, several constraints indicated a metal and metal-oxide combination. In order to minimize the uncertainty in oxygen absorbed dose associated with the subtraction technique, the absorbed dose of the oxygen bearing compound should be due to oxygen, to the greatest extent possible. This can be achieved by selecting compounds with high oxygen mass fractions and small cross sections for all other non-oxygen constituents. Based on the above constraints and others, metallic zirconium and ceramic zirconium oxide counters were built. A $10 \mathrm{~nm}$ conducting layer of $\mathrm{Zr}$ was evaporated onto the $\mathrm{ZrO}_{2}$ cavity surface. The spherical $\mathrm{Zr}$ and $\mathrm{ZrO}_{2}$ detectors were built with identical cavity dimensions as commercially available units and are shown in figure 4 . The counters are equipped with gravity operated alpha-particle emitting sources and are in general very similar to the commercial C and A-150 plastic counters described above. While the cavity and stem were specially fabricated, Far West Technologies supplied the remaining parts.

These new counters show excellent performance, as demonstrated with preliminary analysis of measurements made with these counters at LANL in 1993. 


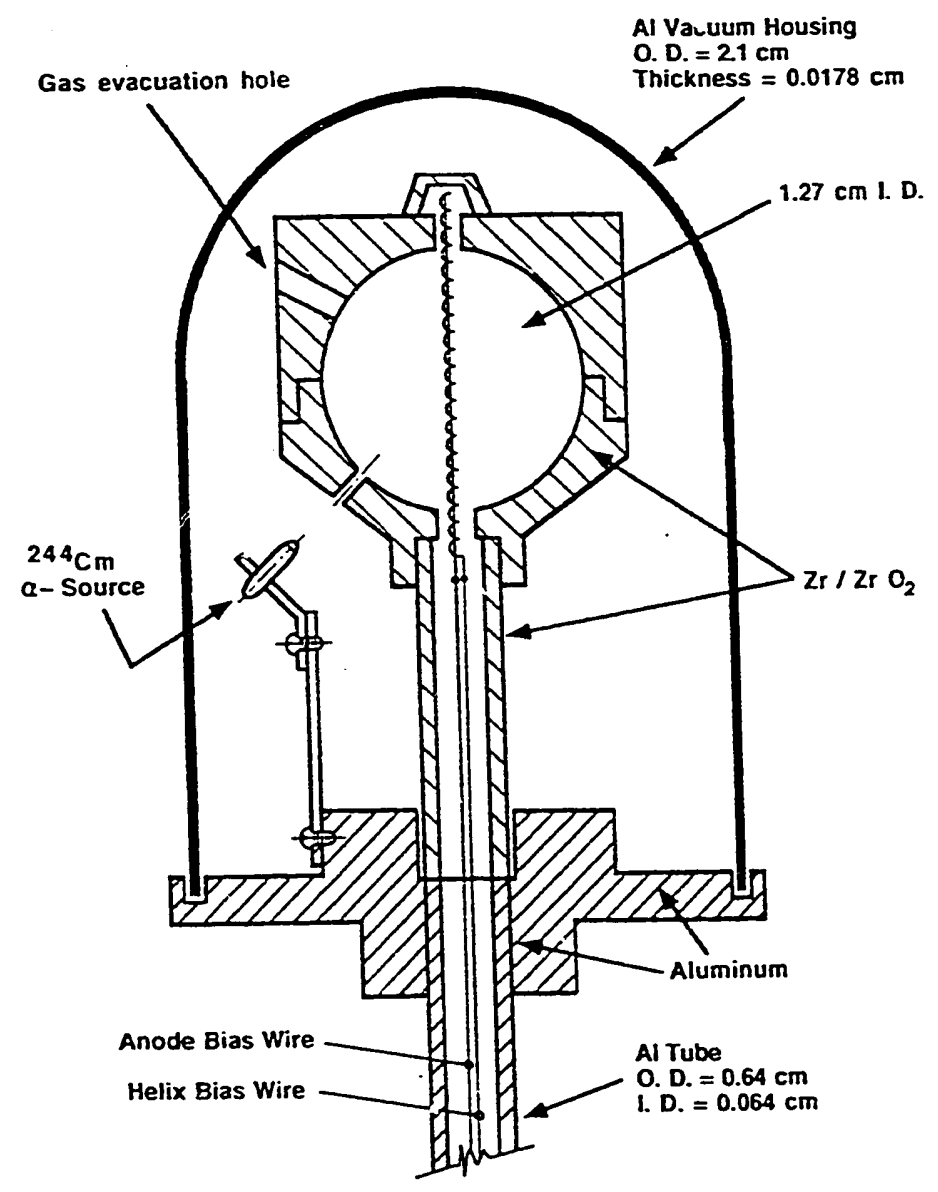

Figure 4: Diagram of the $\mathrm{Zr}, \mathrm{ZrO}_{2}$ matched pair spherical proportional counters. Cavity, helix, and anode wire diameters are $1.27 \mathrm{~cm}, 395 \mu \mathrm{m}$, and $46 \mu \mathrm{m}$, respectively. The helix serves to provide a uniform electric field along the length of the anode, thereby making the gain independent of the position of the original ionization in the cavity.

\subsection{Analysis and Results So Far}

\subsubsection{Oxygen Absorbed Dose by Subtraction of Matched Pair LPPC Spectra}

Bragg-Gray (BG) cavity theory provides the simple relationship between absorbed dose in the gas cavity and that in the surrounding wall medium $[6,12,13]$.

$$
D_{m}=r_{m, g} D_{g-m}
$$


where, if there are no neutron interactions in the cavity,

$$
r_{m, g}=\frac{\left.\Sigma_{i} \Sigma s_{j}\right|_{m}}{\left.\Sigma_{i} \Sigma s_{j}\right|_{g}}
$$

is the ratio of average mass collision stopping powers. The subscripts $i$ and $j$ indicate the charged particle type and energy; $m$ and $g$ denote wall and gas material. $D_{g \leftarrow m}$ is the absorbed dose to the gas from charged particles generated in the wall.

If the material of interest is a homogeneous mixture of materials, the absorbed dose is a mass fraction weighted sum of the elemental constituent absorbed doses, or

$$
D=\Sigma_{i} w_{i} D_{i},
$$

where $i$ indicates constituent element and $w$ indicates mass fraction. For example, the $\mathrm{ZrO}_{2}$ absorbed dose is,

$$
D_{Z \tau O_{2}}=w_{O} D_{O}+w_{Z \tau} D_{Z \tau},
$$

where

$$
w_{O}=\frac{2 \times 16}{92+32}=0.258
$$

and

$$
w_{Z_{\tau}}=\frac{92}{92+32}=0.742 \text {. }
$$

Solving (4) for $\mathrm{D}_{O}$,

$$
D_{O}=\frac{1}{w_{O}}\left(D_{Z_{r} O_{2}}-w_{Z r} D_{Z r}\right) \text {. }
$$

Substituting the BG relation (1) into (7), the oxygen kerma is

$$
D_{O}=\frac{1}{w_{O}}\left(r_{Z \tau O_{2, g}} D_{g-Z \tau} O_{2}-w_{Z r} r_{Z \tau, g} D_{g-Z \tau}\right) .
$$

Neglecting uncertainty in the mass fractions, the relative uncertainty in the oxygen absorbed dose is

$$
\frac{\sigma_{D_{O}}}{D_{O}}=\sqrt{\frac{\sigma_{D_{Z r O_{2}}}^{2}+w_{Z r O_{2}}^{2} \sigma_{D_{Z r}}^{2}}{D_{Z r O_{2}}^{2}-w_{Z r O_{2}}^{2} D_{Z r}^{2}}},
$$

which, incidentally, indicates that $w_{Z r} \sigma_{D_{Z r}} / \sigma_{D_{Z r O_{2}}}$ and $D_{Z_{\tau}} / D_{Z_{\tau} O_{2}}$ should be minimized.

If the quantity of interest is neutron kerma, we may still use equations (3), (4), ( 7$),(8)$, and (9), substituting kerma as the numerical equivalent of absorbed dose, but must then provice charged particle equilibrium (CPE) spectra to the detector cavities. CPE in the wall exists if the wall thickness equals the range of the most 
penetrating charged particle present there, while there is negligible attenuation of the primary particle fluence. A direct measurement of the secondary charged particle initial kinetic energies (proportional to kerma) is not possible because the charged particles lose some energy in the wall before reaching the cavity. Thus, the LPPC responds to energy deposition (proportional to absorbed dose) from a "slowing down spectrum" of charged particles.

\subsubsection{Absorbed Dose Gas-to-Wall Conversion Factor $r_{m, g}$ Determination}

The response of the low pressure proportional counters is dependent on the amount of energy deposited in the gas cavity which leads to ioniza. uns. The material of interest is generally not the gas, with the exception of TE gas in a A-150-plastic counter, but rather that of the wall. Cavity theory allows the determination of wall dose from gas dose using the ratio of average stopping powers.

In the case of neutron interactions in matter, several types of charged particles may be produced. In tissue for example, elastic and inelastic scattering produce $\mathrm{H}$, $\mathrm{C}, \mathrm{N}, \mathrm{O}, \mathrm{Ca}$, and $\mathrm{F}$ recoil nuclei, and nonelastic reactions may produce $\mathrm{R}+\mathrm{p}, \mathrm{R}+\mathrm{d}$, $\mathrm{R}+\mathrm{T}, \mathrm{R}+\alpha$, and other fragments.

Bragg-Gray cavity theory states that the absorbed dose in the wall is the product of the absorbed dose in the gas and the ratio of average mass stopping powers. The fluence weighted mean stopping power ratio is given by

$$
\frac{{ }_{m} S_{g}}{{ }_{m} \bar{S}_{w}}=\frac{\frac{1}{\Phi} \int_{0}^{T_{\circ}} \Phi_{T}(d T / \rho d x)_{c, g} d T}{\frac{1}{\Phi} \int_{0}^{T_{0}} \Phi_{T}(d T / \rho d x)_{c, w} d T}
$$

as noted in Attix [2].

This formulation requires that the charged particle energy spectrum be known for each type of particle crossing the cavity. The charged particle crossing spectra, which are degraded in energy compared to the initial or production spectra, are not directly measurable. Given the absence of experimental kerma factors, much less doubly differential charged particle production cross sections, the following two approaches are being undertaken to estimate the initial charged particle spectra. The slowing down spectrum under CPE, as required by the BG relation of absorbed dose and kerma, is then calculated by degrading the initial spectrum using tabulated charged particle stopping power values.

A first approximation to the initial charged particle spectrum is based on classical scattering kinematics, namely that the energy distribution of recoil particles scattered isotropically in the center of mass frame is a constant value in the lab frame. The value is constant up to the kinematically maximum possible energy. Thus, only recoil nuclei are considered and are assumed to scatter isotropically in 
the CM frame. At higher neutron energies the reaction products become increasingly forward directed, so this approximation may not be satisfactory.

The second approach, also in progress, is to use calculated nuclear reaction models. LAHET and INCA codes are now being used for these calculations.

As the ratio of average stopping powers is basically a correction factor to the gas absorbed dose measurements and is believed to be relatively insensitive to input charged particle spectrum, this comprises a relatively small fraction of the activity in the last year. Work is still in progress.

\subsubsection{LPPC Time-of-Flight Measurement}

Several investigators have demonstrated the suitability of low-pressure spherical proportional counters for simultaneous microdosimetric and TOF measurements $[4,21,2]$. Schrewe et al. modified a spherical LET $1 / 2$ LPPC for this purpose by adding a separate high voltage connection to the helix [22]. The expected improvement in time resolution, attributed to reducing the electron drift time by reducing the active volume of the detector to that bounded by the helix, is achieved by applying a negative potential to the helix. Finite electron drift velocity and variable drift lengths limit the resolving time of the counters. The resolving time of unmodified proportional counters is presently about 60 ns FWHM but reductions down to 10 ns FWHM have been observed[3]. One disadvantage of the helix mode of operation is that the chord-length distribution of particles crossing a cylinder (the region bounded by the helix) makes ionization spectra more difficult to interpret. Also, the smaller collection volume reduces sensitivity, necessitating a greater neutron fluence.

Longer flight paths, which increase the spread in neutron flight times, are an attractive alternative to helix mode for increasing time resolution since the spherical chord-length distribution is retained. The disadvantages are that longer flight paths give rise to contaminating "frame overlap" neutrons from preceeding beam pulses.

\subsubsection{LPPC TOF Calibration}

Calibration of the TOF neutron energy spectrum takes two steps: (1) determining the time interval per channel in the ADC TOF spectrum, and (2) finding a time fiducial which is related to the neutron departure time at the source. Combined, these allow a determination of flight time from ADC channel number.

The time per channel $\frac{\Delta t}{\Delta h}$ is determined by sequentially injecting pairs of START and STOP logic pulses at calibrated intervals. A commercially available TAC calibrator was used for this purpose ${ }^{2}$.

\footnotetext{
${ }^{2}$ EG\&G Ortec Model 462 Time Calibrator, Oak Ridge, TN.
} 
If the gamma flash is the observable time fiducial in the TOF spectrum, the neutron flight time is

$$
t=t_{\gamma}+\left|t-t_{\gamma}\right|,
$$

where $t_{\gamma}=d / c$ and the quantity $\left|t-t_{\gamma}\right|$ is from inspection of the TOF spectrum. The absolute value of the difference makes the calculation independent of the spectrum orientation.

In terms of ADC TOF neutron and gamma channel numbers $h$ and $h_{\gamma}$, this is

$$
t=t_{\gamma}+\left(h-h_{\gamma}\right) \frac{\Delta t}{\Delta h} .
$$

The time resolution of the LPPCs, about 60 ns FWHM, is not sufficient to resolve the gamma flash of the protons on target at the $40 \mathrm{~m}$ flight path distance used at LAMPF in 1992. At $40 \mathrm{~m}$ a $700 \mathrm{MeV}$ neutron arrives $29.3 \mathrm{~ns}$ after the gamma flash. Also, the gamma events (in TE propane for example), appearing mostly below about $30 \mathrm{MeV} \mathrm{cm} \mathrm{g}^{-1}$ in event size, are lost due to similar $30 \mathrm{MeV} \mathrm{cm}^{2} \mathrm{~g}^{-1}$ electronic noise threshold. Since in all cases except the LANL93 data set, it was not possible to find a time fiducial based on the gamma flash, we instead assume the largest events at the shortest flight times are from $700 \mathrm{MeV}$ neutron reactions leading to diameter crossings. A time where the gamma flash would be observed is used for all subsequent TOF neutron energy calculations where the gamma-ray flash was not observable.

\subsubsection{LPPC TOF and PH Electronics}

The time of flight and pulse height neutron energy discrimination techniques are quite standard, though the combined use of TOF and microdosimetric techniques have only recently been fully utilized.

We have made significant progress in the data processing electronics since the first measurement at LANL in 1991. Principally noise reduction and improved flight time pick-off techniques have lead to drastically improved data sets. Unfortunately, this development work is only possible at LANL and with the neutron source on. The combined improvements in the electronics and flight path led to LPPC spectra in which a gamma-ray flash was clearly discernable, greatly simplifying data reduction.

The wide dynamic range of p:alses from the LPPC necessitated two sets of pulse height electronics, each with a dynamic range of about two decades and differing in gain by about a factor of 10 . Flight times, converted into amplitude pulses, and both linear signal gains were synchronously presented to a single CAMAC ADC. A STROBE pulse, needed by the ADC to initiate conversion, was derived from an energy level discriminator on the linear signal. Invalid events were rejected by a number of logic gates on the STROBE pulse generation. 


\subsubsection{Neutron Fluence Measurement Techniques Used at LANL}

The neutron energy spectrum was measured with a WNR type fission foil ionization detector[24]. This detector is thin in the sense that is does not perturb the neutron spectrum - another detector can be conveniently placed just down beam. It responds to neutrons ranging from less than $1 \mathrm{MeV}$ to over $400 \mathrm{MeV}$. Fissions in a thin layer of $U$, coated on the inside of the detector wall, present highly ionizing fission fragments to the detector's cavity gas. Most fissions produce large ionization pulses compared to those from alpha decays of $U$ or noise. Using TOF and PHA to discriminate neutron energy and background, a relative fluence is obtained. The time resolution is about $2 \mathrm{~ns}$ FWHM. With the differential fission cross section, the absolute differential neutron fluence can be calculated. The $U$ coating thickness is selected for minimal self-absorption of the fission fragments yet adequate sensitivity for the neutron fluences expected.

Figure 5 shows major components of the FFC. There are 8 foils inside a gas tight enclosure. The first and last foils are kept at ground for electrical shielding. The remaining six foils form three parallel plate ion chambers. The first foil of each pair is the target and is held at negative potential. That is, the down beam side of that foil is loaded with a thin layer of $U$, for example. The other foil in a pair, held at ground, is the signal plate. Interchangeable foils coated with about 200 to 1000 $\mu \mathrm{g} \mathrm{cm}{ }^{-2}$ of ${ }^{238} \mathrm{U},{ }^{235} \mathrm{U},{ }^{237} \mathrm{~Np},{ }^{10} \mathrm{~B},{ }^{208} \mathrm{~Pb}$, and ${ }^{206} \mathrm{~Pb}$ are available. Blank foils have been used to correct for pulses from knock-out recoil reactions in the backing foil. Figure 6 shows the electrical components of the FFC.

LAMPF-WNR built eight such FFCs for use on various flight paths. We used a chamber with ${ }^{235} \mathrm{U}$ loaded foils for this work. The counter was biased to -400 volts and filled with $168 \mathrm{kPa}$ of $\mathrm{Ar}(90 \%)$ and methane (10\%).

The FFC generates pulses mainly from four sources: 1) neutron induced fissions, 2) photon induced fissions, 3) particles from knock out reactions in the backing foil, and 4) radioactive alpha decay of the fissionable coating. By acquiring spectra of both TOF and energy, we can visually distinguish the fissions from the alpha decays and knock-outs. The number of fissions is then later determined by integrating a region of interest which contains the fissions but not the alphas or knock-outs.

A two-parameter FFC spectrum and its TOF and energy projections are shown in figure $\bar{T}$, figure 8 and figure 9 . These spectra show several interesting features. First notice the U $(\gamma, \mathrm{f})$ "gamma flash" in TOF channel number 238, visible in figure 7 and figure 8. The $700 \mathrm{MeV}$ neutrons, with a flight time of $152 \mathrm{~ns}$, are clearly observed. A background of $U$ alpha decay pulses appears at small pulse heights in figure 7 , figure 8 and figure 9 and is not time correlated. Figure 9 reveals the alpha and fission peaks. The fission peak does extend to zero pulse heights, but is masked by the alpha peak.

Self-absorption of fission fragment energy within the foil causes small fission 


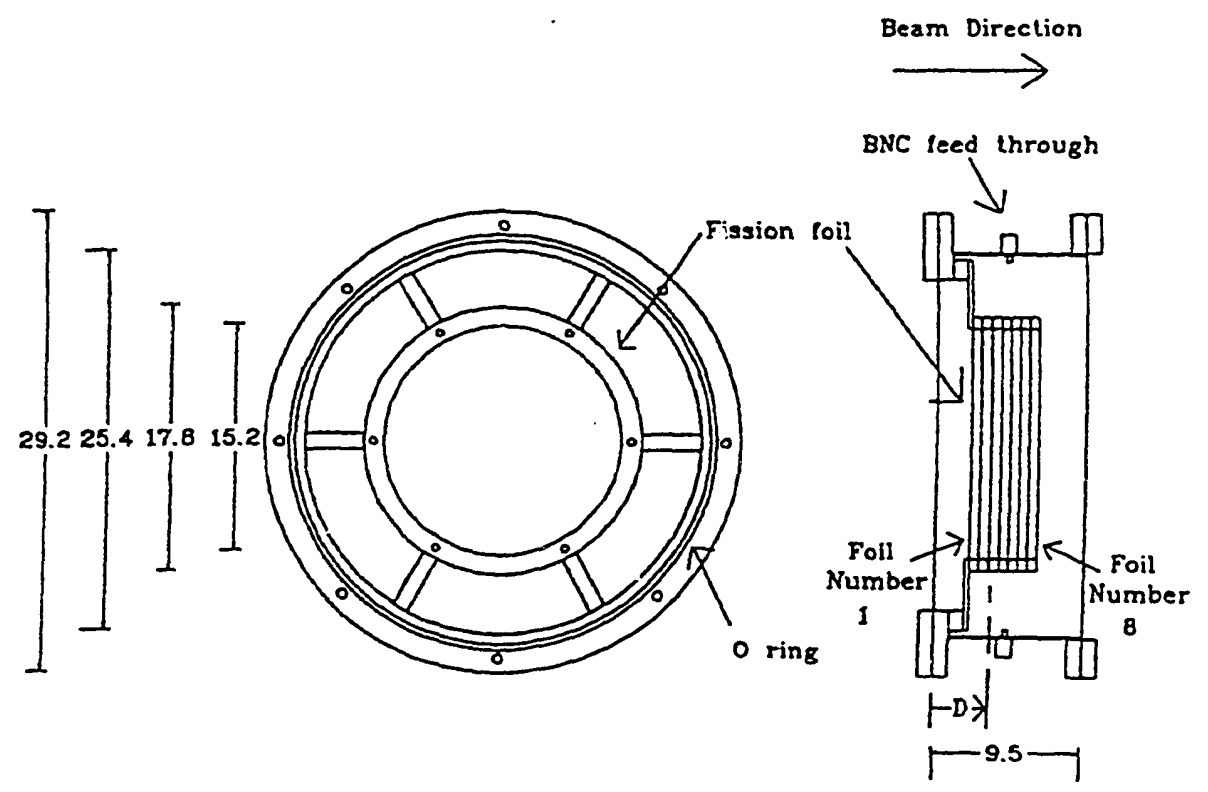

Figure 5: Schematic diagram of the fission foil counter used at National Laboratory's Weapons Neutron Research Facility [19]. The device is operated as a parallel plate ionization chamber which responds in proportion to the number of fast fissions induced by bombarding neutrons. Note the presence of several pairs of parallel plates within the detector. There are interchangeable foils with coatings of ${ }^{238} \mathrm{U},{ }^{235} \mathrm{U},{ }^{237} \mathrm{~Np},{ }^{10} \mathrm{~B},{ }^{208} \mathrm{~Pb},{ }^{206} \mathrm{~Pb}$ as well as an uncoated foil for the assessment of the contamination from knock-out reactions in the backing foil. The first and last foils are kept at ground for electrical shielding. 


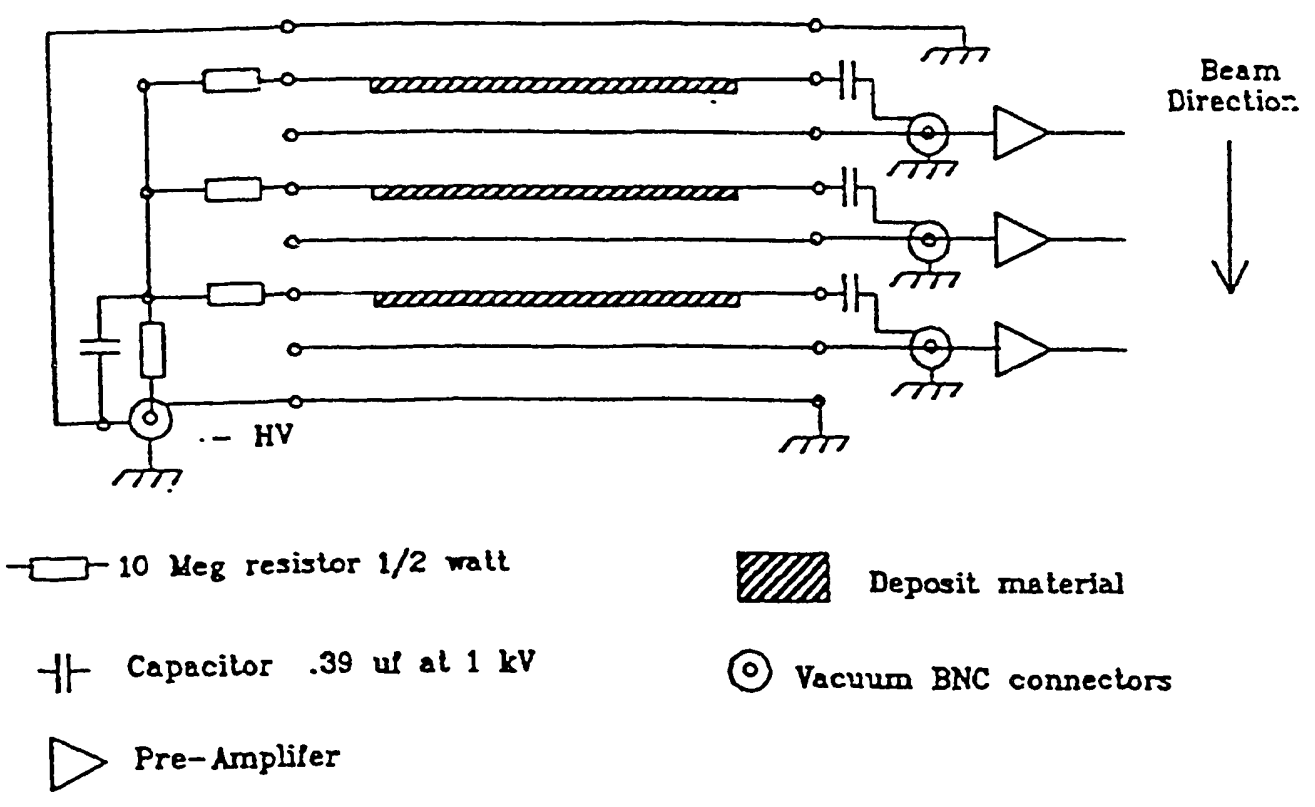

Figure 6: Schematic diagram of the fission foil counter's electrical components[24]. The first and last plates are held at ground potential for electrical shielding. The remaining 6 foils form three parallel plate ionization chambers which are operated in pulse mode. On the down beam side of the first foils in each pair is the deposited reaction material, such as $U$. These foils are held at about $-400 \mathrm{~V}$, the second foil in each pair serves as the signal plate. The efficiency of detecting fission events is near unity. 
events, indistinguishable from alpha decays. Geometric loss of the fragments from the active cavity of the chamber also produces small fission pulses. Techniques have been developed correct for self-absorption losses by extrapolating the distribution to zero pulse height size[7,17]. This effect is estimated to be less than $1 \%$ and no attempt is made to account for it.

\subsubsection{FFC Fluence Calibration}

In order to unfold the neutron spectrum, the differential fission cross section must be known. Measurements of the ${ }^{235} \mathrm{U}(\mathrm{n}, \mathrm{f})$ cross section by Ullmann, shown in figure 10 were used above $20 \mathrm{MeV}$. Below $20 \mathrm{MeV}$ values are from the Evaluated Nuclear Data Files (ENDF).

The mass of ${ }^{235} \mathrm{U}$ in the beam must also be known. If the $\mathrm{U}$ coating is completely within the beam, one can use the total U mass. However, for this experiment the beam spot area was smaller than that of the coating, necessitating knowledge of the beam spot area. Assuming that the $U$ coating is uniform in thickness, the its mass in the beam is the product of the density, thickness, and beam spot area.

WNR staff previously measured the beam spot size at $30^{\circ}$ left $37 \mathrm{~m}$ with a diode detector on a rectilinear scanner. The measurements are in good agreement with calculations based on ray tracing[18]. This calculation assumed an an isotropic source and black collimation. WNR provided the beam spot solid angle $\Omega$ of $3.7 \times 10^{-6}$ $\mathrm{Sr}$ at a distance $d$ of $37.3 \mathrm{~m}$ for the $30^{\circ} \mathrm{L}$ flight path. WNR has also previously measured the mass thicknesses of the ${ }^{235} \mathrm{U}$ foils used in 1992 and 1993 to be $187 \mu \mathrm{g}$ $\mathrm{cm}^{-2}[18]$ and $1.0 \mathrm{mg} \mathrm{cm}^{-2}[23]$.

No accounting of the knock-out particles is made here. Wender $e t$ al. previously found this effect to be observable only above $200 \mathrm{MeV}$ with either $U$ foils [24]. At 300,400 , and $600 \mathrm{MeV}$ they report less than $0.5 \%, 1 \%$, and $3 \%$ corrections.

\subsubsection{FFC Signal Processing Electronics}

The fission foil counter electronics are similar to the LPPC electronics to the extent that the TOF and PH discrimination are used. The FFC high voltage and front end signal processing electronics were located in the detector station, including a preamp, preamp power supply, passive signal filter, linear fanout, constant fraction discriminator, timing-filter amplifier, and high voltage power supply. To avoid ground loops, the NIM bin containing all the electronic modules was powered through an isolation transformer.

While the fission foil counter provides an accurate neutron energy fluence, it is not sufficiently sensitive to measure small neutron fluences. Therefore, an NE102 "paddle" $(5 \mathrm{~cm} \times 5 \mathrm{~cm})$ scintillator was used to monitor the integral neutron fluence. The scintillator was placed in the center of the beam $38.1 \mathrm{~m}$ from the target, or 


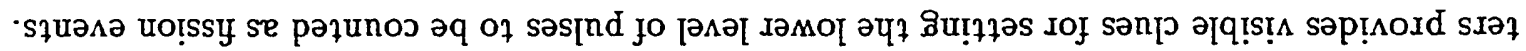

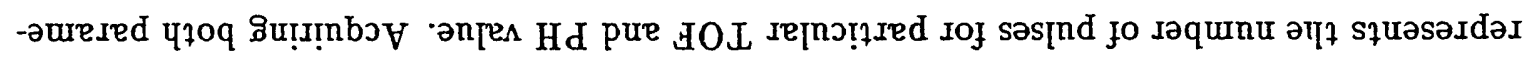

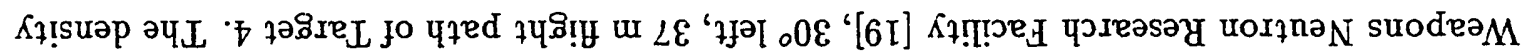

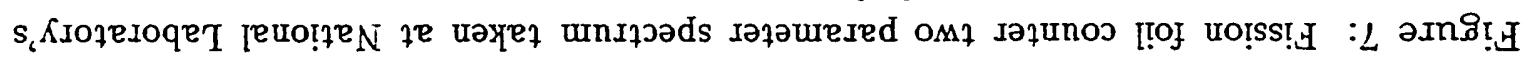

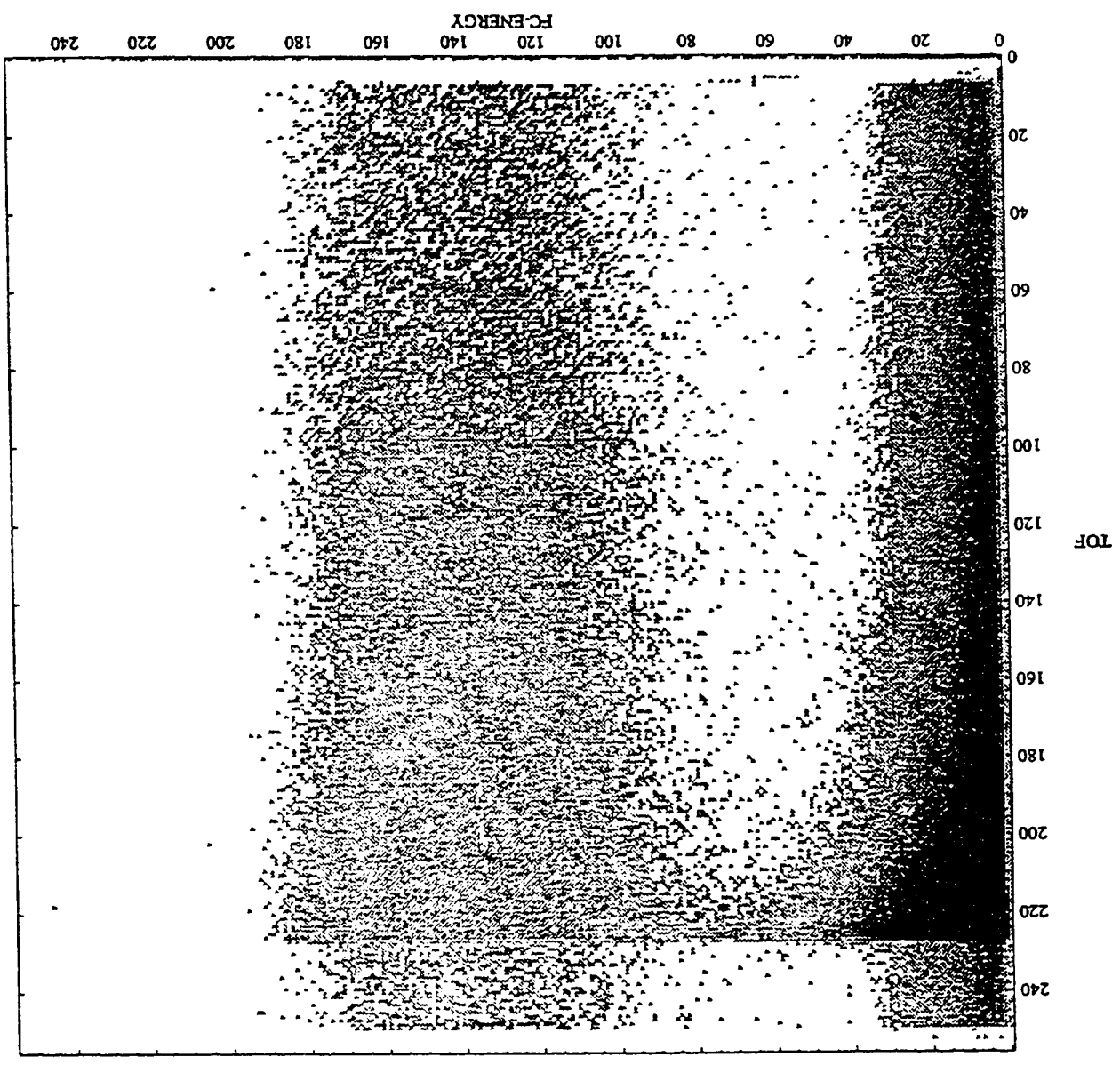




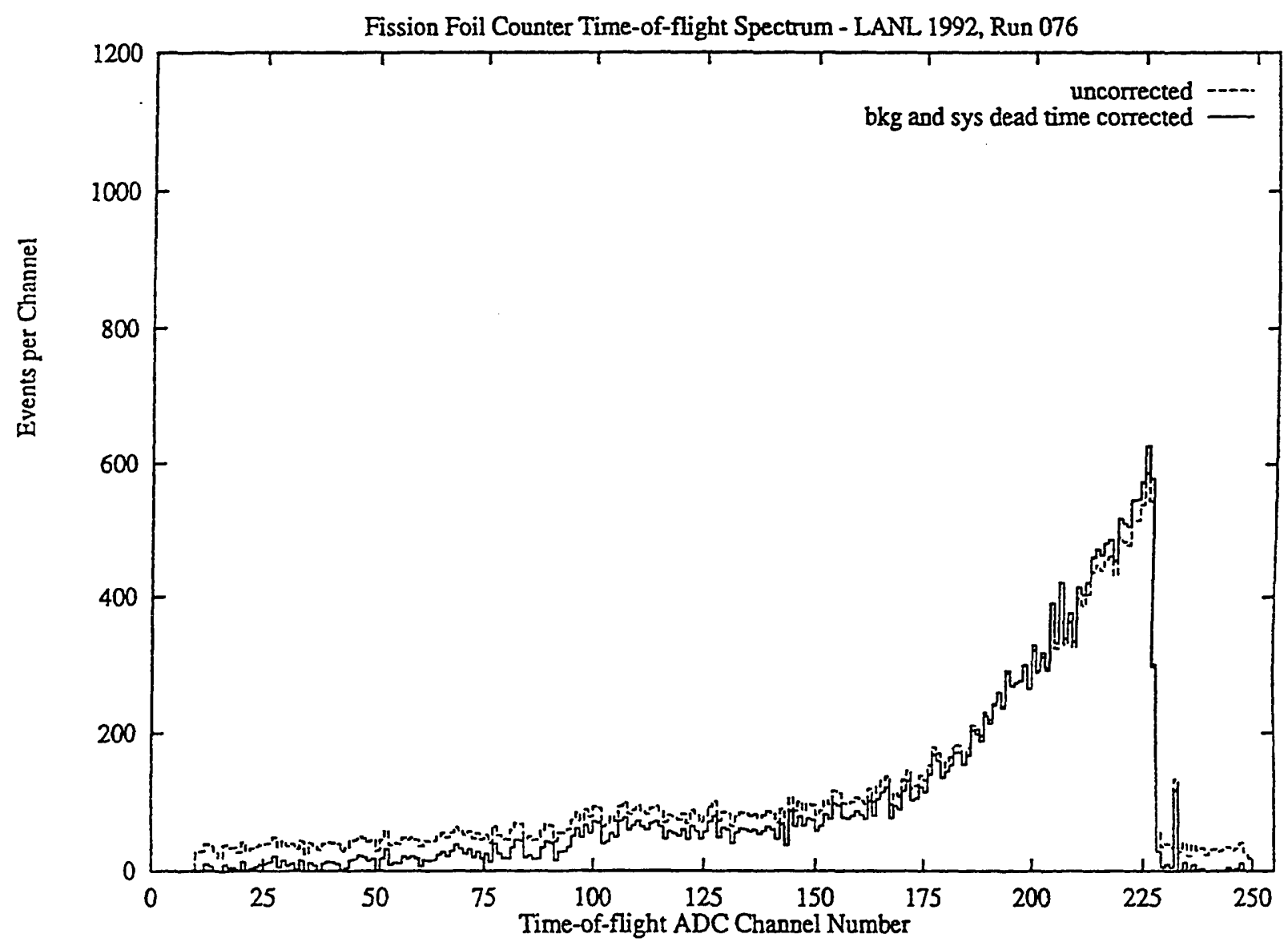

Figure 8: Fission foil counter spectrum TOF projection taken at LAMPF's Weapons Neutron Research Facility [19], 30 left, $37 \mathrm{~m}$ flight path of Target 4. Alpha decay of the U is seen as small pulses which have no TOF correlation. The fissions from the gamma flash appear in TOF channel 238 while the fast neutron induced fissions first appear in channel 228. 


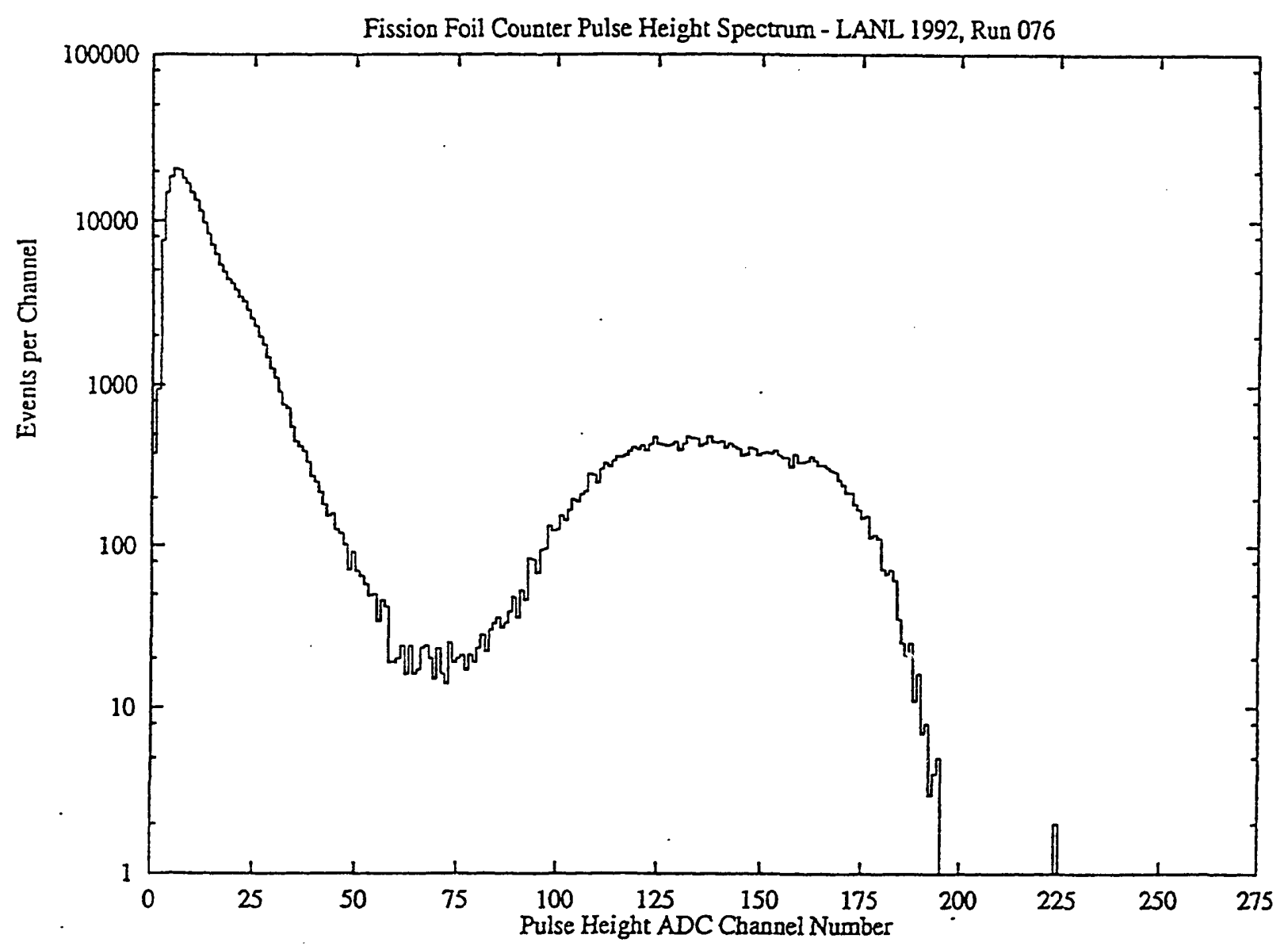

Figure 9: Fission foil counter one parameter spectrum taken at LAMPF's Laboratory's Weapons Neutron Research Facility [19], 30 left, $37 \mathrm{~m}$ flight path of Target 4 . Alpha decay of the $U$ is seen as small pulses below about channel 65 . The centroid of the fissions appears in channel 140. Self-absorption of fission fragments within the foil causes small fission events, indistinguishable from alpha decays. Techniques have been developed correct for self-absorption losses by extrapolating the fission fragment pulse height distribution to zero pulse height size[7,17]. 


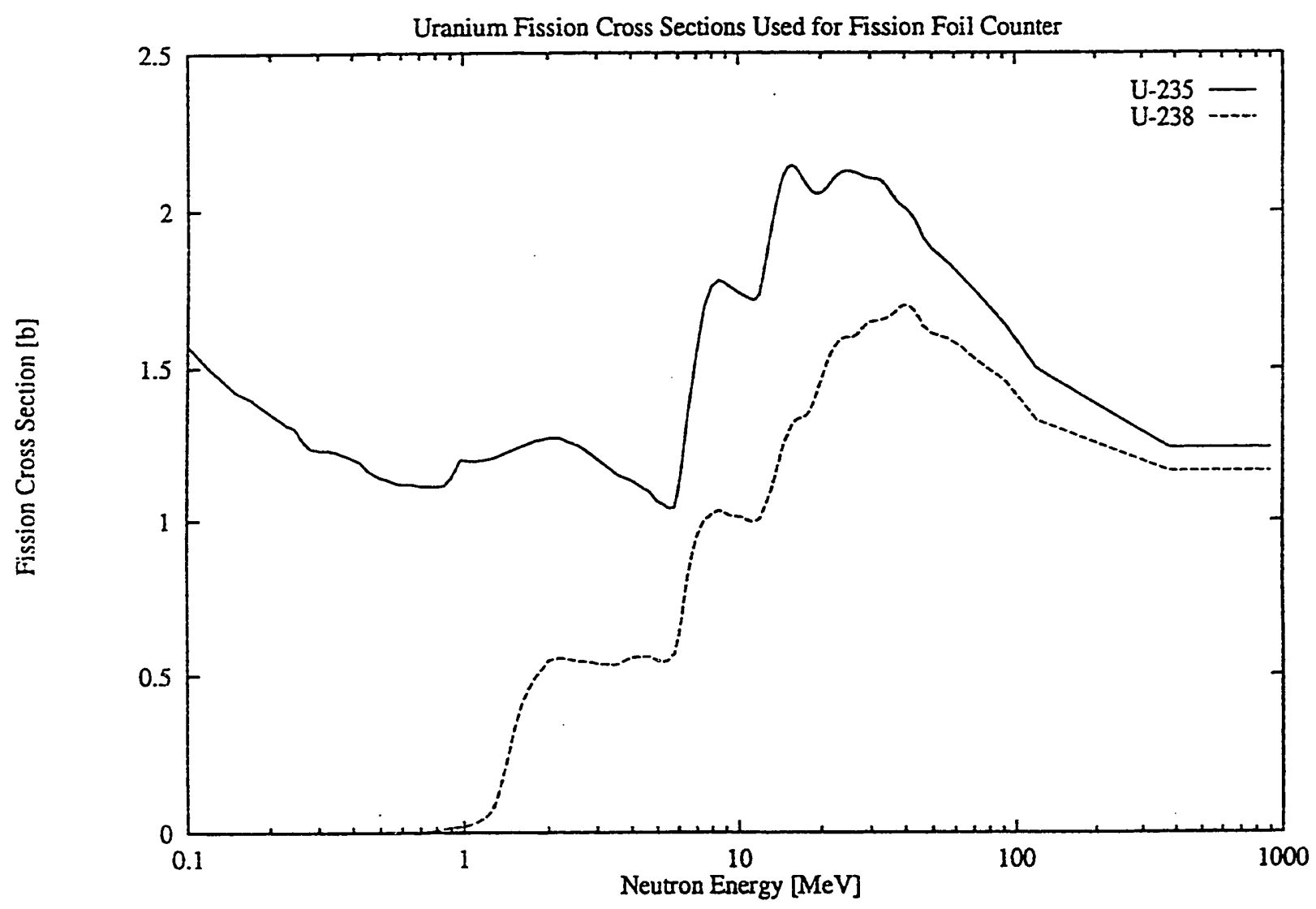

Figure 10: ${ }^{235} \mathrm{U}$ and ${ }^{238} \mathrm{U}$ differential neutron fission cross sections used in these fluence determinations. Below $20 \mathrm{MeV}$ ENDF cross sections were used[11]. Above $20 \mathrm{MeV}$ the measurements of Ullmann[23] were used. The ${ }^{235} \mathrm{U}$ foil was used for the present work. By using different foils, one can effectively select the sensitivity of the device to low energy neutrons. Note the fission threshold of ${ }^{238} \mathrm{U}$ at about $1.5 \mathrm{MeV}$. 
about $1 \mathrm{~m}$ behind the fission foil counter. Amplified scintillator pulses from the anode were input into a constant fraction discriminator. The (CFD), with the threshold set to exclude noise and gamma ray events, produced logic pulses which were counted in a CAMAC scaler. Thus the number of scalar counts is proportional to the integral neutron fluence.

As with the FFC electronics, front end electronics were located in the detector station and powered with an $\mathrm{AC}$ isolation transformer. These units included a high voltage power supply, a linear fanout, and a constant fraction discriminator. The CFD logic pulse input tc a CAMAC scaler located in the data acquisition trailer. Note that the scalers were gated off between macropulses and if the beam shutter was closed.

\subsection{Data Acquisition Systems}

A microcomputer based data acquisition system was used at LANL. The LANL kerma measurements were acquired with an Apple Quadra Computer and commercial software called KMAX. ${ }^{3}$

\subsection{Data Reduction Techniques for Kerma Determinations}

The conversion of two parameter (TOF and PHA) spectra into kerma factors as a function of neutron energy requires several major steps. First the neutron flight time is converted to relativistic energy. Second, ionization pulse sizes are converted to absorbed dose in the material of interest. Then an absorbed dose integral over some neutron energy range is computed. The absorbed dose divided by the neutron fluence, integrated over the same neutron energy range, is then the kerma factor.

Practical limitations in the performance of the detectors and the data acquistion electronics brought about the need for several corrections. The most significant of these corrections is for the variable electron drift times within the LPPCs. This additional time, which has a nonlinear defenderice on ionization pulse size, greatly degrades the quality of the neutron time of flight measurement. While the amount of this distortion depends on the location of the original ionization track in the counter, the electric field strength throughout the counter, as well as some nonideal performance characteristics associated with the electronic module used for the flight time pick-off, a satisfactory empirical correction technique has been developed.

A basic assumption of the correction al-rithm is that there should be neutron induced events of all sizes at flight times corresponding to the arrival of the fastest neutrons. The correction algorithm consists of two basic steps, the identification of the pulse height dependence on the drift time, followed by an appropriate shearing

\footnotetext{
${ }^{3}$ Sparrow Corporation, Mississippi Sta te,MS
} 
of the two parameter arrays. Figure 12 shows the time of flight edge before correction in the A-150 plastic LPPC. While the curves droop at smaller pulse heights, incorrectly indicating longer flight times, the corrected matrix exhibits no such defect. A projection of the two parameter arrays to the time of flight axis, for two different ranges of event sizes, are shown in figure 13 and figure 14. A dramatic improvement in the time response of the proportional cointer is seen.

Other corrections include electronic deadtime of the data acquistion systems and so called frame overlap in the time of flight spectra. The latter effect arises from the coincident arrival of neutrons from previous neutron beam pulses. This makes energy discrimination based on flight time impossible. Instead, overlap contribution is assumed constant in time, which then allows a simple background subtraction of a constant value from all time of flight intervals. The effects of these corrections can also be seen in figure 15 .

\subsection{Results}

The Los Alamos measurements are a collaborative effort by the University of Wisconsin - Madison, the Weapons Neutrons Research (WNR) facility of LANL and the Physikalisch-Technische Bundesanstalt (PTB).

The first Rossi type proportional counters for the measurement of oxygen have been successfully developed during this grant period. The new detectori, a matched pair of metal and metal-oxide counters, ultimately offer a lower uncertainty in kerma, superior pulse height resolution, and greater signal to noise than was previously achieved.

The construction of these new counters, along with improvements in data acquistion electronics and software, represent progress towards recent measurements of carbon, oxygen, and A-150 plastic kerma factors. These measurements were essentially identical to those made in 1992, but with many improvements in the experimental apparatus. Preliminary analysis of the most recent LANL spectra show, for the first time, visible gamma-ray flashes, which greatly simplifies the time-of-flight to relativistic neutron energy analysis.

\subsubsection{LANL 92 Results}

The neutron kerma and fluence measurements made at LANL in 1992 are now in the final stages of analysis. Microdosimetric plots of the proportional counter data are shown for $\mathrm{C}, \mathrm{Zr}, \mathrm{ZrO}_{2}$, and $\mathrm{A}-150$ plastic.

All microdosimetric plots shown here are in arbitrary $\mathrm{Y} \cdot \mathrm{D}(\mathrm{Y})$ units. Further, all such spectra are the projection of two parameter data from all neutron energies present (i.e. $100 \mathrm{keV}$ to $750 \mathrm{MeV}$ ). The analysis code to produce such curves for several binned relativistic neutron energies is still in progress. All spectra show the 


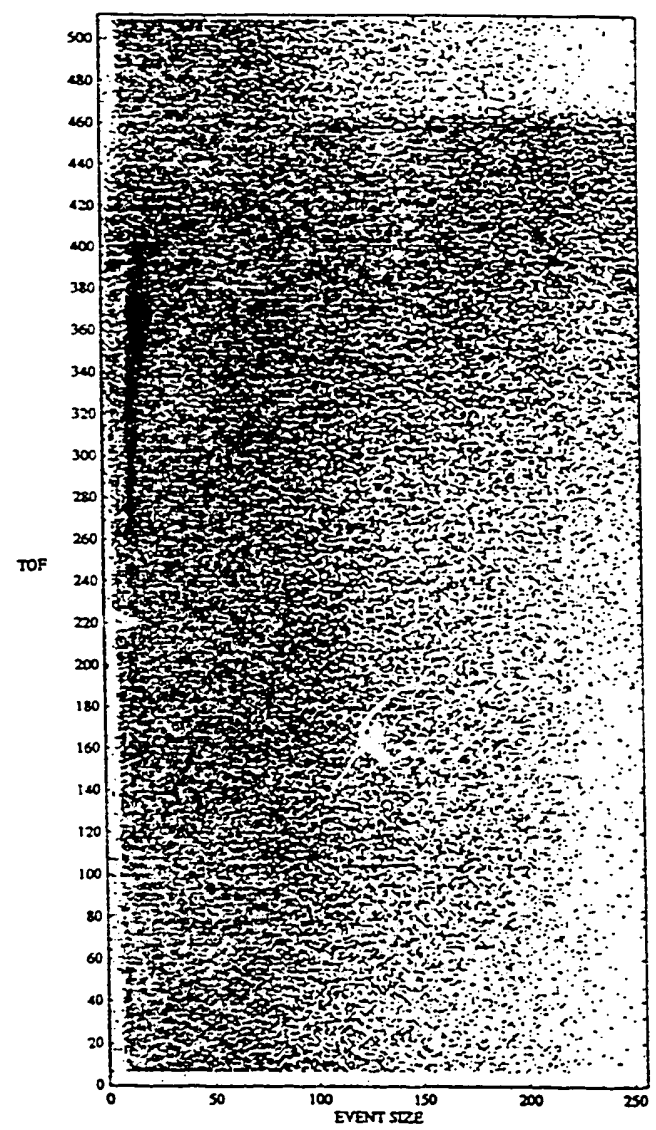

Figure 11: A-150 plastic low pressure proportional counter two parameter spectrum taken at LAMPF's Weapons Neutron Research Facility, $30^{\circ}$ left, $40 \mathrm{~m}$ flight path of Target 4 . The grayscale density represents the number of pulses for particular TOF and $\mathrm{PH}$ value. The downward curvature in the TOF edge arises from the addition of the electron drift time within the chamber to the neutron flight time. As the distance from the anode increases, the chord length decreases, resulting in a less energy deposition and a smaller pulse which is delayed by the electron drift time. 


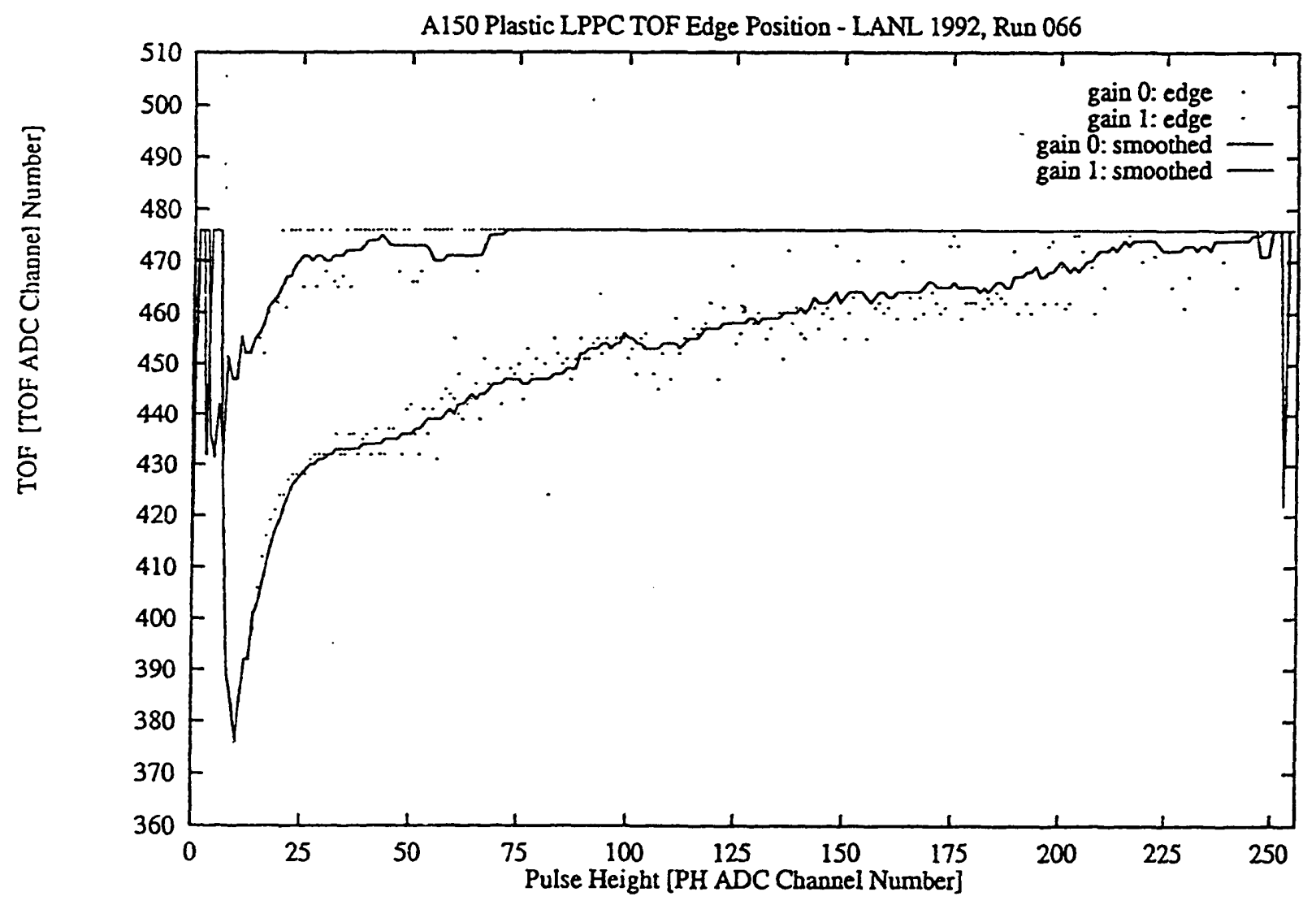

Figure 12: The curves show the time-of-flight of the fastest neutron induced events registered in the LPPC. Both curves are from the same detector, but cover different ionization event size ranges. The upper curve corresponds to the larger events, the lower to smaller events. The spike at very small pulse height sizes results from the algorithms inability to find such an edge. Actually, there are no time correlated events at these small event sizes. 


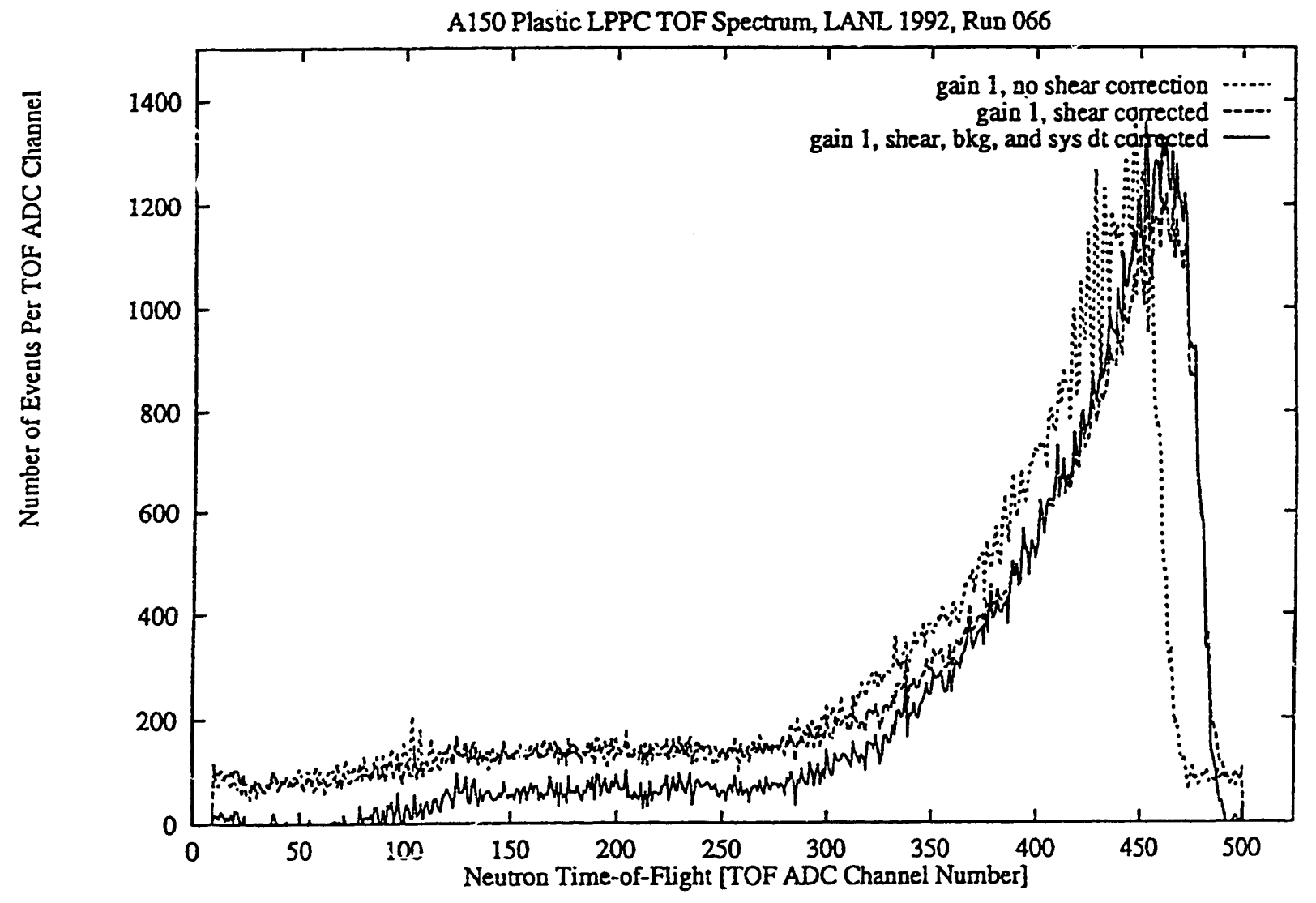

Figure 13: A-150 low gain low pressure propurtional counter TOF projection taken from the A-150 spectrum in Figure 11. 


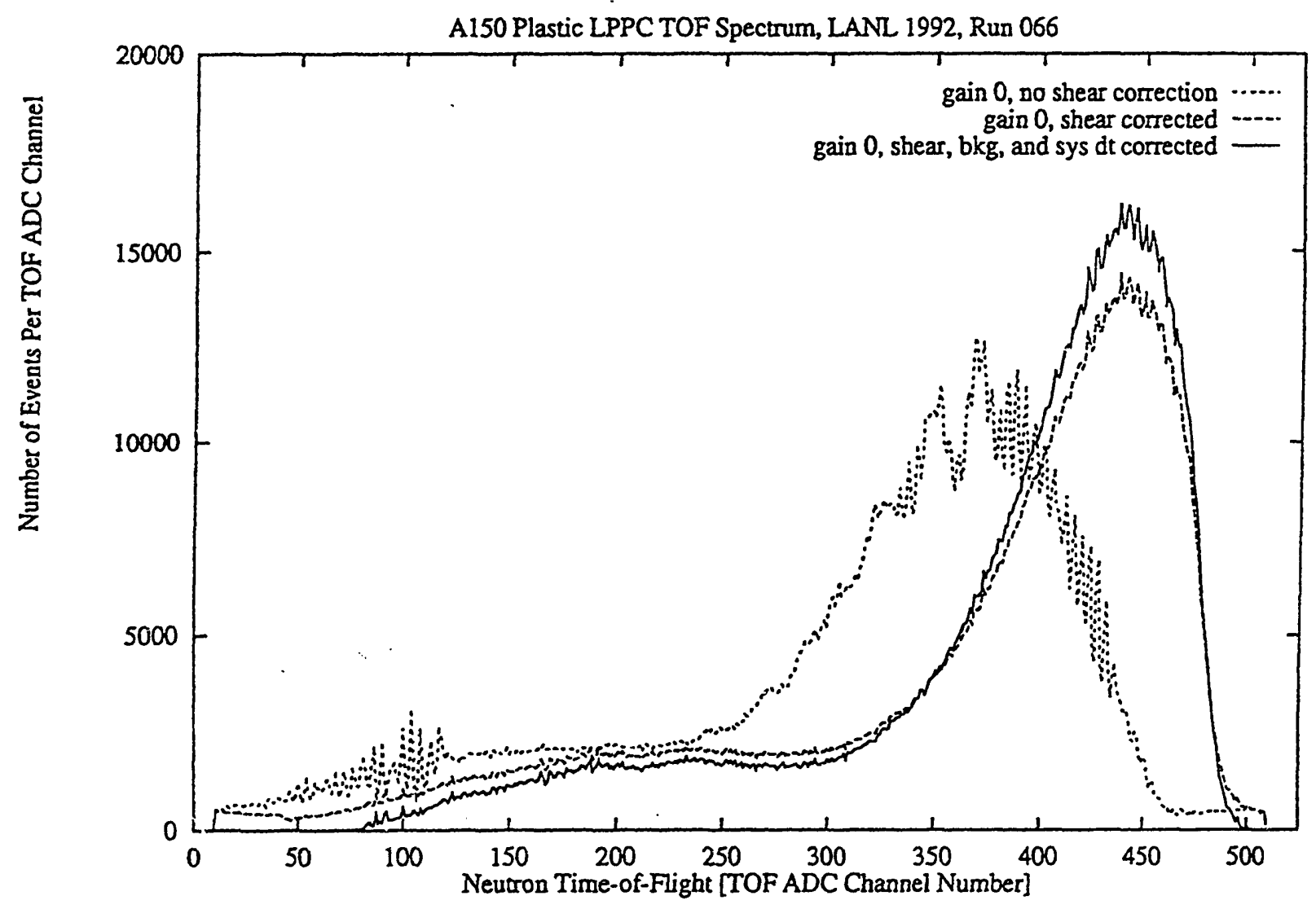

Figure 14: A-150 low pressure proportional counter TOF projection taken from the A-150 spectrum in Figure 11. 


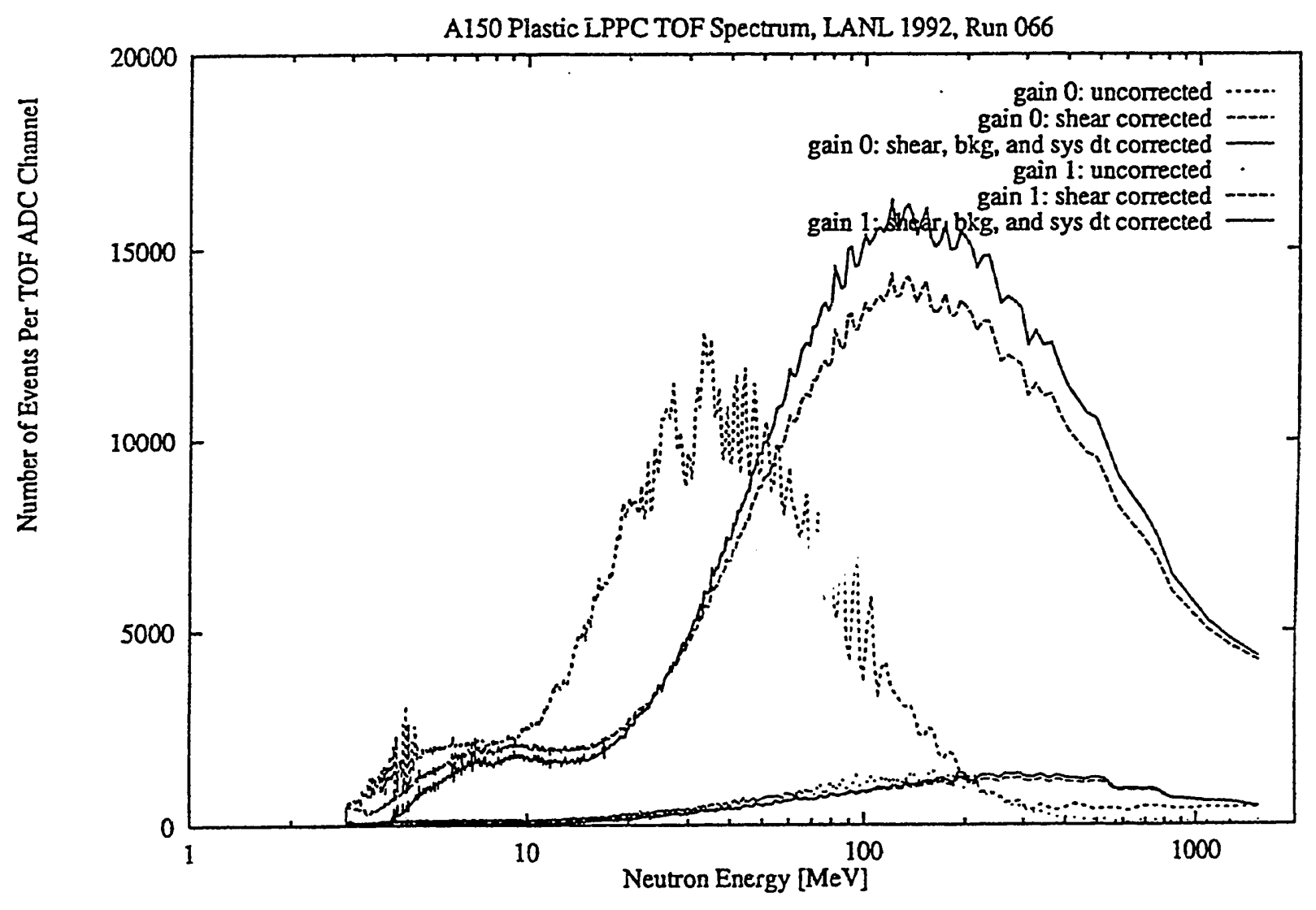

Figure 15: A-150 low pressure proportional counter TOF projection taken from the A-150 spectrum in Figure 11. Abscissa values have been converted from ADC time channels to relativistic neutron energy. Note the poor LPPC energy resolution from the presence of events ascribed to neutron energies up to $3 \mathrm{GeV}$, while the maximum neutron energy is known to be about 700 to $750 \mathrm{MeV}$. Proper binning in the time domain eliminates this problem, with of course data points available at many fewer neutron energies. 
raw data from the high and low gain pulse height channels. The dots represent unbinned values while the solid and dashed lines represent the values binned into variable bin sizes. While the bin sizes monotonically increase with $\mathrm{Y}$, there are always a constant number of bins per decade (30 in this case). Every bin size appears to have equal width when viewed logarithmically.

The results of the $\mathrm{Zr}$ and $\mathrm{ZrO}_{2}$ counters are shown in figures 16 and 17. Note that these counters are of the cylindrical design and do not contain helices. Additional build up material was installed to provide equilibrium charged particle spectra. The higher alpha production of the oxygen bearing counter is apparent.

A typical spectrum from the commercial A-150 tissue equivalent plastic LET 1/2 LPPC is shown in figure 18. Two series of measurements were made with this detector, one with 3 different amounts of A-150 plastic buildup material and another series at various positions in a water phantom, each on the beam central axis. In general, integral spectra (over all neutron energies) show very similar structure for different amounts of build up. It is clear that the additional material results in a somewhat greater proportion of dose being delivered by proton events, as would be expected. Equilibrium spectra of alpha and heavier charged particles are produced in very small mass thicknesses while proton equilibrium spectra require relatively large amounts of material.

Spectra from a carbon (graphite) LET 1/2 LPPC appear in figures 19 and 20. Three different amounts of carbon buildup material are shown. Integral spectra, again over all neutron energies, show a dramatic increase in absorbed dose contribution by the protons as additional buildup material is introduced. Measurements were made with the bare detector and with a cylindrical graphite buildup cap. The performance of this counter was somewhat impaired by a poor electrical connection within the gas tight container. This was not positively identified until disassembly by the manufacturer after the LANL 92 experiment was completed. Corrections for the reduced performance in time response seem to give acceptable results, though comparison of the final kerma factor values at energies below $25 \mathrm{MeV}$ will be a good basis for deciding if the measurements are indeed valid.

Additional similar measurements were made with silicon, iron, and magnesium. Analysis of these data sets is postponed until the carbon, oxygen, and A-150 plastic results are completed.

\subsection{Summary}

The accuracy of tissue absorbed dose measurements is generally recognized to be inadequate in fast neutron therapy facilities treating with neutrons above $30 \mathrm{MeV}$. Significant improvements can be made by including a correction for the differences between dosimeter materials and real tissue. The principle differences are carbon and oxygen content. Knowledge of kerma factors for these elements, the goal of this 
work, are needed for this correction.

Carbon and oxygen kerma measurements at the Los Alamos National Laboratory, along with neutron fluence measurements, have been successfully completed. Analysis is still in progress with final results expected by January 1994.

The first matched-pair $\left(\mathrm{Zr}, \mathrm{ZrO}_{2}\right)$ of Rossi type proportional counters have been built to measure oxygen kerma using the difference technique. Oxygen and carbon kerma factors were again measured at LANL in 1993. Preliminary results of these measurements show excelient detector performance and indeed are very promising. 


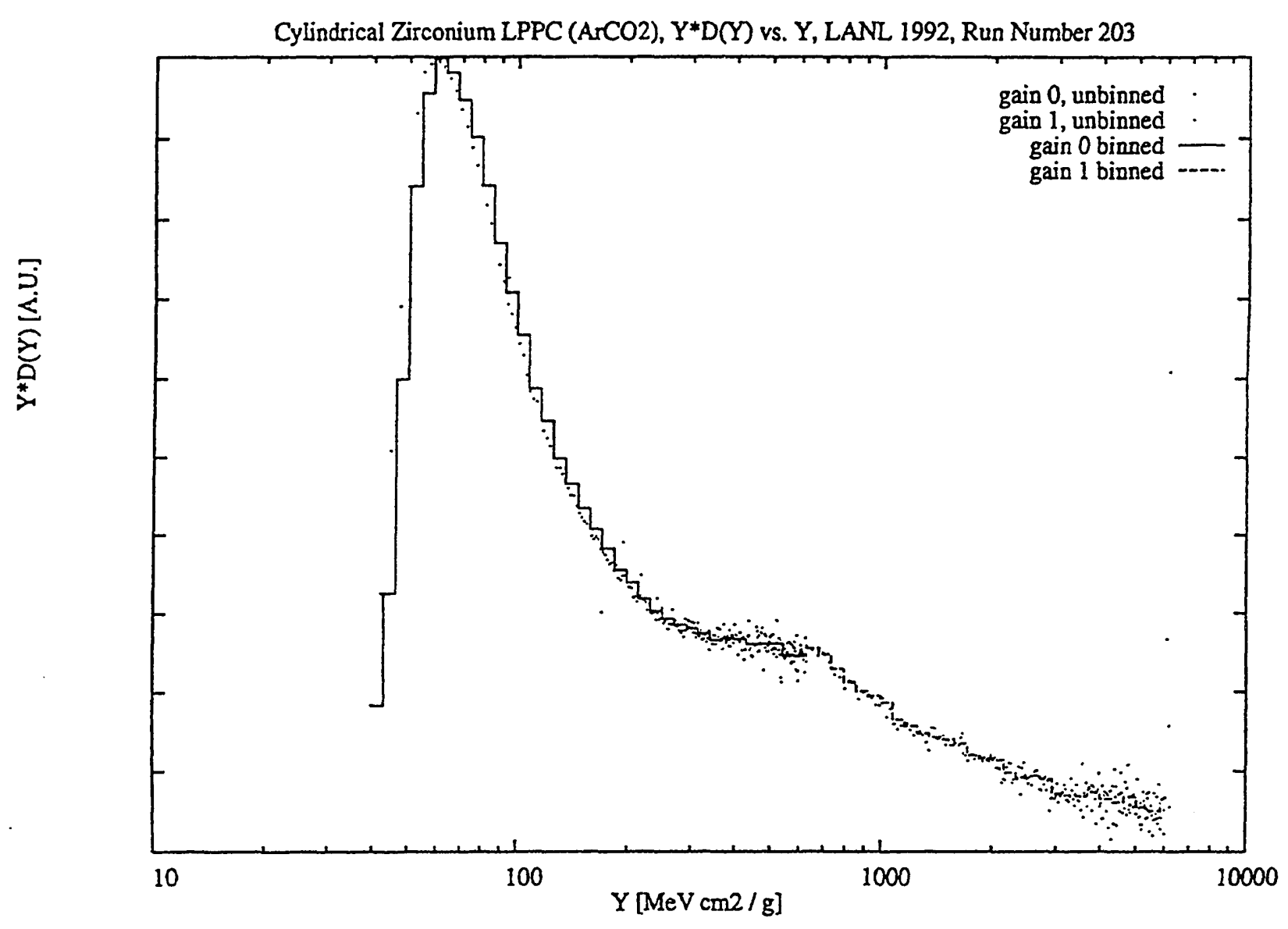

Figure 16: $\mathrm{Z}$ r microdosimetric spectrum from LANL-WNR white source neutrons. 


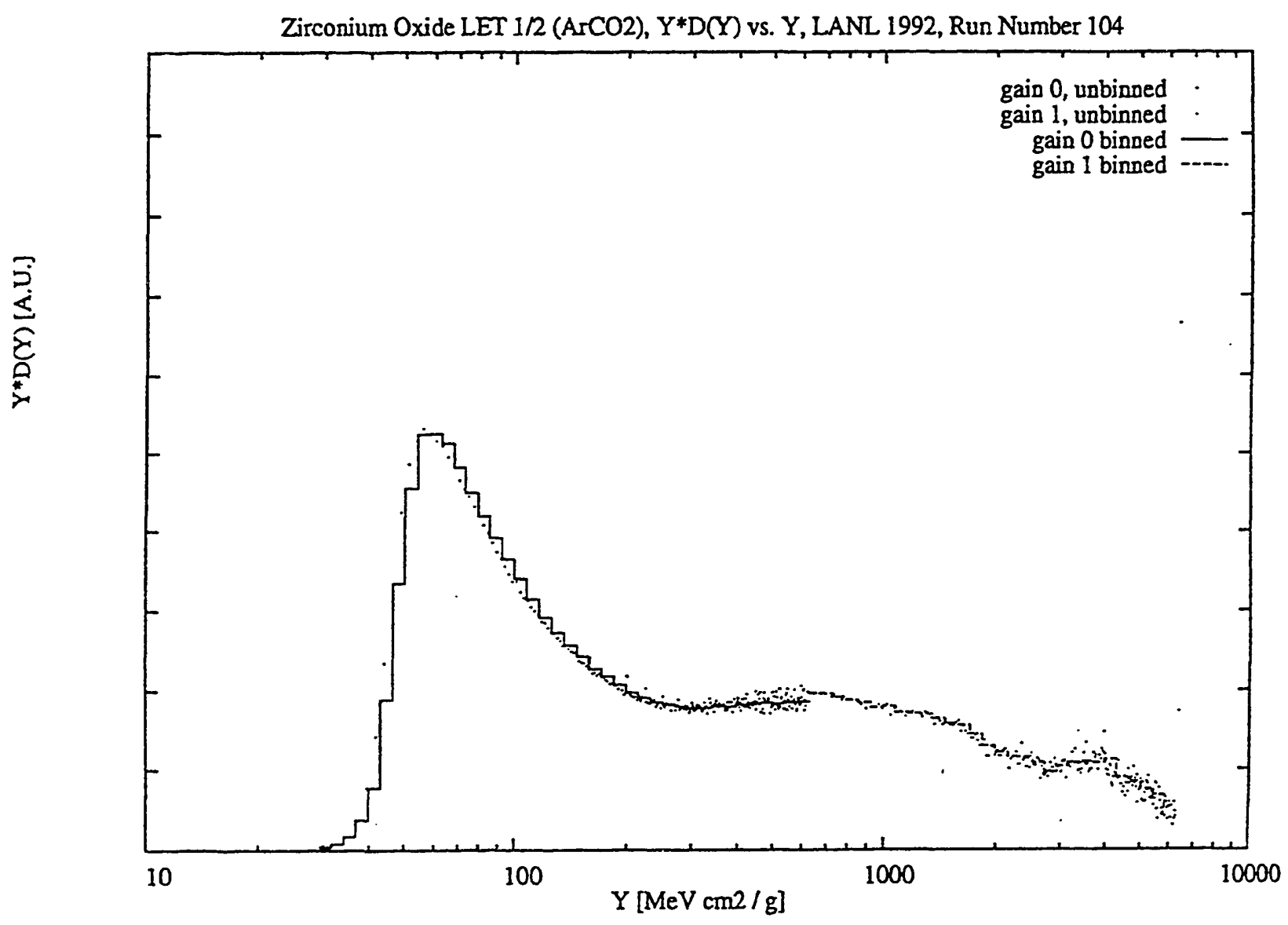

Figure 17: $\mathrm{ZrO}_{2}$ microdosimetric spectrum from LANL-WNR white source neutrons. 


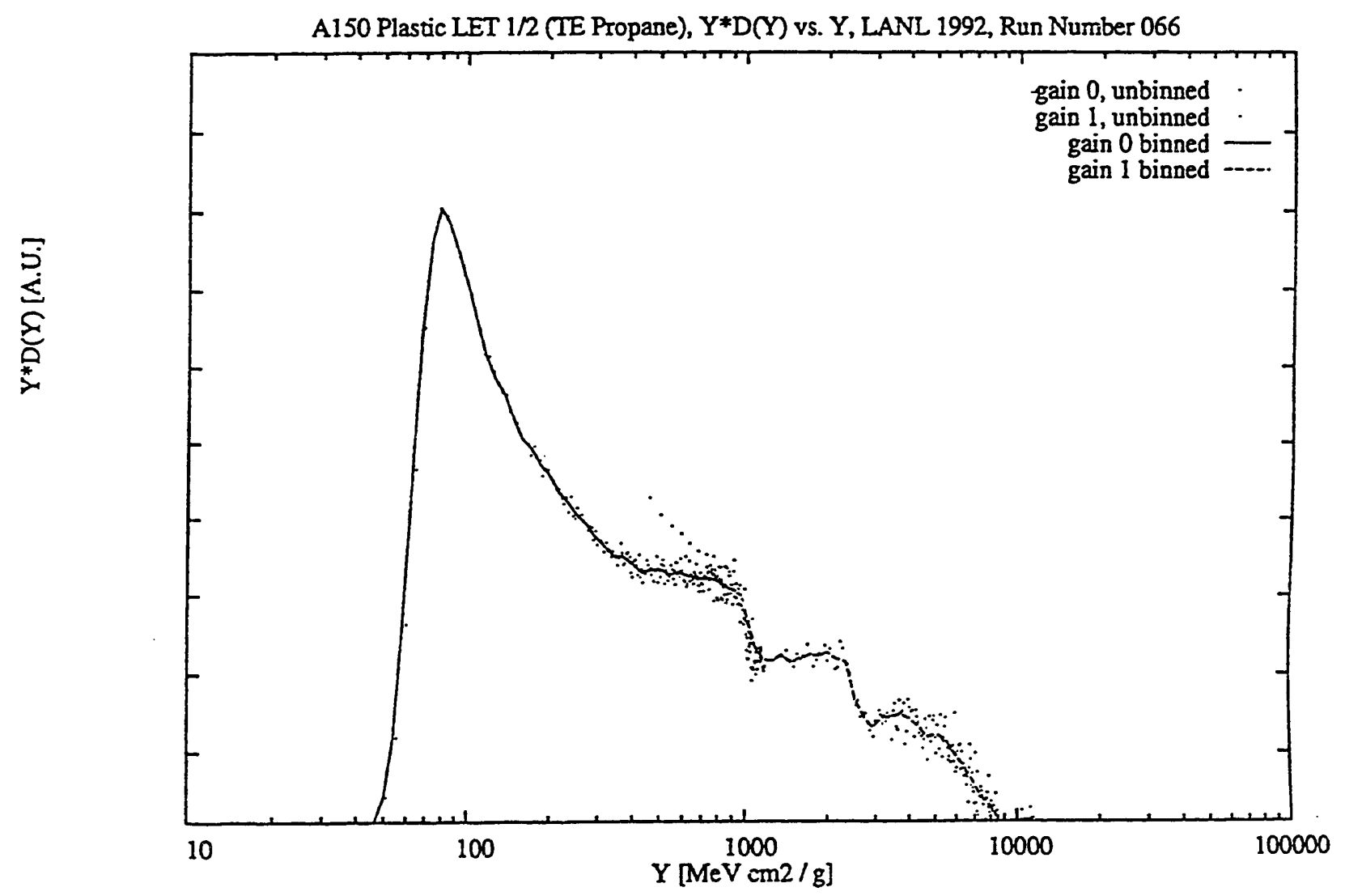

Figure 18: A-150 Tissue Equivalent Plastic LET $1 / 2$ microdosimetric spectrum from LANL-WNR white source neutrons. 


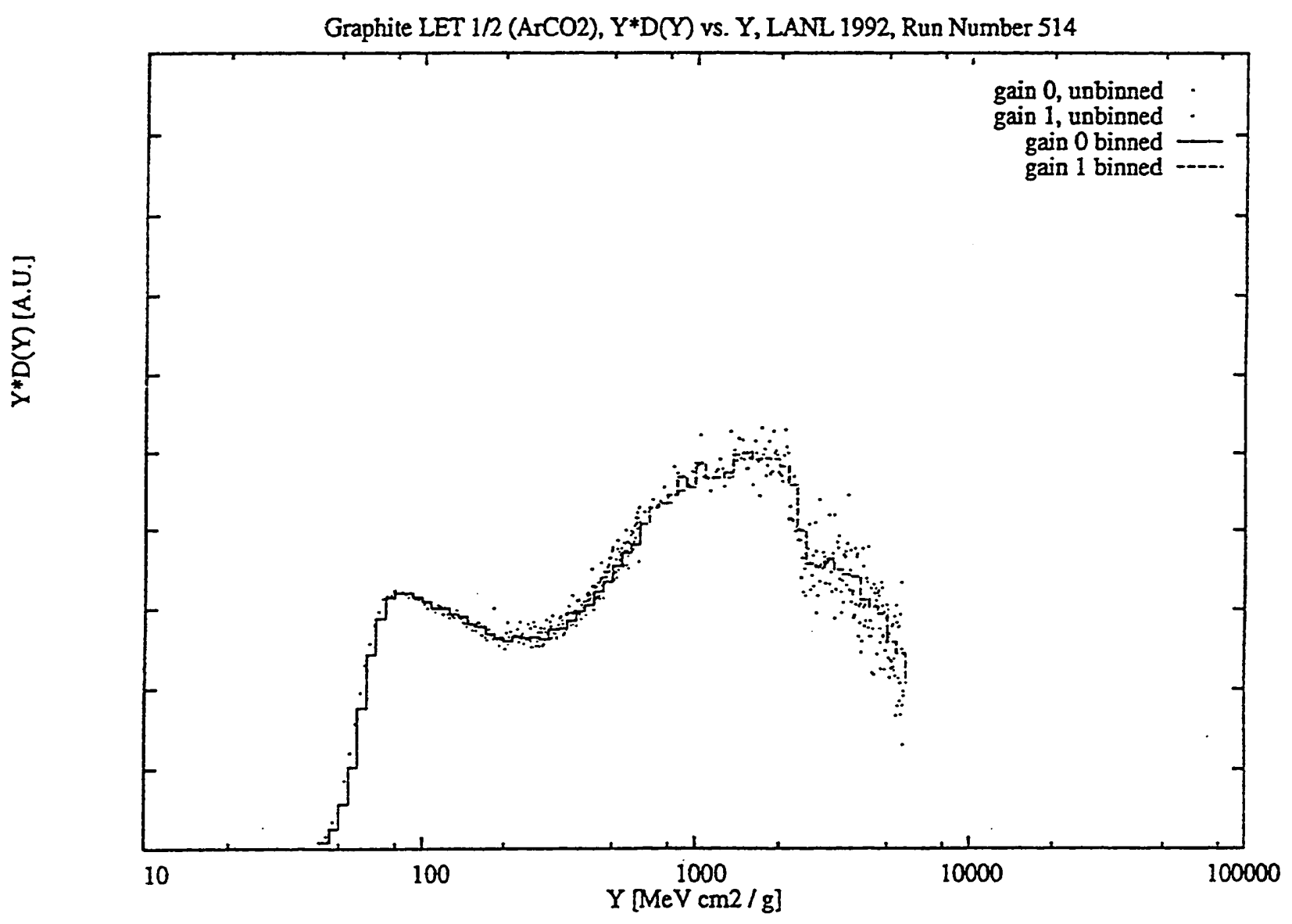

Figure 19: Carbon (graphite) LET 1/2 LPPC microdosimetric spectrum from LAMPF's WNR white source neutrons. This irradiation was made without any additional buildup material (see text). 


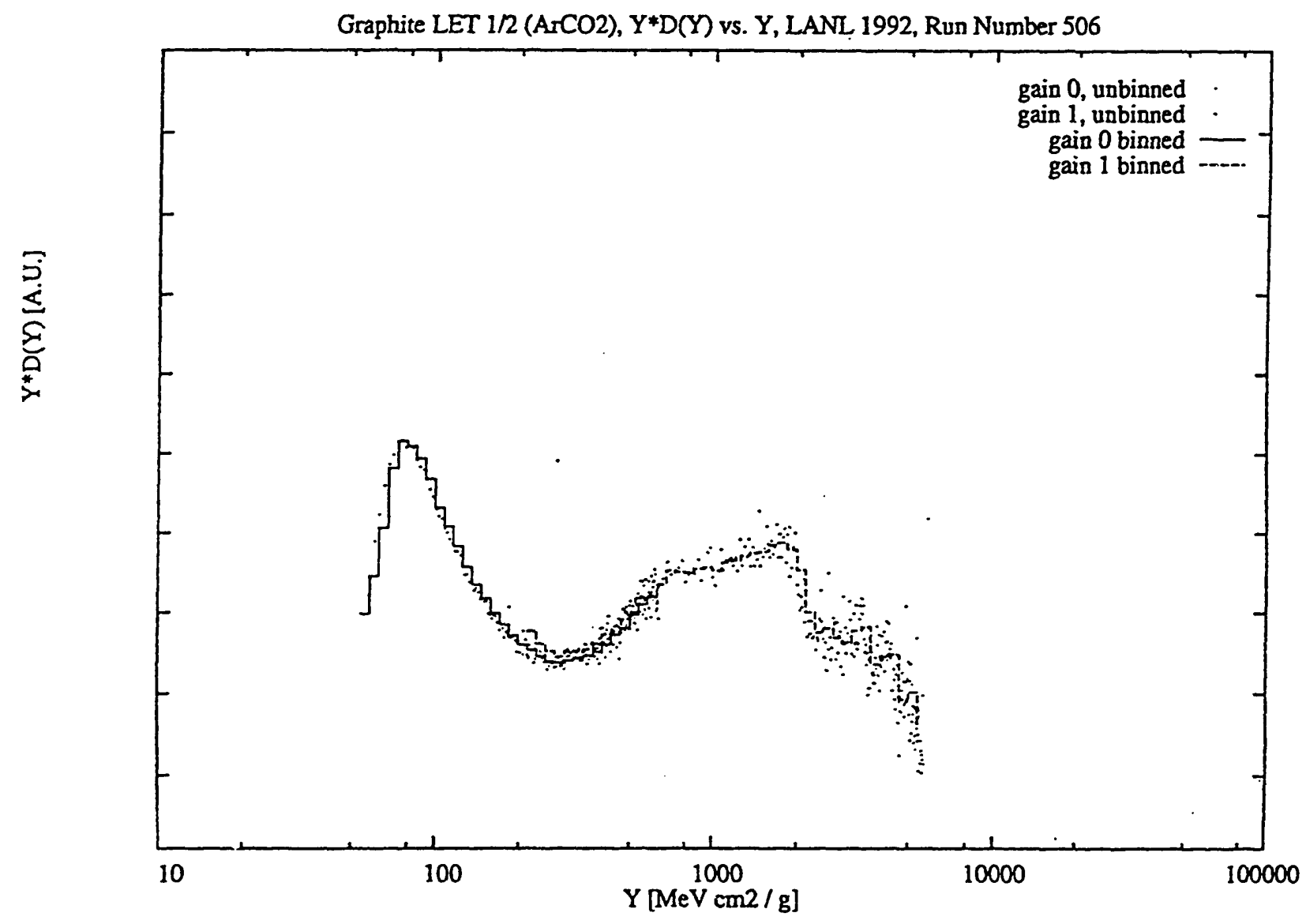

Figure 20: Carbon (graphite) LET 1/2 LPPC microdosimetric spectrum from LAMPF's WNR white source neutrons. This spectrum was made with a cylindrical buildup cap of graphite. 


\subsection{BIBLIOGRAPHY}

\section{References}

[1] H.H. Andersen and J.F. Ziegler. Hydrogen Stopping Powers and Ranges in All Elements. Pergamon Press, New York, 1977.

[2] F.H. Attix. Introduction to Radiological Physics and Radiation Dosimetry. John Wiley \& Sons, New York, 1986.

[3] P.J. Binns. Microdosimetry for a fast neutron therapy beam. PhD thesis, University of Cape Town, Cape Town, Republic of South Africa, June 1993.

[4] P.J. Binns, J.H. Hough, and B.R.S. Simpson. Time-resolved microdosimetry in a quasi-monoenergetic neutron beam. Presented at the $7^{\text {th }}$ Symposium on Neutron Dosimetry, Berlin, 1991.

[5] F.P. Brady and J.L. Romero. Neutron Induced Reactions in Tissue Resident Elements, Final Report to the National Cancer Institute, Grant No. 1R01 CA16261. Technical Report, University of California-Davis, Davis, CA, 1979.

[6] W.H. Bragg. Consequences of the corpuscular hypothesis of the gamma and $\mathrm{x}$ rays. Phil. Mag., 20:385, 1910.

[7] G.W. Carlson. The effect of fragment anisotropy on fission-chamber efficiency. Nucl. Instr. and Meth., 119:97-100, 1974.

[8] P.M. DeLuca, Jr., H.H. Barschall, M. Burhoe, and R.C. Haight. Carbon kerma factor for 18- and 20-MeV neutron. Nucl. Sci. Eng., 94:192, 1986.

[9] P.M. DeLuca, Jr., H.H. Barschall, R.C. Haight, and J.C. McDonald. Kerma factor of carbon for $14.1 \mathrm{MeV}$ neutrons. Radiat. Res., 100:78, 1984.

[10] P.M. DeLuca, Jr., H.H. Barschall, Y. Sun, and R.C. Haight. Kerma factor of oxygen, aluminum, and silicon for $15-$ and $20-\mathrm{MeV}$ neutrons. Radiat. Prot. Dos., 23:27, 1988.

[11] ENDF. ENDF/B-V: Evaluated Nuclear Data File. Technical Fieport, Brookhaven National Laboratory, National Nuclear Data Center, Upton, NY, 1980.

[12] L.H. Gray. Absorption of penetrating radiation. Proc. Roy. Soc. (London), A122:647, 1929.

[13] L.H. Gray. Ionization method for the absolute measurement of gamma ray energy. Proc. Roy. Soc. (London), A156:578, 1936. 
[14] C.L. Hartmann. Measurements of neutron kerma factors at 18, 23, and 25 MeV. PhD thesis, University of Wisconsin, Madison, Wisconsin, 1991.

[15] C.L. Hartmann, P.M. DeLuca, Jr., and D.W. Pearson. Measurement of C, $\mathrm{Mg}$, and $\mathrm{Fe}$ kerma factors and the ${ }^{19} \mathrm{~F}(\mathrm{n}, 2 \mathrm{n}){ }^{18} \mathrm{~F}$ cross section for 18 to $27 \mathrm{MeV}$ neutrons. In S.M. Qaim, editor, Nuclear Data for Science and Technology, pages 589-591, Springer-Verlag, Berlin, Germany, 1992.

[16] C.L. Hartmann, P.M. DeLuca Jr., and D.W. Pearson. Measurement of neutron kerma factors in $\mathrm{C}, \mathrm{O}$, and $\mathrm{Si}$ at 18,23 , and $25 \mathrm{MeV}$. Radiat. Frót. Dos., $44(1 / 4): 25-30,1992$.

[17] S. Kahn, R. Harman, and V. Forgue. Energy distributions of fission fragments from uranium dioxide films. Nuclear Science and Engineering, 23:8-20, 1965.

[18] P.W Lisowski. Private communication, 1992.

[19] P.W. Lisowski, C.D. Bowman, G.J. Russell, and S.A. Wender. Los Alamos National Laboratory Spallation Neutron Sources. Nucl. Sci. Eng., 106:208, 1990.

[20] International Commission on Radiation Units and Measurements. Tissue Substitutes in Radiation Dosimetry and Measure. Volume Report 44, International Commission on Radiation Units and Measurements, Bethesda, MD, 1989.

[21] G. Randers-Pehrson, R. W. Finlay, J. F. Dicello, and J. C. McDonanld. In Proc. $8^{\text {th }}$ Symposium on Microdosimetry, EUR 8395, page 1169, Commission of the European Communities, Brussels, 1982.

[22] U.J. Schrewe, H.J. Brede, and H. Schuhmacher. The use of microdosimetric detectors combined with time-of-flight techniques. Nucl. Instr. and Meth. in Phys. Res., 225-230, 1990.

[23] J.G. Ullmann. Personal Communication, 1993.

[24] S. Wender, R. Haight, R Nelson, C Laymon, A. Brown, S. Balestrini, W. McCorkle, and T. Lee. A fission ionization detector for neutron flux measurements at a spallation source. Los Alamos WNR internal report, 1990. 


\section{Ultra-soft X-Ray Response of TLD}

\subsection{Participants}

Ricardo E. Carrillo, Paul M. DeLuca, Jr., David W. Pearson, and James F. MacKay.

\subsection{Introduction}

Last year's progress report summarized the bulk of this experiment. Since that time, we extended the measurements to higher and lower energies as well as more complete determinations at intervening energies. Herein a selected set of results are reported focussing on the new work. For a complete discussion of this work please refer to the Ph.D. thesis of Ricardo Carrillo [15] which has been issued as a USDOE report. A preliminary report of the initial work was also published [14]. We are now preparing reports of the complete work. What follows highlights some of the principal results.

\subsection{Energy Response}

TLD materials, $\mathrm{LiF}$ and $\mathrm{CaF}_{2}: \mathrm{Dy}$, were exposed to a range of energy fluences at several discrete photon energies. Figures 21 and 22 depict the results for $\mathrm{LiF}$ and $\mathrm{CaF}_{2}$, respectively. 


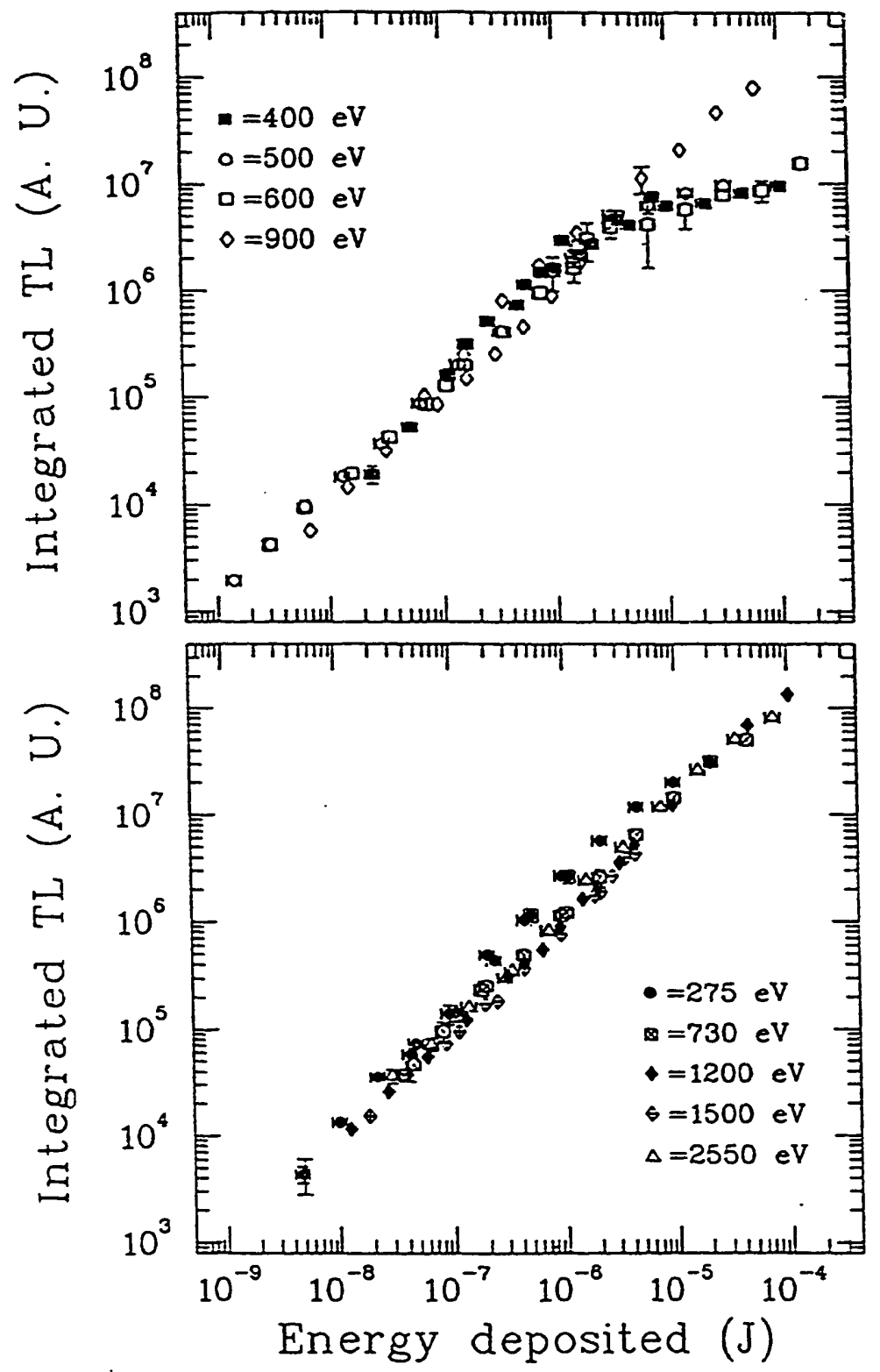

Figure 21: Integrated TL response of TLD-100 crystals vs. energy deposited. Results in the top panel employed an Aluminum window between the accelerator and the samples. Values in the lower panel correspond to irradiations with either a $\mathrm{Be}$ or aluminumized Miylar window. 

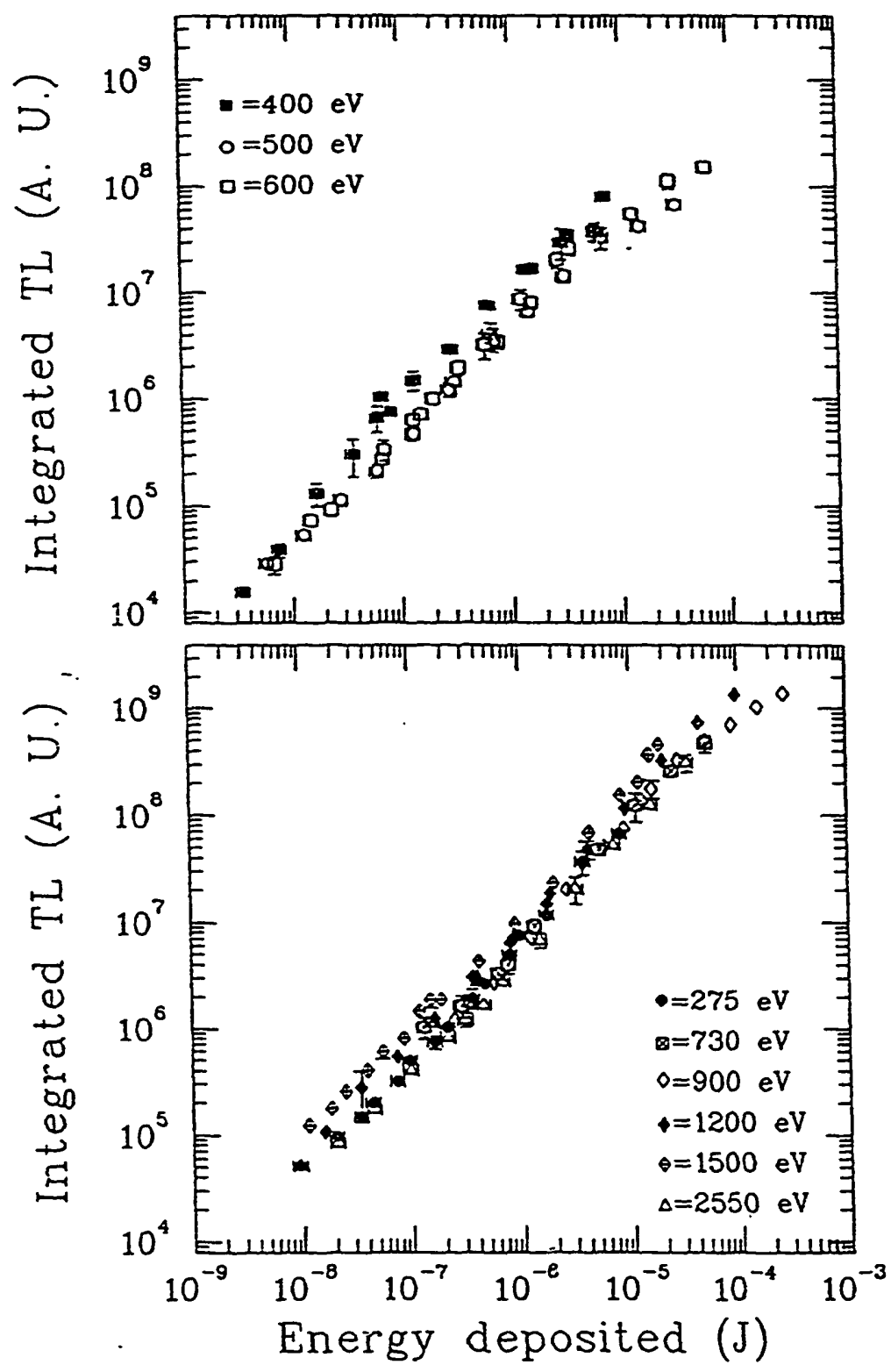

Figure 22: Integrated TL response of TLD-200 vs. energy deposited. Results in the top panel employed an Al window between the accelerator and the samples. Values in the lower panel correspond to irradiations with either a $\mathrm{Be}$ or aluminumized Mylar window. 
From these data, we note that the TL response is linear over a very large range of energy depcsitions. Moreover, the response is independent of photon energy. Above about $10 \mu \mathrm{J}$ a supra-linear response is observed. An interesting saturation response for certain exposure conditions occurs above $4 \mu \mathrm{J}$, specifically when an $\mathrm{Al}$ window is ised to isolate the experimental exposure apparatus from the ultra-high vacuum conditiors present in the electron synchrotron. This window was $\simeq 0.8 \mu \mathrm{m}$ thick. No such response was noted when $\mathrm{Be}, \simeq 7.5 \mu \mathrm{m}$ thick, or Myler, $\simeq 2.5 \mu \mathrm{m}$ thick, windows were employed.

We esiablished that the submicron $\mathrm{Al}$ window was relatively transparent to photons with energies below $70 \mathrm{eV}$. These photons cause a transfer of stored electrons from higher to lower temperature traps. Figure 23 presents a comparison of glow curves for similar energy depositions but exposure through either the $\mathrm{Be}$ and Mylar windows or the $\mathrm{Al}$ window. The energy transfer process is apparent. In essence, low temperature traps are filled by energy transfer producing a saturation like phenomena. 

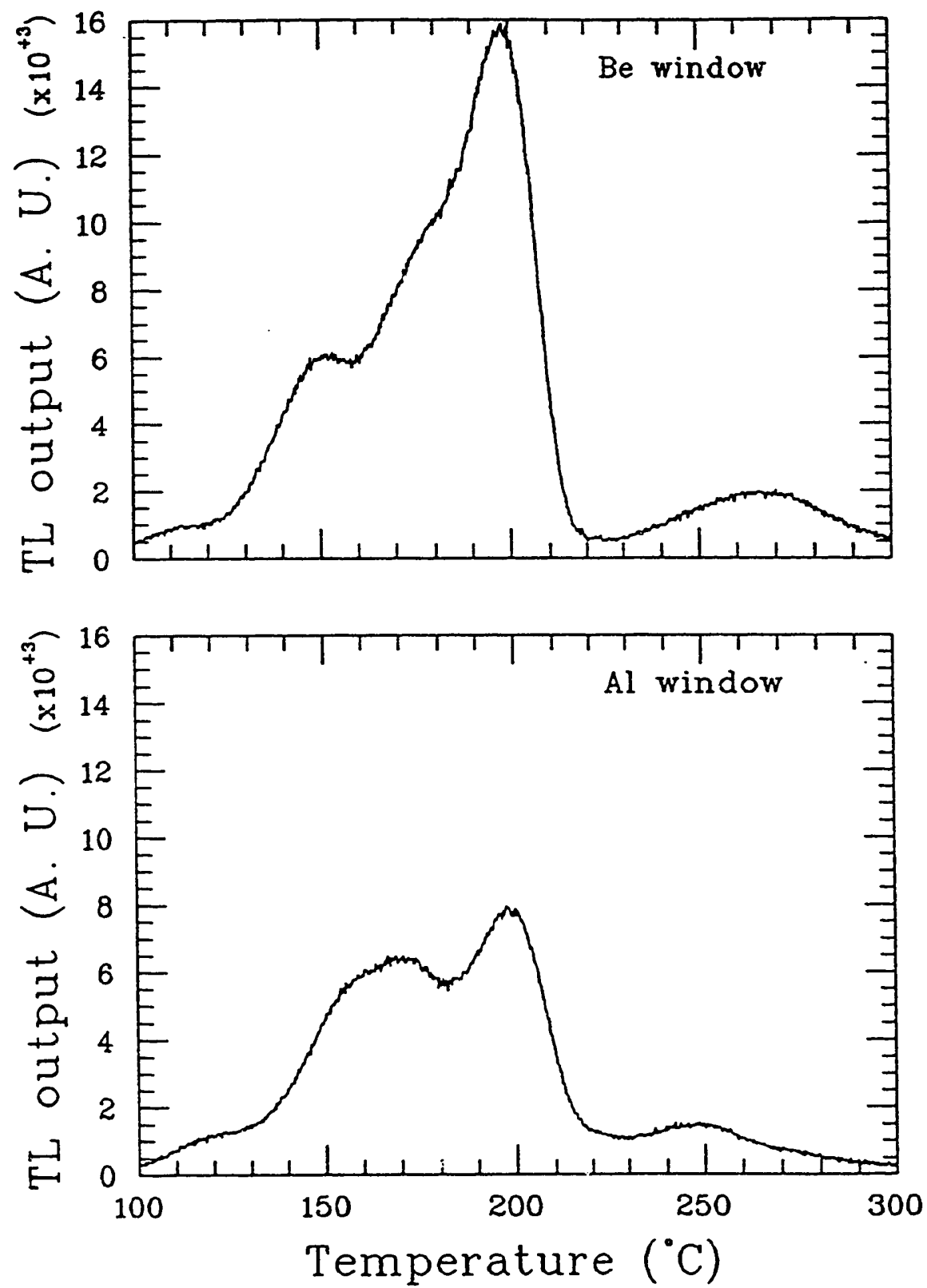

Figure 23: Glow curves of helium annealed lithium fluoride crystals exposed to $600 \mathrm{eV}$ photons with the Be window (top) and the submicron $\mathrm{Al}$ window (bottom). The same total exposure of $1630 \mathrm{~nJ}$ was used in both cases, although UV light contributed by an unknown portion to this value for the $\mathrm{Al}$ window case. 


\subsection{Supra-Linearity}

As measured above, the TL response vs. energy fluence was linear over a range of energies from $\sim 1 \mathrm{~nJ}$ to about $1 \mu \mathrm{J}$. Above that level, a supra-linear response was noted. An example of this is given in Figure 24 for LiF. Exposures with the Al and $\mathrm{Be}$ windows are depicted. The bleaching phenomena is clearly seen for the Al window exposures. Values shown for any photon energy represent a single data gathering exposure. Averaging all data sets by energy yielded the supra-linearity factors shown in Table 4. No values are reported for the "bleached" exposures. 


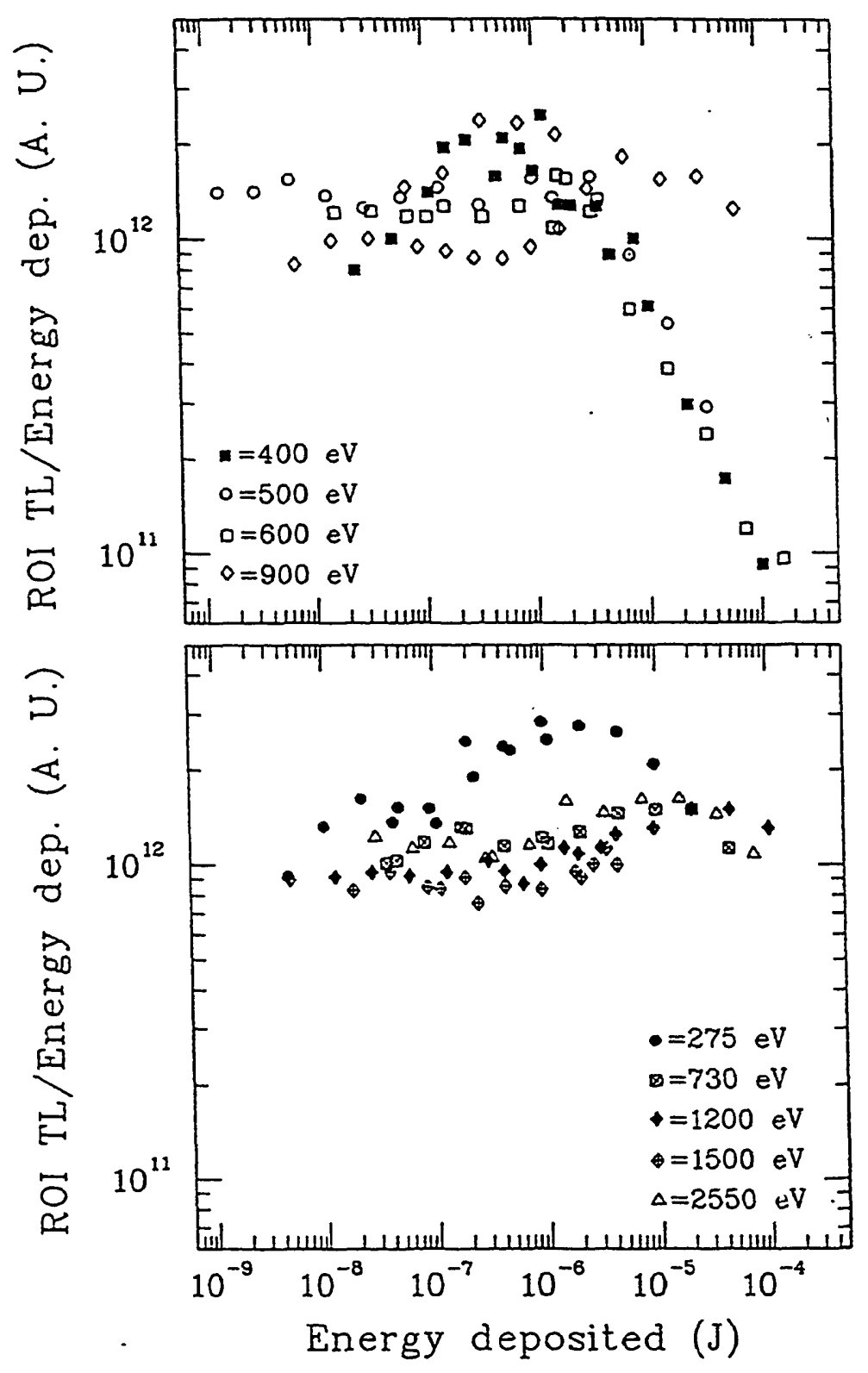

Figure 24: Integrated TL response per unit total energy deposited values plotted vs. total energy deposited for TLD-100 crystals at several energies. Some of the irradiations at $400,500,600$, and $900 \mathrm{eV}$ (top panel) employed submicron Al window. Results depicted in the bottom panel employed either a Mylar or Be window. Error bars, not shown, are about $\pm 15 \%$. 
Table 4: TLD-100 crystal supra-linearity factors, ROI response. Exposure values were the onset and maximum supra-linearity are seen are given in columns 3 and 4 .

\begin{tabular}{|c|c|c|c|}
\hline $\begin{array}{c}\text { Energy } \\
(\mathrm{eV})\end{array}$ & $\begin{array}{c}\text { Supra-linearity } \\
\text { factor }\end{array}$ & $\begin{array}{c}\text { Onset } \\
(\mu J)\end{array}$ & $\begin{array}{c}\text { Maximum } \\
(\mu J)\end{array}$ \\
\hline \hline 2550 & $1.5 \pm 0.3$ & 0.3 & 20 \\
1500 & $1.5 \pm 0.3$ & 0.7 & 4 \\
1200 & $1.6 \pm 0.4$ & 0.6 & 50 \\
900 & $1.7 \pm 0.5$ & 0.5 & 30 \\
730 & $1.3 \pm 0.4$ & 0.8 & 20 \\
600 & $\geq 1.3 \pm 0.3$ & 0.5 & \\
275 & $1.9 \pm 0.5$ & 0.1 & 1 \\
\hline
\end{tabular}

In summary, with a caveat regarding elimination of UV-light contamination, both $\mathrm{LiF}$ and $\mathrm{CaF}_{2}:$ Dy can provide routine determination of energy fluences for 275 to $3000-\mathrm{eV}$ photons. As a result of these measurements, we now have complete information of $\mathrm{TL}$ response for $\mathrm{LiF}$ and $\mathrm{CaF}_{2}$ : $\mathrm{Dy}$ from $275 \mathrm{eV}$ to $\sim 20-\mathrm{MeV}$ photon energy. Please note that a portion of Dr. Carrillo's support was provided by El Consejo Nacional de Ciencia y Technologia, Mexico as well as by the John R. Cameron Medical Physics Foundation.

The references tabulated below provide a comprehensive listing of relevant prior and related work.

\section{References}

[1] Meger, C. M., Pearson, D. W., DeLuca, P. M., Jr., Wells, G. M., Redaelli, R. and Cerrina, F., "A comparison of three detectors for soft X-ray dosimetry," Nucl. Inst. Meth. A266 608-611 (1988).

[2] Meger, C. M. Dosimetry and Radiobiology of synchrotron-produced ultrasoft $X$-rays. Ph.D. Thesis. UW-Madison (1989).

[3] Meger, C. M., Pearson, D. W., DeLuca, P. M., Jr., Wells, G. M., Redaelli, R. and Cerrina, F., "A simple total absorption calorimetry technique to measure soft X-ray energy fluence," Radiat. Prot. Dos. 21(4), 219-222 (1987).

[4] Meger, C. M., Pearson, D. W., DeLuca, P. M., Jr., Wells, G. M., Cerrina, F. and Gould, M., "A beamline and irradiation chamber for dosimetry and 
biology studies using synchrotron radiation," Rev. Sci. Inst. 60(7), 2235-2238 (1989).

[5] Meger, C. M., Pearson, D. W., DeLuca, P. M., Jr., Kennan, W. S. and Gould, M., "Synchrotron produced ultrasoft X-rays: a tool to study the biophysical model of radiation damage," Int. J. of Radiat. Biology 59(4), 985-996 (1991).

[6] Lasky, J. and Moran, P., "Thermoluminescent response of LiF (TLD-100) to $5-30 \mathrm{keV}$ electrons and the effect of annealing in various atmospheres," Phys. Med. Biol. 22(5), 852-862 (1977).

[7] Lasky, J. and Moran, P., "Thermoluminescent response of LiF (TLD-100) to 0.1-5 keV electrons: An energy-range relationship and comparison of the TL glow with TSEE glow curves," J. Appl. Phys. 50(7), 4951-4957 (1979).

[8] Carrillo, R. E. and DeLuca, P. M., Jr., Low energy beta ray thermoluminescent dosimetry. Available as University of Wisconsin WMP Report \# 189 from the Department of Medical Physics, University of Wisconsin, Madison, WI (1990).

[9] Carrillo, R. E. and DeLuca, P. M., Jr., "Thermoluminescent dosimetry of 0.1$30 \mathrm{keV}$ electrons with lithium fluoride," in Proc. of the IV Congreso Nacional sobre Dosimetria Termoluminiscente, Mexico DF, 12-13 Sep 1991.

[10] Carrillo, R. E., and DeLuca, P. M., Jr., "High level gamma ray thermoluminescent dosimetry," in Proc. of the III Seminario Nacional sobre Dosimetria Termoluminescente, Mexico DF, 17-18 Sep 1990. This is also available as University of Wisconsin WMP Report \# 190 from the Department of Medical Physics, University of Wisconsin, Madison, WI (1990).

[11] Carrillo, R. E. and DeLuca, P. M., Jr., "U.V. dosimetry with thermoluminescent materials," in Proc. of the III Seminario Nacional sobre Dosimetria Termoluminescente, Mexico DF, 17-18 Sep 1990. This is also available as University of Wisconsin WMP Report \# 191 from the Department of Medical Physics, University of Wisconsin, Madison, WI (1990).

[12] Folkard, M., Roper, M. J., and Michael, B. D., "Measurement and analysis of supralinearity in LiF TLD-100 irradiated by $1.5 \mathrm{keV}$ x-rays," Phys. Med. Biol. 34(6), 707-715 (1989).

[13] Carrillo, R. E., Characterization of the thermoluminescent response of several phosphors to monoenergetic photon beams with energies from 100 to 3,000 eV. Ph.D. Thesis Prospectus, Department of Medical Physics, University of Wisconsin, Madison, WI (1990). 
[14] Carrillo, R.E., Pearson, D.W., DeLuca, Jr. P.M., and Mackay, J.F., "Thermoluminescent Response of Lithium Fluoride (TLD-100) to Monoenergetic Photon Beams of 600, 730, 900, and 1,500 eV", Radiat. Prot. Dos. 47(1/4), 519-524, 1993.

[15] Carrillo R.E., Ph.D. Thesis, "The Thermoluminescent Response of Several Phosphors to Monoenergetic Photon Beams With Energies From 275 to 2,500 eV", University of Wisconsin-Madison, February 24, 1993.

[16] Becker, K., "Solid State Dosimetry," CRC Press, Ohio (1973).

[17] Attix, F. H., "Introduction to Radiological Physics and Radiation Dosimetry," John Wiley \& Sons, Inc., New York, NY (1986).

[18] Plechaty, E. F., Cullen, D. E., and Howerton, R. J. Tables and Graphs of Photon-interaction cross sections from $0.1 \mathrm{keV}$ to $100 \mathrm{MeV}$ derived from the LLL Evaluated-Nuclear-Data Library. UCRL-50400(6), Rev. 3, Nat. Tech. Inf. Serv., US Dept. of Commerce (1981).

[19] Cameron, J. R., Suntharalingam, N. and Kenney, G. N., "Thermoluminescent dosimetry," University of Wisconsin Press, Madison, WI (1968).

[20] DeWerd, L. A., and Stoebe, T. G., "The influence of hydroxide impurities on TL in LiF," in Proc. Third Int. Symp. Lum. Dosimetry, Riso Rep. 249, Part I 78-89 (1971).

[21] Vana, N., Aiginger, H., and Hager, A., "Supralinearity in LiF," in Proc. Fourth Int. Conf. Lum. Dosimetry, Institute of Nuclear Physics, Krakow, 123 (1974).

[22] Piesch, E., Burgkhardt, B., and Kabadjova, S., "Supralinearity and reevaluation of different LiF dosimeter types," Nucl. Inst. Meth. 126, 563 (1975).

[23] Naylor, G. P., "Thermoluminescent phosphors: variation of quality response with dose," Phys. Med. Biol. 10, 564 (1965).

[24] Horowitz, Y. S., "TL Dose Response," in Thermoluminescence and thermoluminescent dosimetry, Vol, II, Y.S. Horowitz (Ed.), CRC Press, Boca Raton, Florida (1984).

[25] Stoebe, T. G., and Watanabe, S., "Thermoluminescence and lattice defects in LiF," Phys. Stat. Sol. (a) 20, 11-29 (1975).

[26] Jain, V. K., "Thermoluminescence of lithium fluoride," Radiat. Prot. Dosim. 2, 141-167 (1982). 
[27] Gorbics, S. G., and Attix, F. H.. "Thermoluminescent dosimeters for highdose applications," Health Phys. 25, 499-506 (1973).

[28] Oberhofer, M., "High-level photon dosimetry with thermoluminescent materials," Atomkernenergie 31, 209-216 (1978).

[29] Charalambous, S., and Petridou, C., "The thermoluminescence behaviour of LiF (TLD-100) for doses up to 10 MRad," Nucl. Inst. and Meth. 137, 441-444 (1976).

[30] LaRiviere, P. D., "A unique throwaway LiF dosemeter," in Proc. Second Int. Symp. Lum. Dosimetry, 78-81 (1968).

[31] Jain, V. K., Kathuria, S. P., and Ganguly, A. K., "Supralinearity and sensitization in LiF TLD phosphor," J. Phys. C: Solid State Phys. 7, 3810-3816 (1974).

[32] Jones, J. L., and Martin, J. A., "Use of LiF (TLD-700) for doses greater than 0.1 Mrad," Health Phys. 14, 521-522 (1968).

[33] Chandra, B., Lakshmanan, A. R., and Bhatt, R. C., "High level gammadosimetry using high temperature TL peaks in LiF (TLD-100)," Int. J. Appl. Radiat. Isot. 33, 679-680 (1982).

[34] Burgk" ardt, B., Piesch, E., and Singh, D., "High-dose characteristic of LiF and $\mathrm{Li}_{2} \mathrm{~B}_{4} \mathrm{O}_{7}$ thermoluminescent dosemeters," Nucl. Inst. and Meth. 148, 613617 (1978).

[35] Goldstein, N., Tochilin, E., and Miller, W. G., "Millirad and megarad dosimetry with LiF," Health Phys. 14, 159-162 (1968).

[36] Horowitz, Y. S., "General characteristics of TL materials," in Thermoluminescence and thermoluminescent dosimetry, Vol. I, Y.S. Horowitz (Ed.), CRC Press, Boca Raton, Florida (1984).

[37] Lasky, J. B. Thermoluminescent response of LiF (TLD-100) to $70 \mathrm{eV}-30 \mathrm{keV}$ electrons. Ph.D. Thesis. UW-Madison (1976).

[38] Binder, W., Disterhoft, S., and Cameron, J. R., "Dosimetric properties of $\mathrm{CaF}_{2}:$ Dy;" in Proc. Second Int. Conf. Lum. Dosimetry. USAEC Div. Tech. Inf. Rep. CONF-680920 43-53 (1968).

[39] Binder, W., Cameron, J. R. Dosimetric properties of $C a F_{2}: D y$. USAEC Rep. C00-1105-146 Department of Medical Physics, University of Wisconsin, Madison, WI (1969). 
[40] Sunta, C. M., "A review of thermoluminescence of calcium fluoride, calcium sulphate and calcium carbonate," in Thermoluminescent materials, S.W.S. McKeever (Ed.), Rad. Prot. Dos. 8, 25-44 (1984).

[41] Burgkhardt, B., Singh, D., and Piesch, E., "High-dose characteristics of $\mathrm{CaF}_{2}$ and $\mathrm{CaSO}_{4}$ thermoluminescent dosemeters," Nucl. Inst. and Meth. 141, 363368 (1977).

[42] Hasan, F., and Charalambous, S., "The thermoluminescence behaviour of $\mathrm{CaF}_{2}$-Dy (TLD-200) for low up to high doses," J. Phys. C: Solid State Phys. 16, 5921-5928 (1983). 


\section{Carbon to Oxygen Kerma Factor Ratio Mea- surements}

\subsection{Participants}

Katja Langen, Juan Miranda, Paul M. DeLuca, Jr., David W. Pearson, and Richard Maughan.

\subsection{Introduction}

Bombardment by energetic photons is the most common form of radiation therapy of tumors. However, depending on the tumor characteristics, neutron beam treatment would be preferred to photon treatment in $10 \%$ to $15 \%$ of all radiation therapy patients. There are currently eighteen centers worldwide which use neutron beams for radiation therapy [9].

Neutrons deposit their energy indirectly in matter, that is neutron energy is first transferred to charged particles which then deposit energy in the matter by ionization and excitation of target atoms. The kinetic energy released in matter, or KERMA, provides us with the amount of energy that is given to charged particles per mass unit. If the production of charged particle energy is equal to the loss of charged particle energy, or charged particle equilibrium exists (CPE), the kerma is equal to the absorbed dose in the medium. The kerma factor is the kerma per unit neutron fluence and depends on the neutron energy and the interacting material.

The ultimate end point of radiation treatment is to control the tumor and at the same time avoid normal tissue complications. The difference between under-dosing, which fails to control the tumor and over-dosing, which may produce unacceptable normal tissue complications, is less than $5 \%$ [9]. Ordinarily the absorbed dose to tissue should be determined as accurately as possible but certainly to less than $5 \%$.

Absorbed dose in tissue can be inferred from measurements using tissue equivalent phantoms, e.g., TE-plastic (A-150). However, the atomic composition of these phantoms is different than the composition of muscle tissue as can be seen in $\mathrm{Ta}$ ble 1. This situation prohibits the direct measurement of absorbed dose in tissue using tissue equivalent phantoms. The biggest deviation of the atomic composition is in the carbon and oxygen content of tissue and A-150 plastic. To correct for these differences the oxygen to carbon kerma factor ratio must be known. An accurate carbon to oxygen kerma factor ratio allows us to convert the measured dose in A150 plastic to an accurate value for the absorbed dose in tissue for a given energy.

Even complete and accurate knowledge of the oxygen to carbon kerma factor ratio is not sufficient if a broader cGy spectra is used. Detailed knowledge of the bombarding neutron spectra is also required and in many instances very difficult to determine. However, a direct measurement of the oxygen to carbon ratio provides 
exactly the information needed when the measurement is performed in the clinical beam. Without knowledge of the kerma factors for carbon or oxygen, the ratio of the carbon to oxygen kerma factor is assumed constant and applies at all energies present in the beam.

The Gershenson Radiation Oncology Center in Detroit is currently treating patients with a broad energy spectrum neutron beam with a peak neutron energy of about $48 \mathrm{MeV}$. For this energy range several kerma factor measurements for carbon and oxygen were done at the same neutron energies by Brady and Romero [1] and Hartmann, et al. [6]. These measurements allow an estimate of the carbon to oxygen kerma factor ratio for some energies between 10 and $70 \mathrm{MeV}$.

Table 5: Elemental Composition of ICRU muscle tissue and A-150 plastic in percentage by mass [5].

\begin{tabular}{||c|l|l||}
\hline \hline Element & ICRU Tissue & $\mathrm{A}-150$ \\
\hline $\mathrm{H}$ & 10.2 & 10.1 \\
$\mathrm{C}$ & 12.3 & 77.6 \\
$\mathrm{~N}$ & 3.5 & 3.5 \\
$\mathrm{O}$ & 72.9 & 5.2 \\
$\mathrm{~F}$ & - & 1.7 \\
$\mathrm{Na}$ & 0.08 & - \\
$\mathrm{Mg}$ & 0.02 & - \\
$\mathrm{P}$ & 0.2 & - \\
$\mathrm{S}$ & 0.5 & - \\
$\mathrm{K}$ & 0.3 & - \\
$\mathrm{Ca}$ & 0.007 & 1.8 \\
\hline \hline
\end{tabular}

Based upon an interpolation of these measurements and an approximation of the neutron energy spectrum for the treatment facility in Detroit, a carbon to oxygen kerma factor ratio is approximated for the conversion of the A-150 plastic absorbed dose to tissue absorbed dose. At the Detroit facility this conversion factor is used for patient treatment planning. Subsequently, the careful observation of the patients gives an evaluation of the correctness of the treatment plans and the dosimetric estimates.

As can be deduced from the previous discussion, a direct measurement of the effective carbon to oxygen kerma factor ratio using the given broad energy spectrum would allow a more precise determination of the carbon to oxygen kerma factor ratio and therefore a more precise determination of the absorbed dose in tissue. In April 
93 we performed the first measurements to determine the effective oxygen-to-carbon kerma factor ratio for the treatment facility in Detroit.

\subsection{Treatment Facility}

The Gershenson Radiation Oncology Clinic in Detroit, Michigan is one of the eighteen centers in the world which uses neutrons for radiation treatment. A superconducting cyclotron accelerates deuterons to an energy of $48.5 \mathrm{MeV}$. The deuterons then impinge on the thin beryllium target producing a broad neutron energy spectrum with a mean energy of $20.4 \mathrm{MeV}$ [7]. The maximum absorbed dose is at a depth of $9 \mathrm{~mm}$. At this depth the typical dose rate in water is $40 \mathrm{cGy}$ per minute. A multi-rod collimator allows the application of irregular shaped fields. Figure 25 shows the assembly of the cyclotron and the treatment room. Figure 26 shows the details of the clinical components of the treatment facility. First patient treatments were performed in September 1991. In May 93 a total of 426 fields were treated [8]. The facility is available for research purposes at night and during weekends.

\subsection{Measurements}

The kerma was determined by using spherical and cylindrical geometry low pressure proportional counters and applying microdosimetric techniques [2,3,4]. These counters consist of a gas filled cavity enclosed in walls which can be of several materials, e.g., carbon or A-150 plastic. Ionizations in the cavity are produced as charged particles traverse the cavity. These charged particles are produced in the wall material by neutron interactions. The pulse height of the counter signal is proportional to the ionization density in the gas, which itself is proportional to the stopping power of the particle that crosses the sphere. A histogram of the output signal pulse height can then be obtained.

The counter has a built-in alpha-particle source which can be positioned in such a way that alpha particles can enter the cavity through a small opening in the cavity wall and traverse a diameter. The alpha particles have a known stopping power and are used to calibrate the detector output signals in terms of stopping power. A pulser injects pulses of variable height into the system in order to determine the linearity of the system. Using the obtained pulse height histogram and transforming it into a stopping power histogram, one can determine how much energy was deposited in the cavities. To relate the gas absorbed dose to the wall absorbed dose, Bragg-Gray cavity theory is used. Irradiation of two different counters, e.g., carbon and A-150, with the same neutron fluence makes it possible to determine the dose in carbon to absorbed dose in A-150 ratio and hence the carbon to A-150 kerma factor ratio. In order to establish CPE in the wall, external build-up caps were used. The thickness of these caps is determined by the maximum range of the charged particles produced 


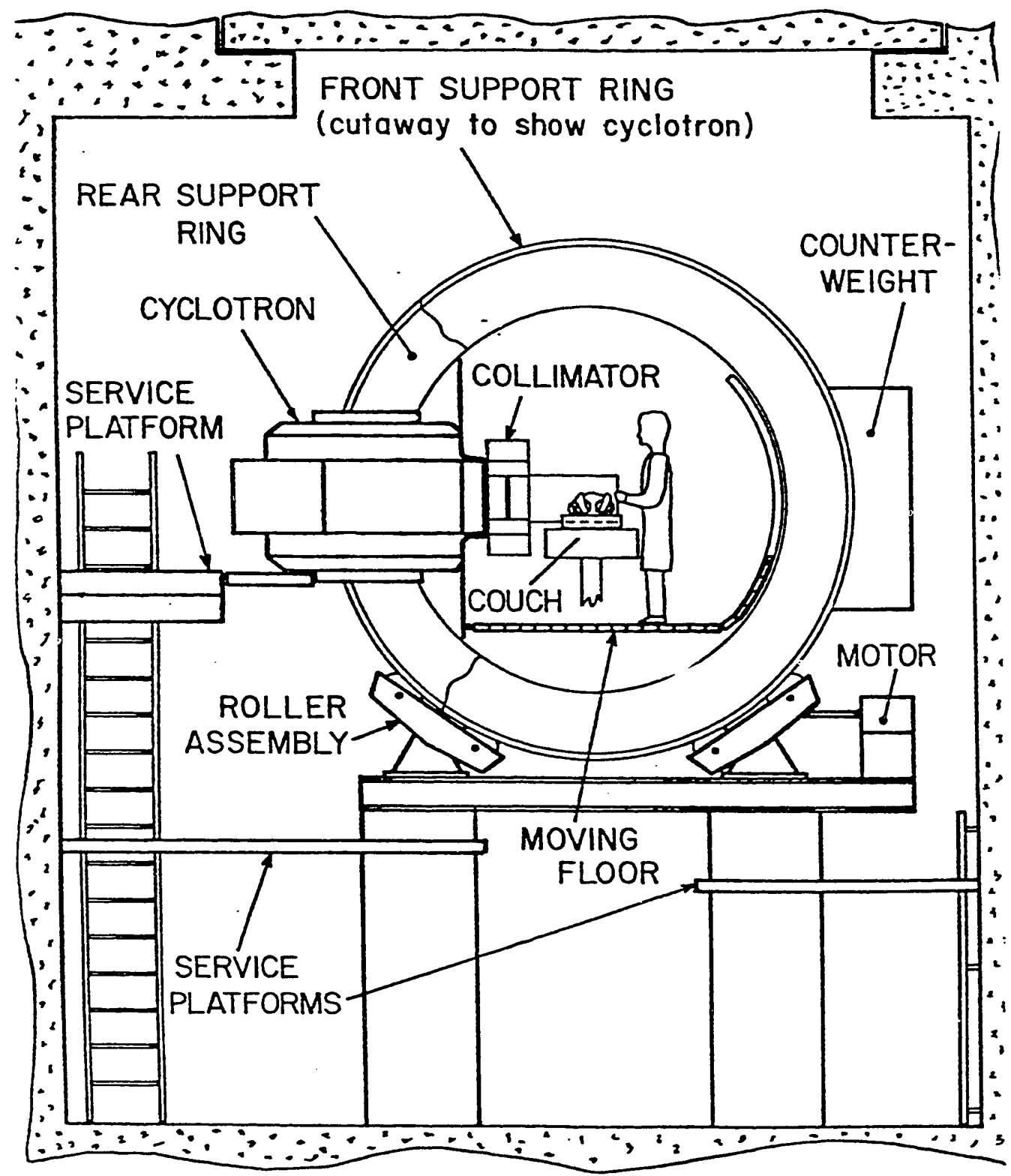

Figure 25: A schematic drawing in cross-section of the Gershenson Radiation Oncology Clinic fast neutron treatment facility at Harper Hospital, Detroit, MI. 


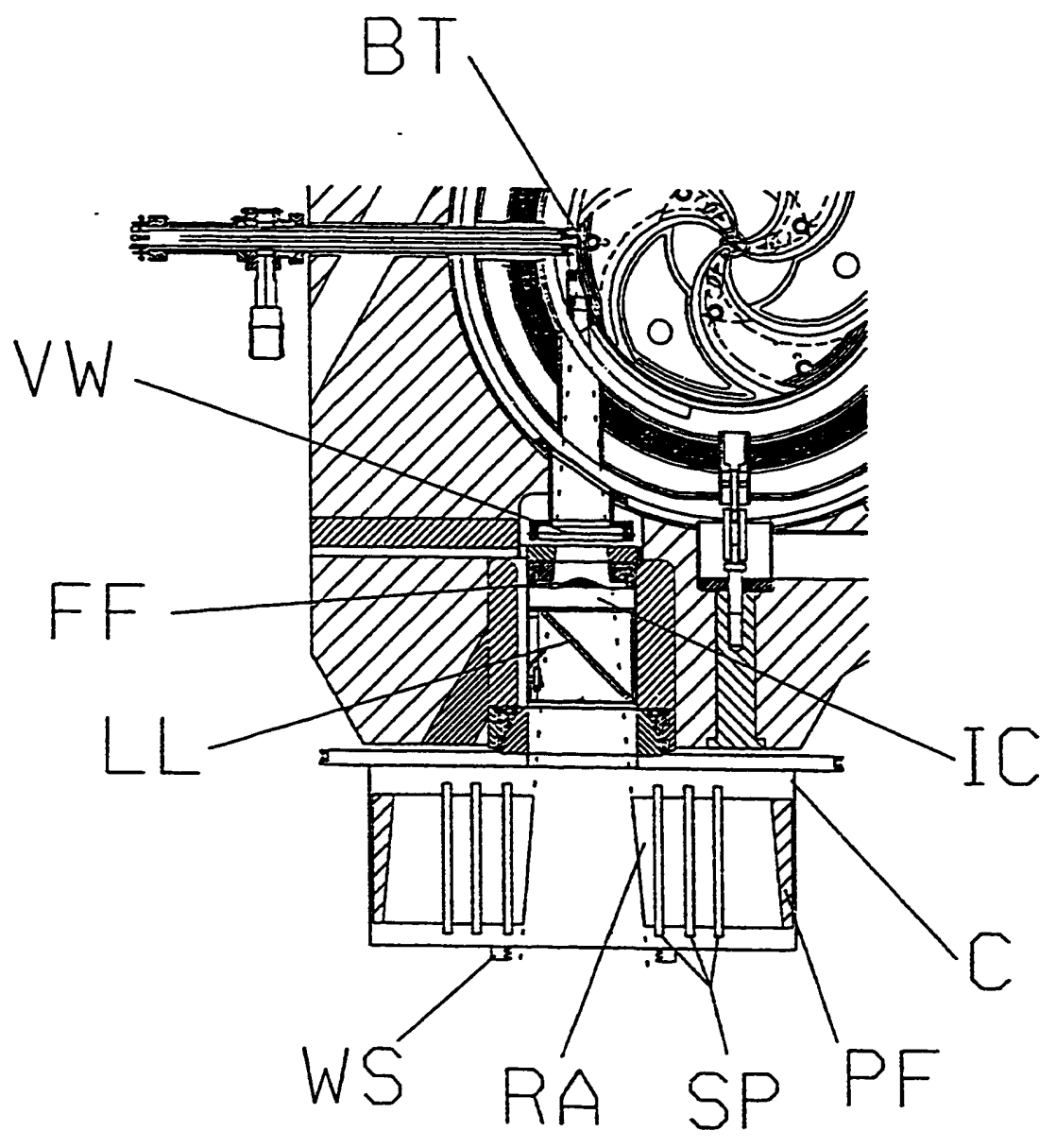

Figure 26: A section through the median plane of the Gershenson Radiation Oncology Clinic cyclotron showing the details of the clinical components of the system. BT: beryllium target, VW: vacuum window, FF: flattening filter, IC: monitor ionization chamber, LL: light localizer, C: collimator, RA: tungsten rod arrays, SP: steel plates, PF: polystyrene foam forms which push the rods into the desired shape, WS: accessory tray support for wedge and compensating filters 
which depends on the highest neutron energy of the beam.

The goal of the measurements which we performed in April was to determine the carbon to oxygen kerma factor ratio for the given neutron distribution at the Detroit facility. Since no absolute kerma factor values have to be determined, there is no need to make an absolute neutron fluence measurement. The absorbed dose measurements only have to be normalized to a quantity which is proportional to the neutron fluence. For this reason we measured the absorbed dose simultaneously with the A-150 counter and the carbon or oxygen counters. The A-150 counter was used for normalization purposes, and was kept in the same position for all runs. Only the second detector was replaced. The neutron irradiation field size was approximately $30 \mathrm{~cm}$ by $20 \mathrm{~cm}$.

To determine the kerma factor for oxygen, a slightly different approach is used since a detector counter wall is not easily constructed of pure oxygen. For this reason a cylindrical detector pair with $\mathrm{Zr}$ and $\mathrm{ZrO}_{2}$ walls was used. The oxygen kerma factor can now be determined by subtraction.

We irradiated the following detector pairs: A-150 and carbon, A-150 and $\mathrm{ZrO}_{2}$, and $\mathrm{A}-150$ and $\mathrm{Zr}$.

From the last two measurements the oxygen to A-150 kerma factor can be deduced. Inclusion of the first measurement allows the determination of the effective carbon to oxygen kerma factor ratio for the given broad energy spectrum. It is possible to irradiate three detectors, namely the carbon, $\mathrm{Zr}$ and $\mathrm{ZrO}$ counters simultaneously if the fluence distribution is constarit or known throughout the radiation field. In the described experiment we chose to only irradiate two counters simultaneously and instead normalize the readings to the A-150 counter as described earlier.

\subsection{Electronics}

Conventional signal processing electronics were employed. Each detector signal was amplified with two separated gains covering a dynamic range is pulse height of 10,000::1 with a gain difference of a factor of ten. As two detectors are operating simultaneously, four signals were read by a CAMAC octal ADC. The CAMAC system was interfaced with a Macintosh Quadra computer and data processing software from Sparrow, KMAX, controlled data acquisition and storage.

\subsection{Results}

Up to this point event size $(Y)$ weighted dose spectra $(Y * D(Y))$ have been calculated for all detector runs. In this case the event size $Y$ is expressed in mass collision stopping power units, $M e V \mathrm{~cm}^{2} \mathrm{~g}^{-1}$, while absorbed dose in the gas, $D(Y)$, corresponds to dose to the gas which is delivered by events of the event-size $Y$ to $Y+\delta Y$. 
Figure 27 depicto one of the measured $\log (Y)$ versus $Y * D(Y)$ distributions for the A-150-plastic counter. The total absorbed dose to the gas can be determined by integrating $D(Y)$ over all observed $Y$ values.

While preparing the setup for the Detroit experiment and during the actual measurements, we observed large initial gain drifts in the carbon counter. After the measurements, an internal high resistance was identified in the anode collection system. The counter was repaired by the manufacturer and its performance notably increased. Unfortunatly the observed high initial gain drift may have affected the carbon counter readings. Following the intial experiments we designed and constructed a new set of spherical $\mathrm{Zr} / \mathrm{ZrO}_{2}$ counters. The detector pair which was used in Detroit consisted of cylindrical counters. Since the carbon and A-150 counters are spherical counters the overall uncertainty would be reduced if the measurement would be repeated with uniformly spherical counters.

During analysis of the data, a major problem was encountered in determining the data acquisition dead time. This cyclotron is operated in macro pulse mode, that is beam is extracted for about $400 \mathrm{msec}$ out of every second. By suitable choice of the source injection parameters it is possible to restrict the beam extraction to even shorter intervals. The neutron beam is then monitored by transmission ionization chambers located proximal to the cyclotron target. Using a voltage proportional to the current flow from the transmission ionization chambers, we created a beam on gating pulse to enable data acquisition. However, as the proportional counters require modest neutron fluxes, control of the instantaneous beam flux as derived from the transmission ionization chambers was very difficult. In future measurements the neutron flux should be monitored with a high speed NE-213 scintillator. This would enable us to measure the beam pulse length and intensity and would therefore allow us to improve the dead time measurement. A repetition of the experiment with the improved instrumentation and setup is planned for the near future. 


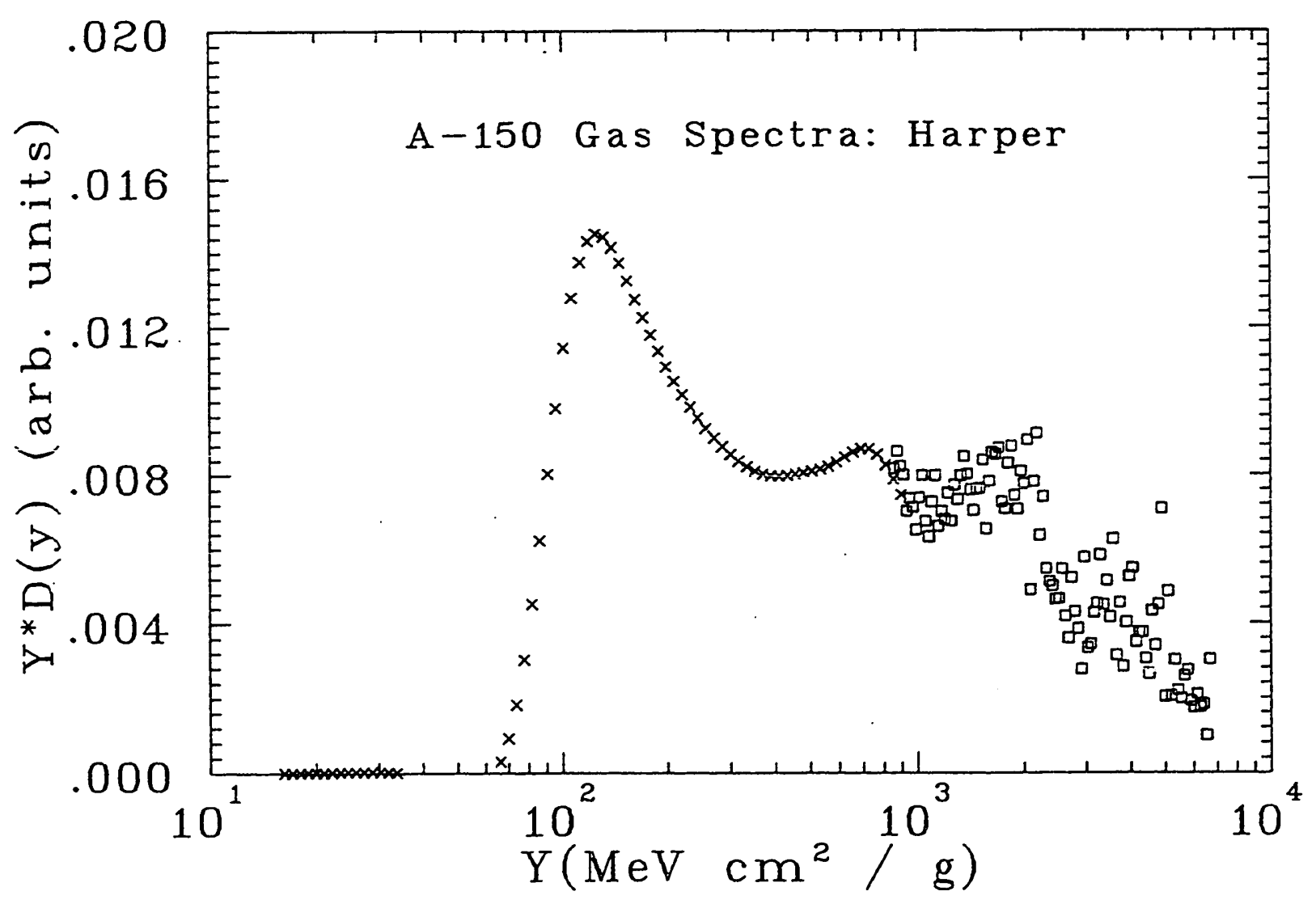

Figure 27: A plot of the event-size weighted gas dose distribution for bombardment of the A-150 plastic counter at Gershenson Radiation Oncology Neutron Facility. 


\section{References}

[1] Brady, F.P. and Romero, J.L., "Neutron Induced Reactions in Tissue Resident Elements, Final Report to the National Cancer Institute, Grant No. 1R01 CA16261," University of California-Davis, Davis, CA, 1979.

[2] DeLuca, P.M., Jr., "Neutron Kerma Factor Measurements in Near 15 MeV Using Microdosimetric Techniques," Nucl. Instr. Meth. B10/11, 915-918 (1984).

[3] DeLuca, P.M., Jr., Barschall, H.H., Haight, R.C. and McDonald, J.C., "Carbon Neutron Kerma Factor Determinations at $14.1 \mathrm{MeV}$," Radiat. Res. 100, 78-86 (1984).

[4] DeLuca, P.M., Jr., Barschall, H.H., Burhoe, M., and Haight, R.C., "Carbon Kerma Factor for 18- and 20-MeV Neutrons," Nucl. Sci. Eng. 94(2), 192-198 (1986).

[5] International Commission on Radiation Units and Measurements, "Microdosimetry: Report 36", 1983, Bethesda, MD.

[6] Hartmann C.L., DeLuca Jr. P.M., Pearson D.W., "Measurement of Neutron kerma Factors in $\mathrm{C}, \mathrm{O}$, and $\mathrm{Si}$, at 18, 23, and $25 \mathrm{MeV}$," Radiat. Prot. Dos. 44(1/4), 25-30 (1992).

[7] Maughan R.L., Kota C., Yudelev M., Phys. Med. Biol., in press (1993).

[8] Maughan R.L., Blosser H.G., Powers W.E., Radiotherapy and Oncology, submitted (1993).

[9] White R.M., Broese J.J., DeLuca Jr. P.M., Dietze G., Haight R.C., Kawashima K., Menzel H.G., Olsson N., Wambersie A., "Status of Nuclear Data for Use in Neutron Therapy," Radiat. Prot. Dos. 44(1/4), 11-20 (1992). 

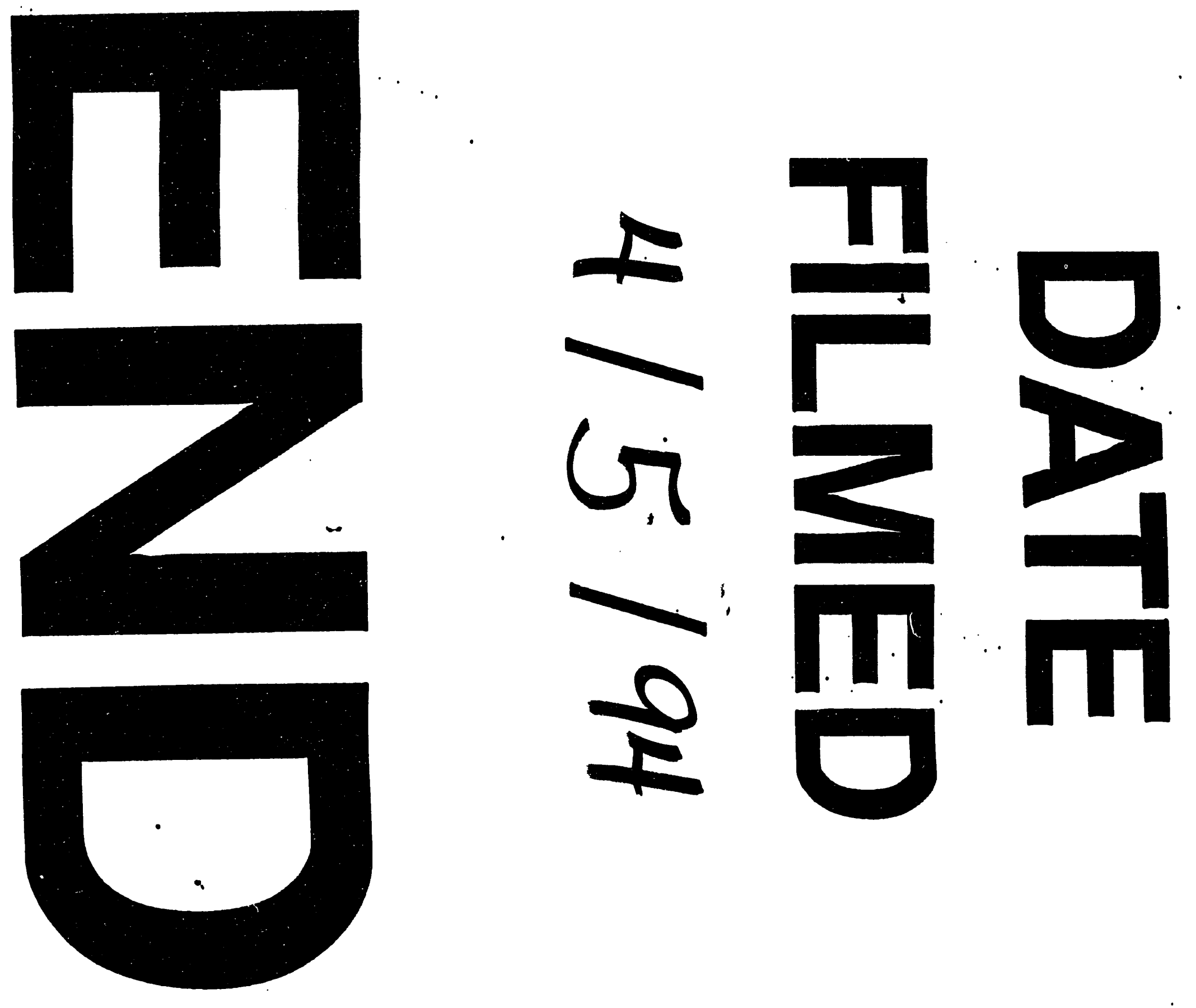